University of Rhode Island

DigitalCommons@URI

Open Access Dissertations

1968

\title{
The Relationship of Dopamine to Blood Pressure in Experimental Renal Hypertension
}

David William Coates

University of Rhode Island

Follow this and additional works at: https://digitalcommons.uri.edu/oa_diss

\section{Recommended Citation}

Coates, David William, "The Relationship of Dopamine to Blood Pressure in Experimental Renal Hypertension" (1968). Open Access Dissertations. Paper 143.

https://digitalcommons.uri.edu/oa_diss/143

This Dissertation is brought to you for free and open access by DigitalCommons@URI. It has been accepted for inclusion in Open Access Dissertations by an authorized administrator of DigitalCommons@URI. For more information, please contact digitalcommons-group@uri.edu. 
THE RELATIONSHIP OF DOPAMINE TO BLOOD PRESSURE

IN EXPERIMENTAL RENAL HYPERTENSION

BY

DAVID WILLIAM COATES

A THESIS SUBMITTED IN PARTIAL FULFILLMENT OF THE REQUIREMENTS FOR THE DEGREE OF DOCTOR OF PHILOSOPHY

(Pha rmacology)

UNIVERSITY OF RHODE ISLAND 1968 


\section{ACKNOWLEDGMENTS}

The author wishes to express his sincere gratitude to his major professor, Dr. David R. DeFanti for his assistance and understanding during the investigation and preparatici of this manuscript. He also wishes to express his gratitude to the chairman of the pharmacology department, Dr. John J. DeFeo, for allowing freedom of thought in the approach to pharmacological problems.

The author wishes to express his gratitude to Dean Heber W. Youngken, Jr. and the University administration for the opportunity to pursue his graduate studies while serving on the college faculty.

The author wishes to express his gratitude to the Rhode Island Heart Association and the United States Public Health Service for financial support of this investigation. 


\section{ABSTRACT}

The possible relationship among urinary dopamine levels, circulating dopamine levels, kidney dopamine levels and arterial blood pressure was studied in hypertensive rats and dogs. The role of the kidney in the formation of dopamine from dihydroxyphenylalanine (DOPA) was also investigated in cats.

Hypertension was produced by right renal nephrectomy followed in two weeks by contralateral renal artery compression.

The blood pressure of both the rats and dogs showed a sharp increase the first week following the second operation and remained elevated for the duration of the study. Individual pressures as high as $205 \mathrm{~mm} \mathrm{Hg}$ were encountered.

Dopamine was extracted from urine by absorption onto alumina, converted to its trihydroxyindole derivative and measured fluorimetrically. Tissue and blood samples were for the most part homogenized in trichloroacetic acid, then passed through alumina columns. Dopamine was separated from DOPA by passing trichloroacetic acid extracts through columns of sodium Dowex 50W-X8 to extract dopamine, then through alumina columns to extract DOPA .

Urinary dopamine levels were reported as micrograms per liter ( $\mu \mathrm{g} / 1)$, micrograms per 24 hours $(\mu g / 24 h$ ) and micrograms per killogram per 24 hours $(\mu \mathrm{g} / \mathrm{kg} / 24 \mathrm{~h})$. In comparisons with a control group, the dopamine levels $(\mu \mathrm{g} / 1)$ were significantly lower in the hypertensive group on several occasions, however dopamine levels expressed as $\mu \mathrm{g} / 24 \mathrm{~h}$ or $\mu \mathrm{g} / \mathrm{kg} / 24 \mathrm{~h}$ differed only on two occasions; once prior to any operational procedures and then the first week following renal artery compression. A diuresis was 
observed in the hypertensive animals which could account for the decrease in urinary dopamine concentration $(\mu \mathrm{g} / 1)$ which was obtained. Over the duration of the rat study, mean dopamine levels $(\mu \mathrm{g} / 1)$ remained relatively constant and varied between 168 and $418 \mu \mathrm{g} / 1$, paired mean dopamine levels $(\mu \mathrm{g} / 24 \mathrm{~h})$ showed a tendency to rise and varied between 4.61 and $10.80 \mu \mathrm{g} / 24 \mathrm{~h}$ and mean dopamine levels $(\mu \mathrm{g} / \mathrm{kg} / 24 \mathrm{~h})$ showed a slight tendency to decrease, ranging from 11.51 to $18.53 \mu \mathrm{g} / \mathrm{kg} / 24 \mathrm{~h}$.

Correlation and regression analyses for the dependency of arterial blood pressure on urinary dopamine levels $(\mu \mathrm{g} / \mathrm{l}, \mu \mathrm{g} / 24 \mathrm{~h}$ and $\mu \mathrm{g} / \mathrm{kg} / 24 \mathrm{~h})$. did not detect any statistically significant relationships. No significant relationship was established between dopamine levels $(\mu \mathrm{g} / \mathrm{kg} / 24 \mathrm{~h})$ and welght $(g m)$.

Dopamine could not be detected in the blood of hypertensive rats or dogs, or in the ischemic kidneys of hypertensive rats.

The Infusion of DOPA into cats with and without functional renal tissue produced similar tissue dopamine levels in the liver, heart and spleen, However, renal arterio-venous differences showed that some DOPA was decarboxylated to dopamine in the kidney.

No evidence was obtained in the study which implicated dopamine in the hypertensive process and no relationship between arterial blood pressure and urinary or circulating dopamine was established. 
DOCTOR OF PHILOSOPHY THESIS

OF

DAVID WILLIAM COATES

\section{Approved:}

Thes1s Committee:

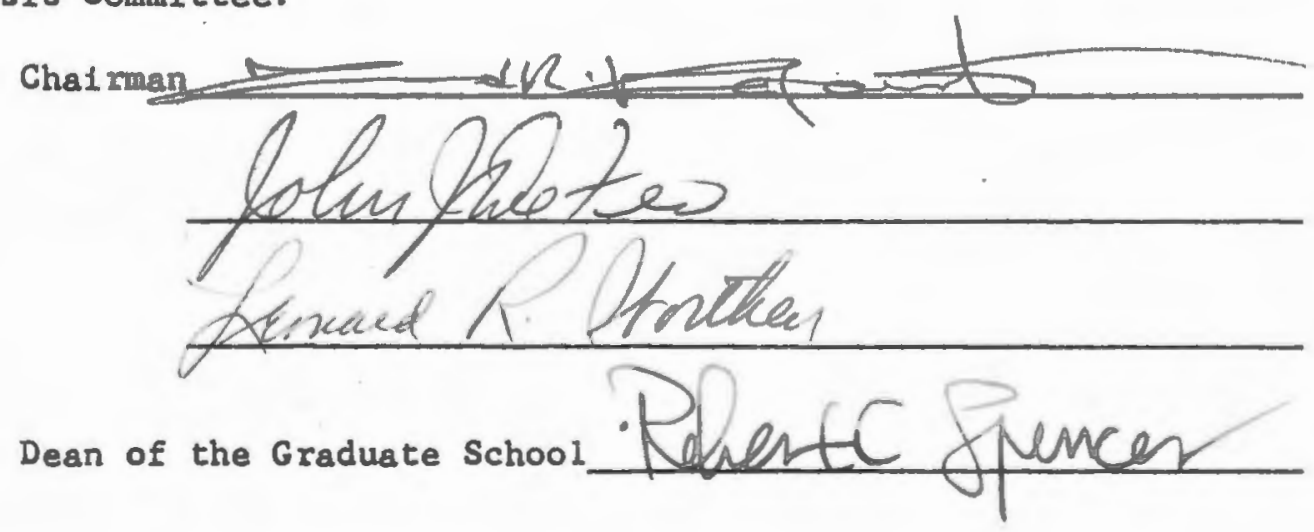

UNIVERSITY OF RHODE ISLAND

1968 
ACKNOWLEDGMENTS . . . . . . . . . . . . . . . . . . .

ABSTRACT . . . . . . . . . . . . . . . . . . . . . .

TABLE OF CONTENTS . . . . . . . . . . . . . . . . . . . . I

LIST OF TABLES . . . . . . . . . . . . . . . . . . 2

LIST OF FIGURES . . . . . . . . . . . . . . . 5

I. INTRODUCTION ................... . . . 6

II. REVIEW OF LITERATURE . . . . . . . . . . . . . . . . . 8

III. INVESTIGATION . . . . . . . . . . . . . . 26

A. OBJECTIVES . . . . . . . . . . . . . . 26

B. MATERIALS AND METHODS . . . . . . . . . . . . 26

1. Production of Experimental Hypertension . . . . 26

2. Collection of Urine . . . . . . . . . . . 27

3. Collection of Blood Samples . . . . . . . . . 28

4. Comparison of Kidney Dopamine Content . . . . . . 28

5. Hypertensive Dogs . . . . . . . . . . . . 29

6. Cat Infusion Studies............. 30

7. Determination of Dopamine and DOPA . . . . . . 32

8. Extraction of Catecholamines from Urine . . . . 35

9. Extraction of Catecholamines from Rat Rlasma . . 38

10. Extraction of Catecholamines from Whole Blood and Tissues . . . . . . . . . . . . 38

11. Separation of Dopamine and DOPA ........ 41

C. RESULTS ................... . . . 4 44

1. Rat Control Group .. . . . . . . . . . . 44

2. Experimental Rat Group ............ 56

3. Statistical Analysis of Rat Data........ 68

4. Rat Plasma Dopamine Levels . . . . . . . . . 71

5. Rat Ischemic Kidney Dopamine Levels . . . . . 72

6. Data from Dog Experiments . . . . . . . . 74

7. Cat Infusion Data ........... . 76

IV. DISCUSSION . . . . . . . . . . . . . . 80

V. SUMMARY AND CONCLUSIONS .................. . . . 94

VI. REFERENCES ...................... . . . . 97 


\section{LIST OF TABLES}

1 Percent recovery of dopamine from $0.2 \mathrm{~N}$ acetic acid... . 39

2 Percent recovery of dopamine added to urine samples... . 40

3 Percent recovery of DOPA and dopamine from mixtures in $10 \%$ trichloroacetic acid . . . . . . . . . . . . . .

4 Control Group (week one). Relationship of urinary dopamine levels (paired samples) to arterial blood pressure (paired means) in male rats. . . . . . . . . . . . . .

5 Control Group (week two). Relationship of urinary dopamine levels (paired samples) to arterial blood pressure (paired means) in male rats. . . . . . . . . . . . . .

6 Control Group (week four). Relationship of urinary dopamine levels (paired samples) to arterial blood pressure (paired means) in male rats. . . . . . . . . . . . . .

7 Control Group (week six). Relationship of urinary dopamine levels (palred samples) to arterial blood pressure (paired means) in male rats ..................

8 Control Group (week eight). Relationship of urinary dopamine levels (palred samples) to arterlal blood pressure (paired means) in male rats... . . . . . . . . . .

9 Control Group (week ten). Relationship of urinary dopamine levels (paired samples) to arterial blood pressure (paired means) in male rats .................

10 Control Group (week twelve). Relationship of urinary dopamine levels (paired samples) to arterlal blood pressure (paired means) in male rats...............

11 Control Group (week fourteen). Relationship of urinary dopamine levels (paired samples) to arterial blood pressure (paired means) in male rats . . . . . . . . . . .

12 Control Group (week sixteen). Relationship of urinary dopamine levels (palred samples) to arterial blood pressure (palred means) in male rats . . . . . . . . . . . .

13 Control Group (week efghteen). Relationship of urinary dopamine levels (palred samples) to arterlal blood pressure (paired means) in male rats............... 
LIST OF TABLES Continued

Table

Page

14 Control Group (week twenty). Relationship of urinary dopamine levels (paired samples) to arterial blood pressure (paired means) in male rats . . . . . . . . . . . 55

15 Experimental Group (week one). Relationship of urinary dopamine levels (paired samples) to arterial blood pressure (paired means) in male rats ..............

16 Experimental Group (week two). Relationship of urinary dopamine levels (paired samples) to arterial blood pressure (palred means) in male rats..............

17 Experimental Group (week four). Relationship of urinary dopamine levels (paired samples) to arterial blood pressure (paired means) in male rats . . . . . . . . . . . . .

18 Experimental Group (week six). Relationship of urinary dopamine levels (paired samples) to arterial blood pressure (paired means) in male rats . . . . . . . . . . .

19 Experimental Group (week eight). Relationship of urinary dopamine levels (paired samples) to arterial blood pressure (paired means) in male rats . . . . . . . . . . .

20 Experimental Group (week ten). Relationship of urinary dopamine levels (paired samples) to arterial blood pressure (paired means) in male rats.... . . . . . . . . .

21 Experimental Group (week twelve). Relationship of urinary dopamine levels (palred samples) to arterial blood pressure (paired means) in male rats . . . . . . . . . . . .

22 Experimental Group (week fourteen). Relationship of urinary dopamine levels (paired samples) to arterial blood pressure (paired means) in male rats . . . . . . . . . . .

23 Experimental Group (week sixteen). Relationship of urinary dopamine levels (paired samples) to arterial blood pressure (paired means) in male rats ..............

24 Experimental Group (week eighteen). Relationship of urinary dopamine levels (paired samples) to arterial blood pressure (paired means) in male rats . . . . . . . . . . . .

25 Experimental Group (week twenty). Relationship of urinary dopamine levels (paired samples) to arterial blood pressure (palred means) in male rats . . . . . . . . . . . 
LIST OF TABLES Continued

Table

Page

26 Comparisons of the means of the control and experimental groups using "Student's" $t$ distribution. The calculated $/ T /$ is followed by the tabulated $t$ (in parentheses) at the 0.05 confidence level and corresponding degrees of freedom.

27 Regression coefficients and correlation coefficients with confidence intervals and tests of the hypotheses for the rat data of the control and experimental groups from week 6 through week $20 .$. . . . . . . . . . . . 70

28 Influence of renal hypertension of eight weeks duration on kidney dopamine content in male rats . . . . . . . . 73

29 Relationship of urinary dopamine and blood dopamine levels to arterial blood pressure in control and renal hypertensive dogs......................

30 Levels of dopamine and DOPA in various tissues of the untreated cat . . . . . . . . . . . . . . . . .

31 Tissue levels of dopamine and DOPA in various tissues of the cat following intravenous infusion of $50 \mathrm{mg} / \mathrm{kg} \mathrm{d,1-DOPA}$ in cats with left kidney function.............

32 Tissue levels of dopamine and DORA in varlous tissues of the cat following intravenous infusion of $50 \mathrm{mg} / \mathrm{kg} \mathrm{d,1-DOPA}$ in cats without kidney function ............ 


\section{INTRODUCTION}

Although much has been learned within the past several decades regarding the synthesis, distribution, physiological disposition and the role of the catecholamines in regards to nerve physiology, little progress has been made in the possible role of these hormones in organic disease. Except in a few isolated cases such as pheochromocytoma, attempts at demonstrating a causal relationship to various organic disease states have resulted in failure. Because of the prominent pressor effects of the catecholamines on the cardiovascular system, there have been repeated attempts to show a relationship to hypertensive disease. Most of these studies have concerned themselves with the actions of norepinephrine and epinephrine and are inconclusive in their findings. For the most part, the catecholamine dopamine (3-hydroxytyramine) has been ignored even though it is known to possess rather powerful pressor effects. For this reason, DeFanti and DeFeo undertook a study of the possible role of this substance in the etiology of experimental renal hypertension in albino rats. Their findings showed an increased urinary excretion of dopamine which correlated with the severity of hypertension.

The purpose of this problem was to extend their work in the hopes of further elucidating the possible role of dopamine in the etiology of renal hypertension.

Early in the study it was discovered that Dowex $50 W-X 8$ resin extracted a substance with native fluorescence from rat urine and that the blank utilized in the original study, that of Carlsson and Waldeck, quenched this native fluorescence. Therefore, a good portion of this study was directed towards the development of a reliable method for the 
assay of urinary dopamine. Also because of this finding, certain aspects of the original study had to be repeated. In addition to this, an attempt was made to demonstrate the presence of dopamine in the blood of hypertensive rats and dogs, in the kidneys of hypertensive rats, and also to determine the extent of involvement of the kidney in the increased tissue levels of dopamine known to follow the intravenous infusion of dihydroxyphenylalanine (DOPA). 


\section{REVIEW OF LITERATURE}

Since the first successful production of sustained experimental hypertension by Goldblatt in 1934, numerous methods have been reported in the literature for the production of experimental hypertension. Most successful methods either directly or indirectly involve renal function; and as a consequence, etfological studies have centered their attention on the function of the kidneys and other systems known to exert an Influence upon kidney function (i.e., the nervous and endocrine systems).

DeFanti (1961) has extensively reviewed the literature in this area, and the interested reader is referred to his work for developments in the field prior to 1961. The present review will center its attention on more recent advances, making reference to the earlier works only where necessary to establish a background for the present discussion.

There is by no means complete agreement on what inftiates hypertension or maintains it. Most investigators, however, feel that renal hypertension is inftially a consequence of one of the following: (1) the release of a substance from the kidney which in 1 tself is not pressor, but which in turn causes the formation of an extra-renal pressor substance (1.e., the renin-hypertensin or angiotensin system), (2) retention of a pressor substance within the body due to impaired renal elimination or fallure of the kidney to destroy pressor substances (1.e. renoprival hypertension) or (3) the formation and secretion of an active pressor substance from within the ischemic renal tissue 1tself. There is evidence to support all of these theories, and yet the evidence cannot be considered conclusive for any.

The renin-anglotensin theory probably receives the greatest support. Figure I depicts the proposed mechanism: 
RENIN

(An enzyme liberated from the fuxtaglomerulus apparatus of the kidney during inadequate perfusion)
ANGIOTENSIN I

(An Inactive(?) dexapeptide)
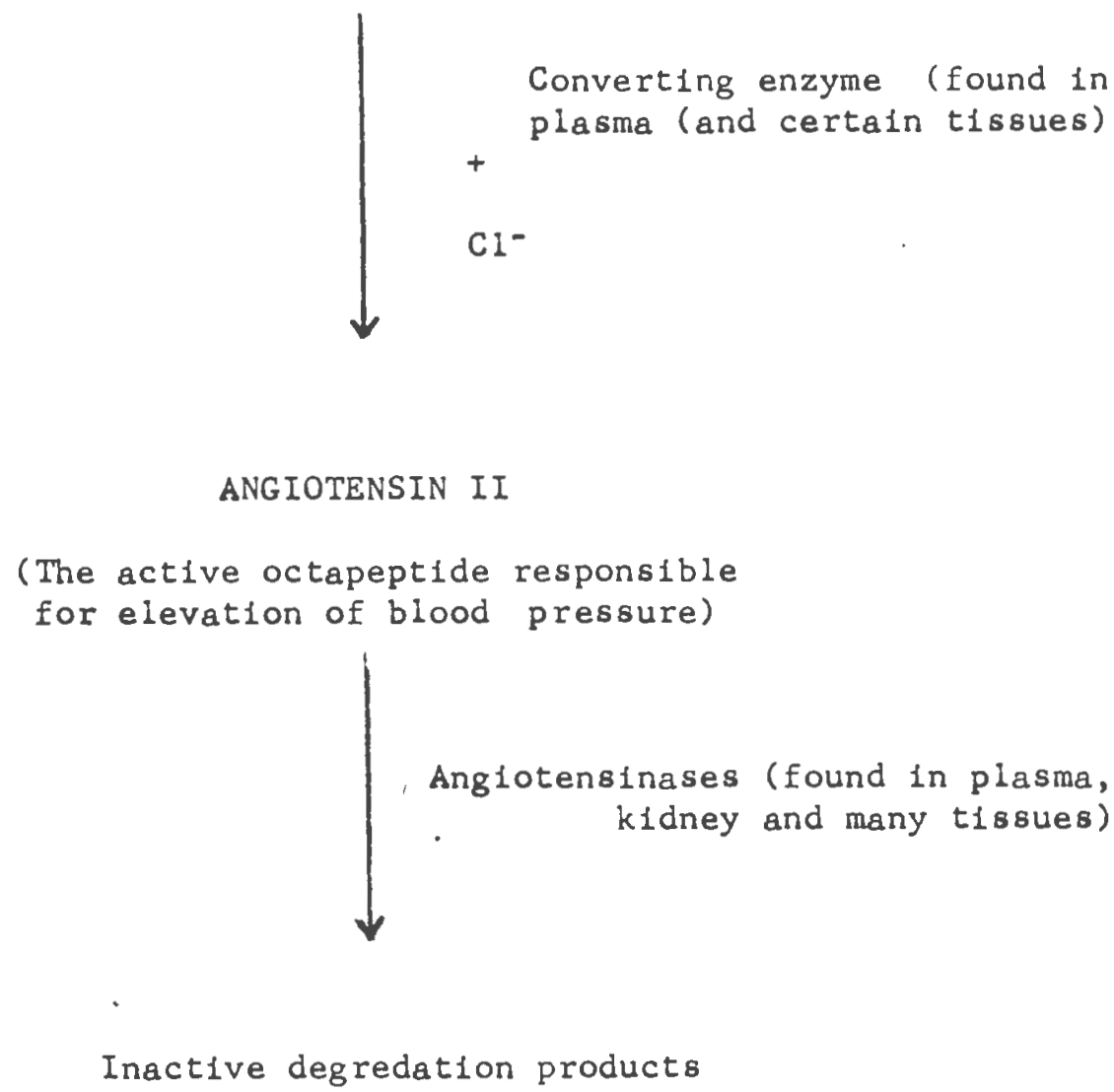

ANGIOTENSIN II

(The active octapeptide responsible

for elevation of biood pressure)

Anglotensinases (found in plasma, kidney and many tissues)

Inactive degredation products

SUBSTRATE

(A protein of hepatic origin contained in the Alpha-2globulin Eraction of the plasma) 
According to this theory, whenever the kidney is endangered by inadequate perfusion pressure, it releases the enzyme renin. It in turn causes the formation of anglotensin II, which elevates the blood pressure by a vaso-constrictive action on the blood vessels-thus restoring adequate perfusion pressure.

Research in this area was stimulated by the findings of Laragh et al. (1960) and Biron et al. (1961), who demonstrated that angiotensin II stimulates the release of aldosterone from the adrenal cortex, thus directly implicating the adrenals in the renin-anglotensin theory of hypertension. A tie-in with the adrenals had been suspected for some time since Goldblatt (195I) found that the adrenals were necessary for the development of hypertension following renal ischemia. Helmer et al. (1951) presented evidence to suggest that the adrenal sterolds are necessary for maintenance of renin substrate in the plasma.

If hypertension is caused by this mechanism, one would expect to find not only elevated levels of angiotensin II but aldosterone as well. The evidence, however, is conflicting. Kahn et al. (1952) reported only slightly elevated angiotensin levels in benign essential hypertensive patients, but levels twenty times the norm in malignant hypertensive patients. Skeggs et al. (1958) obtained similar results. On the other hand, Haynes et a1. (1947) and Taquini et al. (1958) found no evidence of elevated anglotensin levels. More recent work is no less confusing. Genest et al. (1964) falled to demonstrate consistently elevated angiotensin levels in dogs with experimental malignant hypertension, while Scornik et al. (1961) falled to demonstrate abnormal levels in the human form of this disease. Mulrow et a1. (1964) also falled to detect appreciable angiotensin II levels in renal hypertensive patients. However, 
Morris et al. (1964) consistently found anglotensin II to be elevated in renal hypertensive patients. It is quite possible that methodology has contributed to the confusion.

A similar situation exists for aldosterone. While Genest et al. (1958) found the mean urinary aldosterone level to be significantly elevated in a group of patients suffering from essential, renal, and malignant hypertension, $57 \%$ of the individual patients were within the normal range. Laragh $(1960 \mathrm{a} ; 1960 \mathrm{~b})$ found consistently elevated aldosterone levels in malignant hypertension, but could find no abnormality in benign essential hypertension. In a subsequent study (Laragh et al., 1966), the aldosterone level in uncomplicated essential hypertension was elther normal or low.

An interesting observation was made by Ames et al. (1965) when they discovered that prolonged infusions of anglotensin in human subjects, on a normal sodium diet, resulted in an increase in vascular sensitivity to angiotensin. Over the period of the infusion (up to 11 days), less and less angiotensin was required to maintain a consistent pressor response. In addition, the secretion of aldosterone was found to decrease to near normal levels as the dose of angiotensin was decreased. These findings were attributed to sodium retention and a resulting increase in vascular sensitivity since a group of subjects on a low-salt diet did not develop 1ncreased sensitivity. On the basis of these findings, Laragh (1967) has proposed a possible mechanism for the development of hypertension in which neither angiotensin or aldosterone levels remain permanently elevated. Supposedly, the process is initiated by a primary. renal disturbance, causing the formation of excessive angiotensin levels-which in turn Increase the secretion of aldosterone from the adrenal cortex. Sodium 
retention and hypertension develop and act in concert to suppress further formation of angiotensin. Eventually a point is reached where the angiotensin blood level drops below the concentration necessary to stimulate aldosterone production, and the levels of the steroid return to normal. However, the increased vascular sensitivity to anglotensin, as a result of elevated intravascular stores of sodium, maintains the hypertensive state despite the return of angiotensin levels to normal values.

The above data indicate that renin, anglotensin, and aldosterone most likely play a role in certaln phases or types of hypertensive disease. Yet there are discrepancles which have not been adequately explained: the rapid return of blood pressure to normal when the circulation to a clipped kldney is restored and the contralateral kidney removed, but in addition, the malntenance of hypertension when the clipped kidney is removed and the contralateral kidney left in place (Tobian et al., 1959). An investigation into this phenomenon by Singer et al. (1963) found the secretion of aldosterone to be elevated in hypertensive rats in which one renal artery was clipped and the other kidney unaltered but not in rats with one renal artery clipped and the contralateral kidney removed. It is also difficult to understand the failure of severe salt restriction to lower blood pressure In renal hypertensive rats (Redleaf and Tobian, 1958) or the failure of diets low in salt content to lower blood pressure in more than two-thirds of all hypertensive patients (Corcoran, et al., 1951).

Evidence in support of the renoprival theory of hypertension is limited. Grollman et a1. (1949) were the first to demonstrate the development of hypertension in animals following removal of both kidneys. Mu1rhead et al. (1956) suggested that normal kidneys secrete a substance with antihypertensive properties and that hypertension results when the 
kidneys fall to secrete this substance. Later 1 t was demonstrated that peritoneal implantation of renal medullary tissue prevents the development of renoprival hypertension (Muirhead et al., 1959), and in 1966 a lipid displaying antihypertensive properties was isolated from the medullary tissue (Mulrhead et al., 1966). It was proposed that functional renal tissue is necessary for maintenance of the normotensive state. Mendlowitz et al. (1961) state that it is not as yet known if there is a human counterpart for this type of experimental hypertension.

The catecholamines, in particular, norepinephrine (NE) and epinephrine (E), have long been suspected of playing a role in the etiology of hypertension primarlly because of their prominent actions on the cardiovascular system. However, as Pert (1966) points out, there is hardly any evidence of credit which implicates increased circulating catecholamines in ordinary cases of hypertension with the noteable exception of pheochromocytoma. Therefore, if $E$ or $N E$ is to be implicated, some change must be demonstrated in elther their synthesis, degradation, storage, release, or sensitivity of the vascular wall to locally released $\mathrm{NE}$.

The synthetic pathway for the formation of the catecholamines has now been well established with the isolation and characterization of tyrosine hydroxylase by Nagatsu et a1. (1964). Although this enzyme was the first to be involved in the synthesis of the catecholamines, it was the last to be isolated and characterized. The major pathway for the synthesis of NE and $E$ is shown in Figure 2 .

Tyrosine hydroxylase seems to be localized in subcellular particies which sediment at 15,000 to $20,000 \times \mathrm{g}$ (1.e., the mitochondrial fraction). It requires a tetrahydropteridine cofactor, $\mathrm{Fe}^{++}$and oxygen (Udenfriend, 1966). L-Dopa decarboxylase (aromatic L-amino acid decarboxylase) activity 


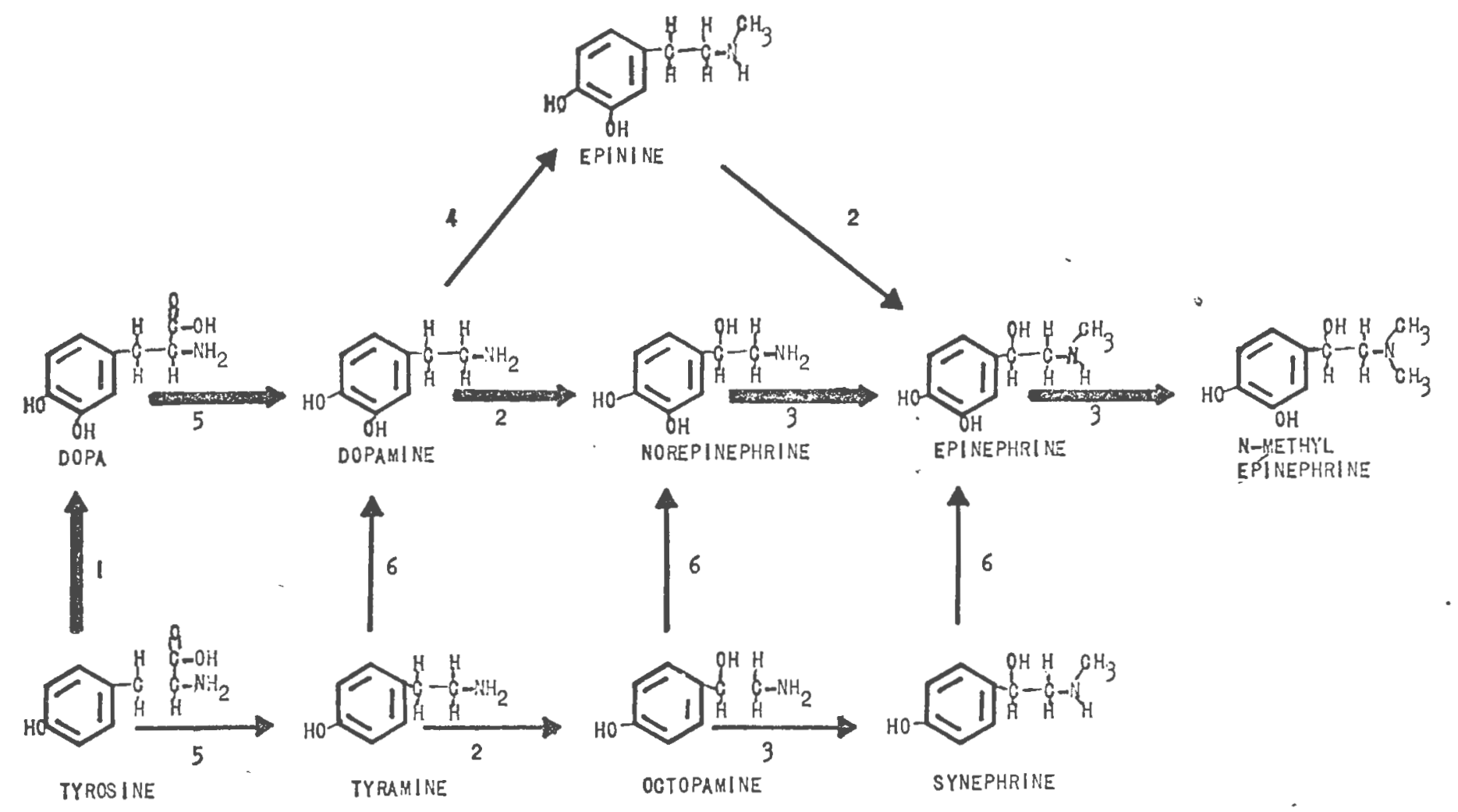

Fig. 2. Main and alternate pathways in the formation of catecholamines: 1) tyrosine hydroxylase, 2) dopamine- $\beta$-oxidase, 3) phenylethanolamine-N-methyl transferase, 4) nonspecific $\mathrm{N}$-methyl transferase in lung, 5) aromatic amino acid decarboxylase, 6) catechol-forming enzyme (After Axelrod, 1966). 
remains in the supernatant fraction following high-speed centrifugation and is not, therefore, particle bound (Lovenberg et al.; 1962). Th1s enzyme requires pyridoxal phosphate as a cofactor (Green, 1945). Dopamine$\beta$-oxidase activity has been linked to the chromaffin granules of the adrenal medulla (Levin et al., 1960; Oka et al., 1967) and the granulated vesicles of sympathetic nerve endings (Potter et al., 1963). It requires oxygen, ascorbic acid, and a dicarboxylic acid as cofactors (Levin et al., 1960). Phenylethanolamine-N-methyl transferase is for the most part confined to the adrenal medulia in mammals and is found in the supernatant of cell homogenates. It requires S-adenosylmethionine as a methyl donor (Axelrod, 1962a). Tyrosine is readily available in the circulation in levels of $10-15 \mathrm{mg} / \mathrm{l}$ (Spector et al., 1963). It is therefore presumed that tyrosine is taken up into sympathetic nerve endings and other sites of catecholamine synthesis by an active transport system similar to that acting in the brain (Chrivos et al., 1960). Within the cell, tyrosine passes from the cytoplasm to the mitochondria where it is converted to 3,4-dihydroxyphenyla lanine (DOPA) which returns to the cytoplasm where it is decarboxylated to dopamine (DM). Finally, DM enters the granulated vesicles where it is converted to $\mathrm{NE}$. In the adrenal medulia some of the formed $\mathrm{NE}$ passes back into the cytoplasm where it is converted to $\mathrm{E}$. The E then re-enters the granulated vesicles for storage (Axelrod, 1966).

The available evidence supports tyrosine as the immediate precursor from which the catecholamines are synthesized. In addition to being readily avallable in the clrculation (hoc. sit), adequate levels are maintained even in starvation states (Melmon et al., 1964). Other possible precursors such as DOPA or DM are not readily available in the circulation (Anton et al., 1964). 
Factors controlling the rates of catecholamine synthesis are not yet fully understood. Udenfriend (1966) presents rather convincing evidence that tyrosine hydroxylase activity represents the rate-limiting step in NE synthesis: Of the three possible precursors (1.e. tyrosine, DOPA and $D M$ ), saturation could be achieved only with tyrosine. The $V_{\max }$ for tyrosine hydroxylase is two or three orders of magnitude lower than the values for DOPA decarboxylase or dopamine- $\beta$-oxidase, its activity being expressed in millimicromoles of tyrosine oxidized per gram of tissue per hour compared with micromoles of DOPA or DM converted per gram of tissue per hour. Thus, tyrosine hydroxylase becomes limiting because the amount of enzyme is limfing. Studies with inhibitors add further support. $\alpha$-Methyl-p-tyrosine, $\alpha$-methylphenylalanine, 3-iodotyrosine, 3-1odo$\alpha$-methyltyrosine and Hassle 22/54, all inhibitors of tyrosine hydroxylase, lower tissue levels of $\mathrm{NE}$ when administered to animals. However, disulfiram, which inhibits dopamine- $\beta$-oxidase, w111 also lower tissue levels (Musacchio et a1., 1964). In contrast, benzyloxyamine and certain benzylhydrazine analogs, also inhibitors of dopamine- $\beta$-oxidase, will not lower NE levels appreclably in vivo (N1kodijevic et al,, 1963). There is therefore a possibility that under certain circumstances dopamine- $\beta$-oxidase could be rate-limiting. DOPA decarboxylase cannot be considered ratelimfing since it apparently cannot be inhibited sufficiently to interfere with catecholamine synthesis (Hess et al., 1961)。

Factors other than enzyme activity could conceivably influence the rate of catecholamine biosynthesis. Availability of substrate, enzyme cofactors, and integrity of the cellular compartments may play a role. In regard to this latter point, it has been shown that reserpine depresses NE synthesis in sympathetic nerves possibly by causing damage to the 
granulated vesicles (Dahlstrom et al., 1965). The activity of the sympathet1c nervous system itself may play a role. NE synthesis from tyrosine is depressed in the denervated submaxillary gland (Musacchio and Weise, 1965). However, avallable evidence, though sparse, suggests that sympathetic tone is normal in hypertension (P1ckering, 1936; Pert, 1966).

Since an increase in synthesis of the catecholamines would necessarily be reflected by an increase in their degradation products, it is necessary to have an understanding of the basic mechanisms of catecholamine metabolism. A great deal of advancement has been made in this area within recent years. Basically two enzymes are involved in the metabolic degradation of the catecholamines: Monoamine oxidase (MAO) and catecholO-methyl transferase (COMT).

MAO is widely distributed in the tissues, being localized in the mitochondria (Blaschko et al., 1957). Especially large quantities occur in sympathetic nerve endings (Snyder et al., 1965). It appears that its role in catecholamine metabolism is limited to disposing of excess stored material within the sympathetic nerve endings (Koplin, 1964). MAO has no apparent role in the physiological inactivation of $\mathrm{NE}$ or $E$ since near total inhibition of the enzyme has no effect on the physiological responses to either injected or nerve-released catecholamines (Burn et a1., 1954; Griesemer et al., 1953). On the contrary, MAO plays an important role in regulating the tissue levels of the catecholamines. Marked inhibition of MAO leads to a rise in the tissue levels of $\mathrm{NE}$ and other endogenous amines, especially serotonin, DM and tyramine which serve as better substrates for MAO than NE and E (Koplin, 1964; Shore et al., 1957). In a latter publication, Shore (1966) points out the importance of MAO in regulating the uptake and storage of blogenic monoamines in sympathetic innervated tissues. 
Catechol-0-methyl transferase (COMT) is found in almost all tissues and is highly concentrated in the liver and kidneys (Axelrod and Torchick, 1958). COMT activity remains in the cytoplasm following high speed centrifugation and its function 1 s considered to be extra-neuronal since tissue levels of $\mathrm{NE}$ are unaffected by the activity of the enzyme (Crout et al., 1961). Axelrod (1966) presents extensive evidence to support the view that COMT acts primarily upon circulating amines and amines released from sympathetic nerve endings. In addition, he presents additional evidence to implicate the enzyme, phenylethanolamine $N$-methyl transferase (PEMT) in the metabolism of $N E$. The major, and some minor, pathways for the catabolism of $N E$ and $E$ are shown in Figure 3.

The three mafor excretory products of $N E$ and $E$ are 3-methoxy-4hydroxymandelic acid (vantlylmandelic acid; VMA), normetanephrine (NMN) and metanephrine (MN) (Armstrong et al., 1957; Axelrod and Tomchick, 1958). The major portion of VMA in the urine probably represents $\mathrm{NE}$ produced and deaminated within the nerve ending before it has a chance to produce a physiological effect (Kopin, 1964). Therefore, NMN for the most part represents NE which has been physiologically discharged from the sympathetic nerves.

There have been surprisingly few well-controlled studies regarding $E$ and $N E$ levels in ordinary cases of hypertension. Euler et al. (1954) found some evidence of increased excretion of free and conjugated $N E$ in a limited number of hypertensive patients. Romano et al. (1966) reported urinary VMA levels to be approximately twice as high in hypertensive subjects as compared to control values. Stott and Robinson (1967) found NMN excretion higher in hypertensives. However, the majority of investigators have failed to find any consistent flevition in tissue or urinary levels 


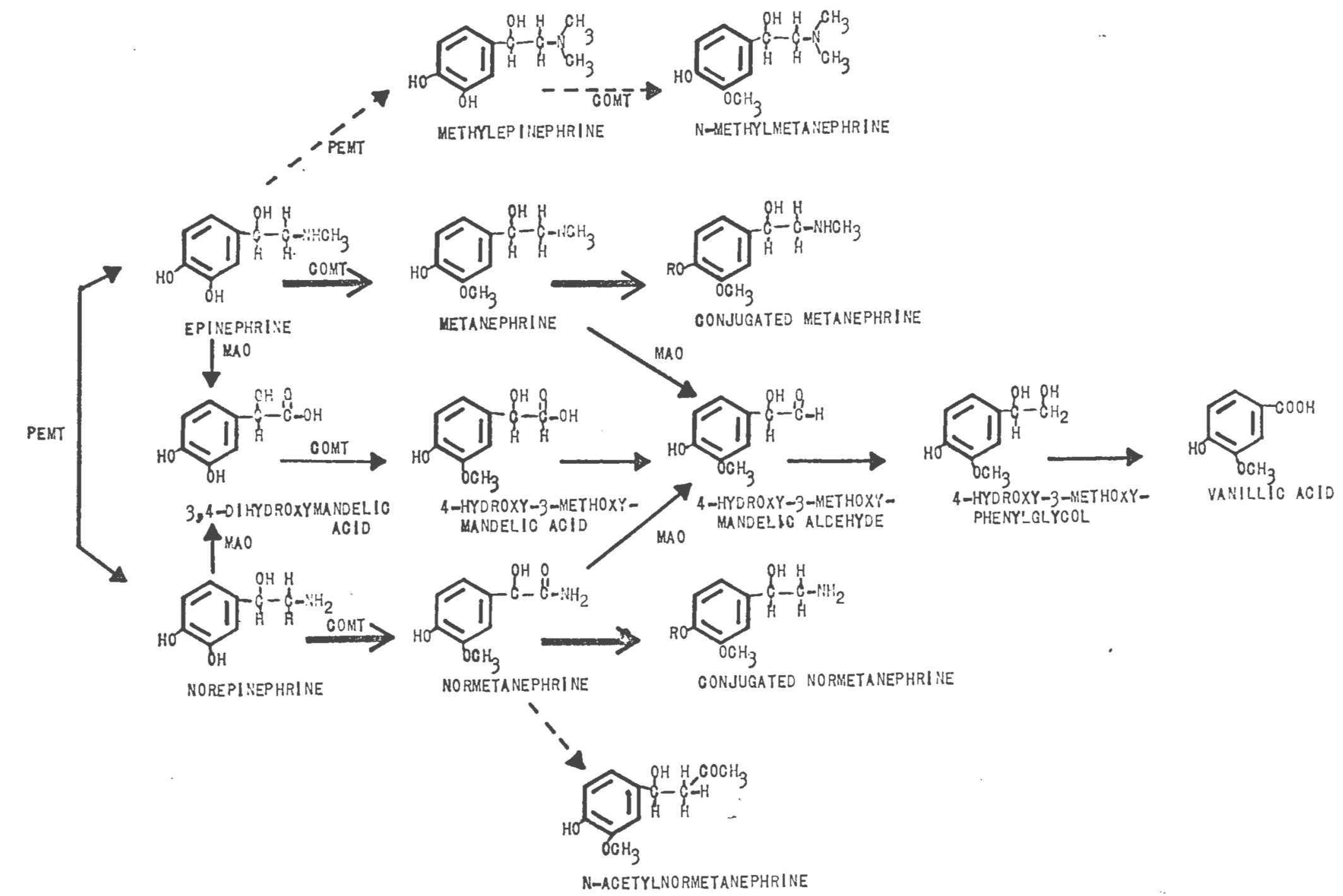

Fig. 3. Metabolism of norepinephrine and epinephrine. Heavy arrows indicate main pathway for tissue metabolism, solid arrows indicate main pathway for intraneuronal metabolism, dashed arrows indicate minor pathways of metabolism. Catechol-0-methyl transferase (COMT), monoamine oxidase (MAO), phenylethanolamine $\mathrm{N}$-methyl transferase (PEMT). (After Axelrod, 1966). 
of $E, N E$ or their metabolites in hypertensive diseaser.Brunfes, 1964; Gitlow et al., 1963; Gitlow et al., 1962; Petrasek et al., 1966; Sjoerdsma, 1961; Raab, 1961; Wegmann et a1., 1962).

It is quite possible tha $\mathrm{NE}$ could particlpate in the hypertensive process at the local tissue level without giving rise to increased plasma levels or excretion rates. If both the release and re-uptake of NE from its storage sites were increased, then increased symbathetic activity would be possible without any outward signs of NE involvement. Studies into the possibility of an increased local turnover have been rather limited. Gitlow et al. (1964), using tritiated NE, found a trend for decreased metabolic clearance in advanced hypertensive patients. Mendlowitz et a1. (1959) proposed a hypothetical deffciency of COMT in the vascular wall. However, Sjoerdsma et al. (1961) could show no deficiency of COMT or MAO activity in hypertension. Reciently DeChamplain et al. (1967) demonstrated decreased accumulation of tritiated $N E$ in certain tissues of DOCA (desoxycorticosterone acetate) hypertensive rats. A highly significant inverse relationship was shown between blood pressure and both endogenous and labeled NE levels in the heart. They also demonstrated an increase in $\mathrm{NE}$ metabolites in the hypertensive animals. A defect in amine storage was offered as a possible explanation.

It is also possible for NE to participate in the hypertensive process at normal tissue levels if the vascular wall becomes over-responsive. There are a growing number of reports which suggest such a possibility (Raab, 1961; Doyle and Fraser, 1961; McCubbin and Page, 1963; Baum and Shropshire, 1967). Pert (1966) sheds doubt on the theory of increased vascular sensitivity and advocates caution in the interpretation of experimental results. Additional studies are necessary in this area before the importance of these findings can be established. 
Recent evidence suggests that angiotensin is a highly potent releaser of adrenal catecholamines (Feldberg and Lewis, 1964; Ibid. 1965). The implications are that the catecholamines may be involved in the reninanglotensin theory of hypertension. Other investigators, however, have not been able to confirm these findings. Vincent et al. (1965) could show no effect of angiotensin administration on VMA excretion in labile hypertensive subjects, and Healy (1967) also could not show any effect on either VMA or urinay catecholamine excretion rates.

One would have to conclude that no convincing evidence currently exists to directly implicate NE or $E$ in the hypertensive process, but one would equally have to conclude that there is no convincing evidence which would completely exonerate them.

The immediate precursor to $N E$, dopamine (DM), has received very little attention as a possible participant in the hypertensive process. And yet, DM possesses all the attributes of a vasoactive substance. It is pressor in the cat (Holtz et al., 1963), predominantly so in the dog (Goldberg and Sjoerdsma, 1959; Maxwell et al., 1960; Holmes and Fowler, 1962; McDonald and Goldberg, 1963), in man (Horwitz et al., 1962; Allwood and Ginsburg, 1964), and in the rat (Holtz et al., 1942). Most of these Investigators attributed the pressor response to an increase in cardiac output since peripheral resistance was found to either decrease or remain relatively unaffected. Small doses of DM, its administration following drugs which block the alpha receptors, and usual doses in the rabbit or guinea pig result in a depressor response which is unaffected by prior administration of beta adrenergic blockers (McDonald and Goldberg, 1963; Vanov, 1963; Holtz et al., 1963; and Eble, 1964). These findings would suggest that the pressor effect of DM is at least partially due to action 
on the alpha receptors while the depressor response results from an action other than stimulation of beta receptors. Prior administration of reserpine does not affect the response to DM but completely prevents the usual pressor response to tyramine, a potent releaser of $N E$ (McNay and Goldberg, 1966). In addition, Stone et al. (1963) showed that DM does not deplete tissue catecholamines. These findings, coupled with those of Horwitz et al. (1960) who showed that MAO inhibition greatly augmented the pressor response of DM but had little effect on the pressor response to $N E$, would suggest that DM itself is pressor and does not act by releasing $\mathrm{NE}$ or by enzymatic conversion to another catecholamine. Horwitz et al. (1962) have estimated the pressor potency of DM to be $1 / 25$ to $1 / 50$ that of $N E$ in man.

Dopamine is widely distributed in the tissues. Schumann (1959) reported DM to comprise $2 \%$ of the total catecholamines in the adrenal medulla, 50\% in sympathetic nerves and ganglia, $90 \%$ in the 11 ver, $98 \%$ in the lungs and 30 to $50 \%$ of the total catecholamines in the spleen, pancreas parotid gland, and brain. Euler and L1shajko (1957) reported similar findings for lung and spleen. Other investigators have not been able to confirm the presence of large quantities of DM in mammalian t1ssues. Wegmann (1963) could detect the presence of DM only in the spleen and kidney of the dog. Anton and Sayre (1964) generally found DM tissue levels to be low, except in the brain for which their values were in general agreement with those of Carlsson (1959). These same authors were unable to detect the presence of either DM or DOPA in the plasma of humans, dogs, or rabbits,

As the immediate precursor to $N E$, $D M$ is taken up from the cytoplasm of sympathetic nerves by granulated vesicles in the nerve endings 
(Kirshner, 1962; Musacchio et al., 1964) and oxidized to NE (Levin et al., 1960; Potter and Axelrod, 1963). Recently an enzyme has been found in rabbit lung which will N-methylate DM to form epinine (Axelrod, 1962b). Dopamine-beta-oxidase will hydroxylate epinine to E (Bridgers and Kaufman, 1962), thus establishing a minor pathway for the synthesis of $E$. The major metabolic pathway for the degredation of DM leads to the formation of homovanilif acid (HVA) Hornyklewicz, 1966). There is evidence, at least in the brain, that DM is first attacked by MAO leading to the formation of 3,4-dihydroxyphenylacetic acid which is subsequently 0-methylated by COMT to produce HVA (Anden et a1., 1963; Carlsson and H1llarp, 1962). Carlsson and Waldeck (1964) have reported the normal occurrence of small amounts of 3-methoxytyramine in the brain and a considerable increase. following administration of MAO inhibitors. This would indicate that small amounts of DM may be O-methylated prior to oxidative deamination. It seems logical that MAO should be the first enzyme involved in the catabolism of DM in light of what is known about the tissue distribution of DM and MAO. Both the enzyme and its substrate are concentrated within sympathetic nerve endings (hoc.sit.), and there is no good evidence to suggest that dopamine is normally released as a consequence of nerve stimulation. The major pathways for the synthesis and catabolism of DM are presented in Figure 4.

Dopamine and 1 ts metabolites are known to increase in the urine in neuroblastoma (Kaser, 1966), melanoma (Duchon and Gregora, 1962), familial dysautonomia (Smith et al., 1963) and malignant pheochromocytoma (Robinson et al., 1964); but the possible role of DM and 1 ts metabolites in hypertension have been given only passing interest. Bischoff and Torres (1962) report the urinary excretion of DM to be within the normal range in a 

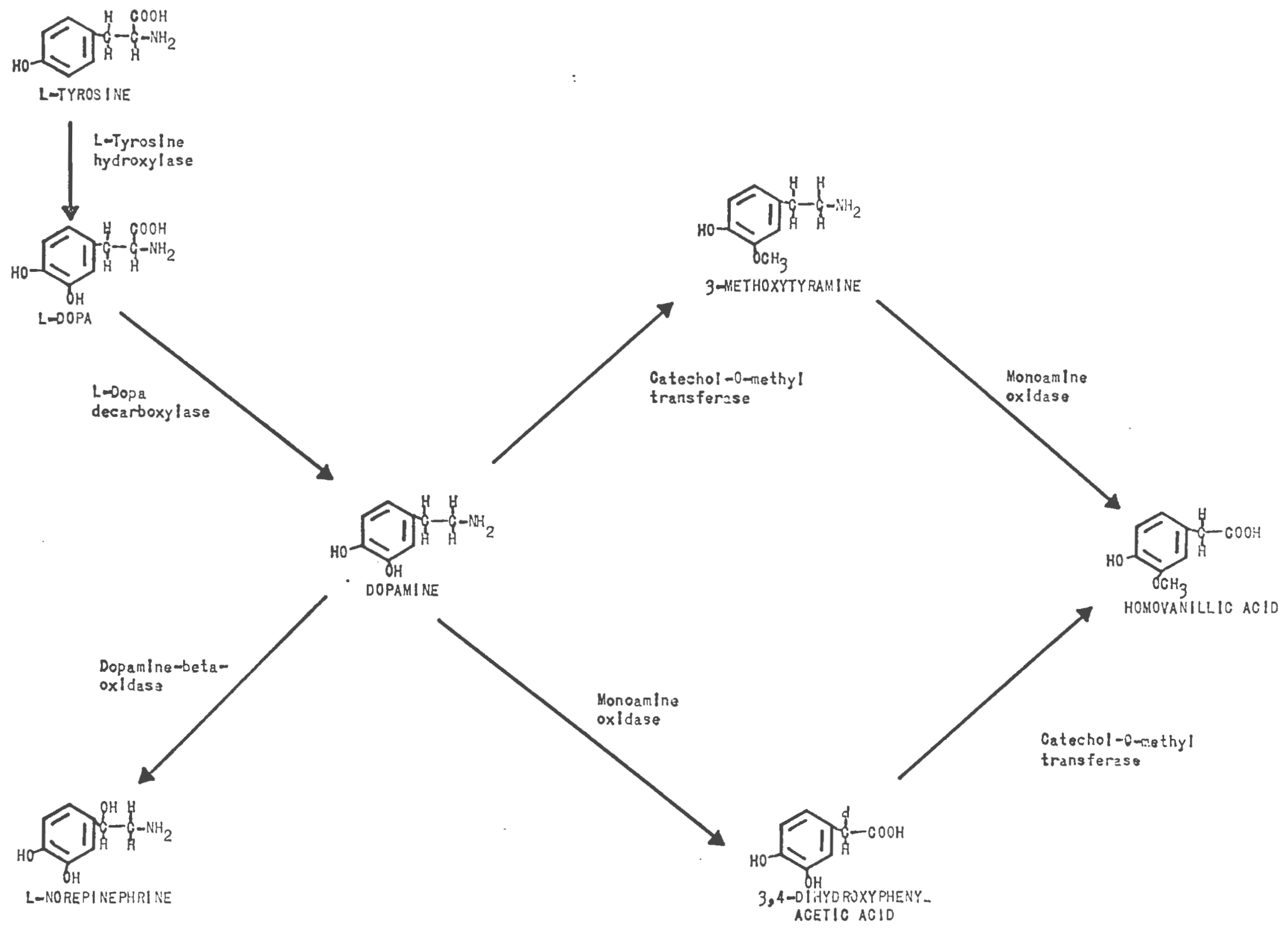

Fig. 4. Main pathway of biosynthesis and catabolism of dopamine in the mammalian organism. L-dopa: L-dihydroxyphenylalanine; MAO: monoamine oxidase; COMT: catechol-0-methyltransferase. (After Hornykiewicz, 1966). 
very limited number of hypertensive patients, and Petrasek et al. (1966) reported HVA excretion to be normal in a larger number of patients. The only study dealing directly with the possible role of DM in hypertension appears to be that of DeFanti and DeFeo (1963). These investigators found the urinary excretion of DM elevated in renal hypertensive rats and found a positive correlation between the blood pressure in these animals and the logarithm DM concentration.

The findings of DeFanti and DeFeo (1963), the established pressor activity of DM in man and animal, and the lack of controlled studies into the possible involvement of DM in renal hypertension suggest the need for further studies in this area. 


\section{A. OBJECTIVES}

The objectives of this inverit, thon are as follows:

1. To develop a reliable method for the assay of dopamine in rat urine.

2. To determine if the winary excretion of dopamine in rats and dogs rendered hypertensive by relias : schemia.

3. To determine if the arterial blood pressure is sigificantly dependent upon the increase in doparine production.

4. To determine the role of the kidney in the elevation of tissue dopamine levels which follow the administration of dihydroxyphenylalanine. B. MATERIALS AND METHODS

1. Production of Experimental Hypertension

Male albino rats of the Sprague Dawley strain weighing 90 to $100 \mathrm{~g}$ were used for this investigation. Experimental renal hypertension was induced by a two-stage operation under ether anesthesia according to the method of Goldblatt et al. (1934) as modifled by Dury (1938). The first consisted of removal of the right kidney through a dorsal incision; and the second, compression of the left renal artery. A period of two weeks separated the two operations to allow time for the animals to recover and to carry out the procedures listed below. Compression of the left renal artery was carried out in the following manner: The artery was located through a ventral midline incision in the lower abdomen and carefully separated from the renal vein and surrounding connective tissue. A wire stylus obtained from either a 19-, 20- or 21-gauge needle was laid alongside the artery, the choice of size being based upon an attempt to produce a 
reduction in renal blood flow of at least $50 \%$. A silk ligature was then double-knotted around both the artery and stylus, temporarily cutting off renal blood flow. The stylus was then carefully removed, leaving the ifgature in place. The muscle layer was sutured and the skin incision closed with wound clamps. The rats were divided into three groups of 16 each and housed 8 to a cage.

A group of sham-operated rats served as controls and was run concurrently with the experimental groups. These animals were also subjected to two operations: the first, removal of the right kidney; the second, manipulation of the left renal artery. The indirect systolic blood pressure of each animal was obtained initially at weekly intervals and then at two-week intervals. An Infraton ${ }^{1}$ unit connected to a sensitive oscilloscope ( $1 \mathrm{mV} / \mathrm{cm}$ deflection) was used to obtaln a pulse wave from the ta11. A special plexiglass holder was devised for the pressure-sensitive microphone which, with a screw, permitted adjustment of the pressure applied to the microphone in order to obtain the maximum pulse wave. A rat tail cuff attached to an aneroid manometer was placed proximal to the microphone on the rat's tail. The cuff was inflated to a pressure well above the anticipated systolic pressure. Systolic blood pressure was recorded as that point, to the nearest $5 \mathrm{~mm} \mathrm{Hg}$, where the pulse wave returned as the pressure was slowly released from the cuff. As temperature variation was found to create difficulties in obtaining an adequate pulse wave, all determinations were carried out in a constant temperature room at $25^{\circ} \mathrm{C}$.

2. Collection of Urine

Following the blood pressure determinations, rats within the same

1. Beckman Instruments Inc., Spinco Division, Ralo Alto, California. 
group having the same or nearly the same blood pressures were paired and placed in stainless steel metabolism cages to collect 24-hour urine samples. A sufficlent quantity (4-5 drops) of concentrated sulfuric acid was added to the collection vessel to insure an acid milleu in order to prevent breakdown of urinary catecholamines. The total urinary output for 24 hours was recorded in $\mathrm{mI}$ and the samples frozen at $-40^{\circ} \mathrm{C}$ for subsequent determination of dopamine content.

\section{Collection of Blood Samples}

At the end of the experiment each of the surviving rats was sacrificed by decapitation and the blood collected. A small amount of heparin was added to each tube to prevent coagulation. The samples were then centrifuged to separate the plasma, which was removed and frozen for subsequent dopamine assay.

\section{Comparison of Kidney Dopamine Content}

An additional group of hypertensive rats was prepared for the purpose of determining any changes in the renal tissue content of dopamine which might be associated with the hypertensive state. Under ether anesthesia the right kidneys were removed, blotted to remove excess blood, welghed, and then frozen in liquid nitrogen and stored at $-40^{\circ} \mathrm{C}$ to awalt assay for dopamine content. Eight weeks following the second operation, the surviving rats were sacrificed by decapitation, and the left kidneys removed and treated as above. The blood from these animals was pooled to form one large sample which was subsequently assayed for dopamine content. The blood pressure of these animals was recorded only twice: fust prior to

the initial operation while under ether anesthesia and fust prior to sacrifice, again under ether anesthesia. 


\section{Hypertensive Dogs}

One female mongrel dog and one male mongrel dog were also rendered hypertensive by a two-stage operation. In the first procedure the right kidney was removed under pentobarbital anesthesia, $30 \mathrm{mg} / \mathrm{kg}$, through an incision made in the dorsal surface just below the rib cage. A double silk ligature was tied around the renal artery, vein and ureter near the renal pelvis. A cut was made proximal to these ties, and the kidney was then removed. Care wa exercised to prevent damage to the adrenal gland. The muscle incision was closed with chromic gut and the skin with dermal silk. After a two-week recovery period, the second stage of the operation was carried out, again under pentobarbital anesthesia. An incision was made in the linea alba from the xyphold process to include the umbilical scar. The left renal artery was freed from the renal vein and stripped clean of fascla. A silk ligature was placed underneath the artery; and a metal stylus, prepared from a series of common finishing nails, was selected with the intent of reducing the lumen of the artery approximately $50 \%$ and was lald alongside the artery. A double-knotted tie was then completed around both the artery and the stylus, momentarlly cutting off renal blood flow. The stylus was then removed, restoring renal blood flow but leaving a constriction in the artery. The loose end of the ligature was anchored to the dorsal muscle surface to prevent slippage. The incision was then closed in the usual manner. Two dogs were utilized as controls, One male underwent surgical removal of the right kidney and simultaneous manipulation of the left renal artery to serve as a sham-operated control; the other, a male, served as an unoperative control. All surgery was carried out under aseptic technique, and post-operative antiblotics were utilized to minlmize the chances of infection. 
Weekly blood pressure recordings were obtained from the tail of the dogs using the Infraton unit and finger-occluding cuff attached to an aneroid manometer. Twenty $\mathrm{ml}$ blood samples were collected at weekly intervals using EDTA-charged Evacuettes ${ }^{2}$. The dogs were also placed in metabolism cages each week for collection of 24-hour urine samples. Some difficulty was encountered in getting the dogs to void while within the confines of the metabolism cage, and $5 \mathrm{mg}$ of Urecholine $\mathrm{Cl}^{3}$ subcutaneously was occasionally employed to force emptying the bladder. Sulfuric acid was again utilized to provide an acid environment during the collection period. The total urinary output for 24 hours was recorded and an aliquot taken and frozen along with the blood samples at $-40^{\circ} \mathrm{C}$ for subsequent dopamine assay.

6. Cat Infusion Studies

A separate experiment was undertaken in cats to determine the role of the kidney in the elevation of tissue dopamine levels known to occur following infusion of d, l-dihydroxyphenylalanine (Wegmann, 1963). Two female cats and two male cats were sacrificed as controls to determine endogenous levels of dopamine. They were first anesthetized with sodium pentobarbital $35 \mathrm{mg} / \mathrm{kg}$ intraperitoneally, then cardiac standstill was produced by the intravenous administration of potassium chloride. The heart, left kidney, spleen and one lobe of the liver were removed, blotted dry and their weights recorded. The organs were immediately placed in $10 \%$ trichloroacetic acid and homogenized in a Virtis " $45^{114}$ homogenizer. The mixture was

2. A product of Becton, Dickinson \& Co., Rutherford, New Jersey 3. Merck, Sharpe \& Dohme's Trade Name for Bethanechol C1. 4. The Virtis Co. Inc., Division of Cenco Instruments, Gardiner, New York 
transferred to centrifuge tubes and centrifuged at 12,000 RPM for 20 minutes in a Lourdes Model $A B$ centrifuge to separate the clear supernatant. The volume of the supermatant was adjusted to $50 \mathrm{ml}$ with $10 \%$ trichloroacetic acid and a $25 \mathrm{ml}$ allquot utilized for the determination of DOPA and dopamine.

In four other cats, d, 1-DOPA $50 \mathrm{mg} / \mathrm{kg}$ was infused into the femoral vein over a 20-minute period. Sodium pentobarbital $35 \mathrm{mg} / \mathrm{kg}$ was used as the anesthetic. An arterial catheter was inserted into the abdominal artery via the femoral artery to a point just below the origin of the left renal artery for the purpose of obtaining $5 \mathrm{ml}$ blood samples midway through the infusion period and one hour after initiation of the infusion. A catheter was likewise inserted through the left ovarian vein or the left spermatic vein into the left renal vein to obtain corresponding venous blood samples. The right renal artery and vein were completely ligated in these experiments. One hour after starting the infusion, the cats were sacrificed by an iv injection of potassium chloride and the heart, left kidney, spleen and a lobe of the liver removed and treated as described above. The blood samples were immediately treated by the addition of $10 \mathrm{ml}$ of $10 \%$ trichloroacetic acid.

In four additional cats $50 \mathrm{mg} / \mathrm{kg}$ of $\mathrm{d}, 1$-DOPA was infused as above except that both renal arteries and veins were tightly ligated to remove the kidneys from the general circulation. Blood samples were not taken in these animals since they would not be representative of a renal A-V difference. The heart, spleen and a lobe of the liver were removed as previously described and assayed for their dopamine and DOPA content.

5. d,i-dihydroxyphenylalanine was obtained from Nutritional Biochemicals Corp., Cleveland 28 , Ohio. 
By a comparison of the results from these studies, it was hoped that the contribution of the kidney to tissue levels of dopamine in the heart, liver and spleen could be determined.

\section{Determination of Dopamine and DOPA}

With certain modifications, the trihydroxyindole method of Carlsson and Waldeck (1958) was used for the fluorimetric estimation of dopamine and DOPA. The blank as employed by these investigators left out sodium sulfite, which is included as an ingredient in one of the reagents used to develop the fluorophore of dopamine and DOPA. The omission of this substance allows a faint lodine color to remain in the blank which acts as a quenching agent resulting in erroneously low blank values. In the present procedure sodium sulfite was added out of the normal sequence, following the addition of all other reagents. Thus, the blank utilized in the present procedure contains all of the chemicals found in a standard assay solution. Additional modifications of the original method included: adjustment of the strength of certain of the reagents, alterations of reaction times and heating the solution prior to UV irradiation. The necessary reagents and a description of the development procedure which was used, are as follows:

$0.1 \mathrm{M}$ Phosphate buffer pH6.5 Dissolve $5.34 \mathrm{~g} \mathrm{Na} 2 \mathrm{HPO}_{4}, 2 \mathrm{H}_{2} \mathrm{O}$ in $500 \mathrm{ml}$ of water. Dissolve $9.52 \mathrm{~g} \mathrm{KH}_{2} \mathrm{PO}_{4}$ (Sorensen) in $500 \mathrm{ml}$ water. Add the former solution to the latter, utilizing a $\mathrm{pH}$ meter to adjust the $\mathrm{pH}$ to 6.5 .

Iodine Solution Dissolve $0.252 \mathrm{~g}$ lodine and $5.0 \mathrm{~g}$ potassium lodide in $100 \mathrm{ml}$ water.

\section{$4.5 \mathrm{~N}$ Sodium Hydroxide Solution}

Alkaline Sulfite Solution Dissolve $5.04 \mathrm{~g} \mathrm{Na}_{2} \mathrm{SO}_{3}, 7 \mathrm{H}_{2} \mathrm{O}$ in - $10 \mathrm{ml}$ water and dilute with $5 \mathrm{~N}$ sodium hydroxide to $100 \mathrm{ml}$.

$6 \mathrm{~N}$ Acetic Acid Solution Dilute $34.2 \mathrm{ml}$ glacial acetic acid with water to $100 \mathrm{ml}$. 
Sodium Sulfite Solution Dissolve $5.04 \mathrm{~g} \mathrm{Na}_{2} \mathrm{SO}_{3}, 7 \mathrm{H}_{2} \mathrm{O}$ in 10 $\mathrm{m} 1$ water.

Glass distilled water was used throughout.

A three $\mathrm{ml}$ aliquot of a column eluate (see sections $8,9,10,11$ ) was transferred to a $15 \mathrm{ml}$ volumetric centrifuge tube and the $\mathrm{pH}$ adjusted to 6.5 by the addition of one $\mathrm{ml}$ of $0.3 \mathrm{M}$ potassium carbonate in the case of a $0.2 \mathrm{~N}$ acetic acid eluate or by the dropwise addition of $5.0 \mathrm{M}$ potassium carbonate to a $2.0 \mathrm{~N}$ hydrochloric acid eluate followed in elther case by the addition of one $\mathrm{ml}$ phosphate buffer $\mathrm{pH}$ 6.5. One-tenth of a $\mathrm{ml}$ of lodine solution was added to the tube, the contents mixed and allowed to react for three minutes. Then one $\mathrm{ml}$ of alkaline sulfite reagent was added, the contents mixed and this reaction allowed to proceed for four minutes. Finally, the $\mathrm{pH}$ of the solution was adjusted to approximately 5.4 by the addition of one $\mathrm{ml}$ of $6 \mathrm{~N}$ acetic acid and the final volume adjusted to $10 \mathrm{ml}$ by the addition of distilled water. The tube was then transferred to a bolling water bath for five minutes, cooled and centrifuged. Two to $3 \mathrm{ml}$ of the resultant solution was transferred to a fused quartz cell and 1 rradiated under a short wave $(254 \mathrm{~m} \mu$ mercury lamp for 10 minutes. ${ }^{6}$ The fluorescence of the solution was read in an AmincoBowman Spectrophotofluorometer ${ }^{7}$ at an activating wavelength of $325 \mathrm{m \mu}$ and a fluorescent wavelength of $380 \mathrm{~m} \mu$ (uncorrected instrument values). A blank was determined for the assay by utilizing an additional $3 \mathrm{ml}$ column aliquot and treating it as outlined above except that $4.5 \mathrm{~N} \mathrm{NaOH}$ was substituted for the alkaline sulfite reagent and $0.1 \mathrm{~m} 1$ of sodium

6. Chromato-Vue, Black Light Eastern Corp., New York, New York.

7. Aminco-Bowman Spectrophotofluorometer, American Instrument Co., Inc., Silver Springs, Maryland. Specifications for the test: Xenon Lamp, Si1t Arrangement Number 5, Photomultiplier Tube iP28. 
sulfite solution was added to $9.9 \mathrm{ml}$ of the resultant solution fust prior to centrifugation. The procedure allowed the handling of up to 18 samples at one time.

Estimation of dopamine or DOPA content in the developed solutions was made by dividing the corrected fluorescent intensities of the unknowns by a value calculated to represent the fluorescent intensity of a solution of dopamine or DOPA containing $0.1 \mu \mathrm{g} / \mathrm{ml}$. This standard value was determined each time a series of unknowns was assayed to guard against deterforation of the reagents and day-to-day variation in fluorescent intensity and was obtained in the following manner: Acldic solutions of dopamine or DOPA to give final concentrations of $0.05,0.1,0.2$ and $0.3 \mu \mathrm{g} / \mathrm{mI}$ and a blank were subjected to the procedures outlined above. These concentrations were all within the range of linearity reported by Carlsson and Waldeck (1958), confirmed by DeFant1 (1961) and supported by the present work. Correction for fluorescence contributed by the reagents was made by subtracting the fluorescent intensity of the blank from the fluorescent intensities of the standard solutions. These corrected values were then adfusted and averaged to obtain a single value representing the fluorescent intensity of a $0.1 \mu \mathrm{g} / \mathrm{ml}$ solution of dopamine or DOPA. The following formulas summarize the mechanics:

$$
I_{s}=\sum\left(F_{s}-R \cdot B \cdot x \frac{0.1}{C}\right) / n
$$

where $I_{s}=$ fluorescent intensity of a $0.1 \mu \mathrm{g} / \mathrm{mI}$ solution of dopamine or DOPA

$F_{S}=$ uncorrected fluorescent intensity of the developed solutions at concentration $\mathrm{C}$

R.B. = fluorescent intensity of the reagent blank

$C=$ final concentrations of dopamine or DOPA in $\mu \mathrm{g} / \mathrm{mI}$

$\mathrm{n}=$ the number of determinations 
and finally:

$$
C_{u}=\left(F_{u}-B_{u}\right) / I_{s}
$$

where $C_{u}=$ the concentration of dopamine or $\mathrm{DOPA}(\mu \mathrm{g} / \mathrm{ml})$ in the developed solution of the unknown

$F_{u}=$ the uncorrected fluorescence intensity of the developed solution of the unknown

$B_{u}=$ the fluorescent intensity of corresponding blank of the unknown

$I_{S}=$ the fluorescent intensity of the standard as determined above

Since the final volume of the developed solutions was $10 \mathrm{ml}$, the total dopamine or DOPA content of a $3 \mathrm{ml}$ column aliquot was equivalent to 10 times the concentration in $\mu \mathrm{g} / \mathrm{ml}\left(10 \mathrm{C}_{\mathrm{u}}\right)$ and the total in a $10 \mathrm{ml}$ eluate to $100 \mathrm{C}_{\mathrm{u}} / 3$. The total amount of dopamine or DOPA in a sample was then calculated by the use of the following formula:

$$
D_{t}=\frac{V_{1}}{V_{2}} \cdot \frac{100 C_{u}}{3}
$$

where $D_{t}=$ the total quantity $(\mu g)$ of dopamine or DOPA in a sample

$V_{1}=$ the volume (mI) of the sample extracted for dopamine or DOPA content

$v_{2}=$ the total volume $(\mathrm{ml})$ of the sample

$C_{u}=$ the concentration of dopamine or DOPA $(\mu \mathrm{g} / \mathrm{ml})$ in the developed solution of the unknown

\section{Extraction of Catecholamines from Urine}

Following modification of the blank as outlined above, it was discovered that the sodium form of Dowex $50 \mathrm{~W}-\mathrm{X} 8$ was extracting a substance from rat urine which displayed native fluorescence interfering with the estimation of dopamine. It was therefore necessary to develop a different method for the extraction of catecholanines from urine other than that 
employed in the original study (DeFanti, 1961; Crawford and Law, 1254; Bertler et al., 1958). Various methods of absorption on alumina at pll 8.4 were tried (Weil-Malherbe and Bone, 1952; v. Euler and Lishajko, 1953; WeilMalherbe, 1961; Weil-Malherbe, 1964; Sma11, 1963) and found to avoid the problems encountered with Dowex. The final extraction method as outlined below is an adaptation of these various methods incorporating what was found by trial and error to give the best urinary recoveries of dopamine. Alumina for chromatographic analysis supplied by British Drug Houses, LTD $^{8}$ was found to possess the most desirable characteristics and was used in this investigation. Prior to use, the alumina was suspended in $500 \mathrm{ml}$ of $2 \mathrm{~N}$ hydrochloric acid and heated to $80^{\circ} \mathrm{C}$ for 20 minutes with constant stirring, filtered onto a glass-sintered filter and washed with an additional $500 \mathrm{ml}$ of $2 \mathrm{~N}$ hydrochloric acid. The alumina was then resuspended in $500 \mathrm{ml}$ of glass-dist1lled water, stirred, allowed to settle for approximately 15 seconds and the water decanted to remove the alumina fines. This was repeated a total of 10 times, and then the alumina was dried at $1050^{\circ} \mathrm{C}$ overnight. Alumina columns were prepared by suspending $0.7 \mathrm{~g}$ of the acid-washed alumina in $10 \mathrm{ml}$ of $0.1 \mathrm{M}$ ammonium acetate buffer $\mathrm{pH} 8.0$ and adjusting the $\mathrm{pH}$ to 8.4 by the addition of $1 \mathrm{~N}$ sodium hydroxide (the quantity of $1 \mathrm{~N}$ sodium hydroxide required was determined for each lot of alumina and was usually about $0.3 \mathrm{ml}$ ). The suspension was agitated for one minute and then poured into a column previously filled with glassdistilled water and plugged with a small pledget of cotton. The columns were constructed of $7 \mathrm{~mm}$ I.D. pyrex glass tubing drawn to a $4 \mathrm{~mm}$ O.D. tip

8. Exclusive United States Distributors: Gallard-Schlesinger Manufacturing Corp., 580 Mineola Avenue, Carle Place, Long Island, New York 11514 
to which polyethylene tubing was attached. The flow rate through the columns was regulated to 2 to $3 \mathrm{ml}$ per minute, when necessary, by adjustable clamps on the tubing. Nalgene ${ }^{R}$ funnels served as the reservolrs. The formed columns were washed with $5 \mathrm{ml}$ of glass-distilled water and clamped until addition of the urine samples. Dog or rat urine aliquots were first centrifuged for 20 minutes in a clinical centrifuge and then $10 \mathrm{ml}$ (minimum $5 \mathrm{ml}$ ) transferred to large pyrex test tubes. Two drops of concentrated hydrochloric acld and $2.0 \mathrm{ml}$ of $0.2 \mathrm{M}$ ethylenediamine tetraacetic acid (disodium salt) were added to each tube. The tubes were stoppered with corks equipped with 21 g needles as relief valves and heated in a bolling water bath for 20 minutes to hydrolyze any dopamine present in conjugated form. The tubes were cooled and their contents. transferred to plastic beakers using three $5 \mathrm{ml}$ rinses of distilled water. The $\mathrm{pH}$ of each was then adjusted to 8.4 with $\mathrm{I} \mathrm{N}$ sodium hydroxide using a model 28 Radiometer automatic titrator ${ }^{9}$ and immediately added to an alumina column. One $\mathrm{ml}$ of $1 \%$ sodium metabisulfite was added to each sample during the $\mathrm{pH}$ adjustment to guard against oxidation of the catecholamines before absorption onto the alumina. After passage of the urine samples, the columns were washed with $5 \mathrm{ml}$ of $1 \mathrm{M}$ sodium acetate followed by $5 \mathrm{ml}$ of distilled water. Elution was performed by the addition of two separate $5 \mathrm{ml}$ portions of $0.2 \mathrm{~N}$ acetic acid. All additions were made just as the meniscus of the previous solution entered the alumina bed. Three $\mathrm{ml}$ aliquots of the combined $10 \mathrm{ml}$ eluates from the columns were then assayed for dopamine content as previously described. If this was not carried out within one-half hour, the eluates had to be frozen to prevent breakdown of their catecholamine content.

9. Radiometer Copenhagen, 811 Sharon Drive, Westlake, Ohio. 
Internal standards were run at various intervals throughout the experimental period by the addition of known amounts of dopamine to the urine prior to processing. The recovery values for these standards are recorded in Table 2 , the average recovery being $82.43 \pm 11.73 \%$ which is somewhat lower than the average recovery of $88.74 \pm 5.93 \%$ obtained for known concentrations of dopamine in $0.2 \mathrm{~N}$ acetic acid (see Table 1 ).

\section{Extraction of Catecholamines from Rat Plasma}

Three methods were used to prepare the blood plasmas of the rats sacrificed at the termination of the experimental period for extraction of their catecholamine content. In one-third of the samples, the plasma proteins were precipitated with perchloric acid and centrifuged; in another third, the samples were hydrolyzed in $1.0 \mathrm{~N}$ perchloric acid at $100^{\circ} \mathrm{C}$ for 10 minutes and centrifuged (Haggendal, 1963); the remaining samples were passed through a column of Sephadex G-25 ${ }^{10}$ which separated the plasma into catecholamine and protein containing portions (Marshall, 1963). The catecholamines were then extracted from the samples for fluorimetric assay using columns of the sodium form of Dowex $50 \mathrm{~W}-\mathrm{X} 8$ as subsequently described in section 11.

10. Extraction of Catecholamines from Whole Blood and Tissues The tissues and whole blood samples from the other portions of this study were all extracted by homogenization in $10 \%$ trichloroacetic acid. These include the rat kidneys and pooled blood sample from section 4, the blood samples obtained from the dog experiments (section 5) and the tissues and blood samples obtained from the cat infusion studies (section 6). Where only the dopamine content was under investigation,

10. A product of Pharmacia Fine Chemicals, Inc., 800 Centennial Ave., Piscataway, New Market, New Jersey 08854 
TABLE 1

Percent recovery of dopamine from $0.2 \mathrm{~N}$ acetic acid

\begin{tabular}{|c|c|c|}
\hline Dopamine Added $(\mu g)$ & Dopamine Found $(\mu g)$ & Percent Recovery \\
\hline 2.00 & 1.80 & 90.00 \\
\hline 2.00 & 1.93 & 96.50 \\
\hline 2.00 & 2.13 & 106.50 \\
\hline 2.00 & 1.67 & 83.50 \\
\hline 2.00 & 1.77 & 88.50 \\
\hline 2.00 & 1.77 & 88.50 \\
\hline 4.00 & 3.57 & 89.25 \\
\hline 4.00 & 3.57 & 89.25 \\
\hline 4.00 & 3.57 & 89.25 \\
\hline 4.00 & 3.67 & 91.75 \\
\hline 4.00 & 3.43 & 85.75 \\
\hline 4.00 & 3.43 & 85.75 \\
\hline 4.00 & 3.57 & 89.25 \\
\hline 6.00 & 4.90 & 81.67 \\
\hline 6.00 & 4.90 & 81.67 \\
\hline 6.00 & 5.47 & 91.17 \\
\hline 6.00 & 4.77 & 79.50 \\
\hline 6.00 & 5.47 & 91.17 \\
\hline 6.00 & 5.23 & 87.17 \\
\hline
\end{tabular}

Mean recovery \pm standard deviation $=88.74 \pm 5.93 \%$ 
TABLE 2

Percent recovery of dopamine added to urine samples

\begin{tabular}{|c|c|c|c|c|}
\hline Endogenous & Dopamine & Total Dop & nine & Percent \\
\hline Dopamine $(\mu g)$ & Added $\left(\mu_{g}\right)$ & Calculated $(\mu g)$ & Found $(\mu g)$ & Recovery \\
\hline 1.50 & 2.00 & 3.50 & 4.00 & 114.28 \\
\hline 1.00 & 2.00 & 3.00 & 2.1 & 70.00 \\
\hline 1.60 & 2.00 & 3.60 & 2.93 & 81.39 \\
\hline 1.30 & 2.00 & 3.30 & 2.33 & 70.61 \\
\hline 2.73 & 2.00 & 4.73 & 4.03 & 85.20 \\
\hline 1.27 & 2.00 & 3.27 & 3.07 & 93.88 \\
\hline 1.70 & 2.00 & 3.70 & 2.77 & 74.86 \\
\hline 2.07 & 2.00 & 4.07 & 3.33 & 81.82 \\
\hline 0.73 & 2.00 & 2.73 & 2.53 & 92.67 \\
\hline 1.10 & 2.00 & 3.10 & 2.10 & 67.74 \\
\hline 0.73 & 2.00 & 2.73 & 2.50 & 91.57 \\
\hline 0.83 & 3.00 & 3.83 & 3.57 & 93.21 \\
\hline 1.03 & 3.00 & 4.03 & 3.73 & 92.55 \\
\hline 0.87 & 3.00 & 3.87 & 2.73 & 70.54 \\
\hline 1.27 & 3.00 & 4.27 & 3.50 & 81.97 \\
\hline 1.57 & 3.00 & 4.57 & 3.67 & 80.31 \\
\hline 1.07 & 4.00 & 5.07 & 3.90 & 76.92 \\
\hline 1.23 & 4.00 & 5.23 & 3.93 & 75.14 \\
\hline 0.93 & 4.00 & 4.93 & 3.53 & 71.60 \\
\hline
\end{tabular}

Mean recovery \pm standard deviation $=82.43 \pm 11.73 \%$ 
the trichloroacetic acid extracts were passed through columns of alumina as described for urine. The samples from the cat infusion studies, however, were passed through a two-column procedure as described in the following section.

\section{Separation of Dopamine and DOPA}

A two-column procedure was used to separate dopamine from DOPA in the samples obtained following the infusion of d,1-DOPA in cats. The first column was prepared using the sodium form of Dowex 50W-X8 which has been shown by Bertler et al. (1958) to selectively bind dopamine while allowing DOPA to pass on through the column. The sodium form of the resin was prepared by cycling the resin first through $2 \mathrm{~N}$ hydrochloric acid followed by several washes with glass-distilled water, then through several changes of $5 \mathrm{~N}$ sodium hydroxide and finally washed with glassdistilled water until the supernatant was neutral. The resin was then filtered by suction onto a glass-sintered filter and stored in molst form in a tightly stoppered bottle. The columns were prepared by suspending $500 \mathrm{mg}$ of the prepared resin in distilled water and pouring the mixture into columns constructed from the discarded barrels of $1 \mathrm{mI}$ tuberculin syringes which had been previously filled with distilled water and plugged with small pledgets of cotton. After the columns had formed, $10 \mathrm{ml}$ of $1.0 \mathrm{~N}$ sodium acetate-acetic acid buffer $\mathrm{pH} 6.0$ was passed through each column followed by $5 \mathrm{ml}$ of distilled water. The columns were then ready for use. The samples were prepared for addition to the columns by selecting sultable aliquots of the trichloroacetic acid extracts, adfusting the $\mathrm{pH}$ to 6.5 with 5 M potassium carbonate, adding $2 \mathrm{ml}$ of $0.2 \mathrm{M}$ ethylenediamine tetraacetic actd (disodium salt) and $1 \mathrm{ml}$ of $1 \%$ sodium metabisulfite to each sample. As a sample passed through a 
column (flow rate $=0.25 \mathrm{ml} / \mathrm{minute}$ ), the effluent $(E-1)$ was collected in a small plastic beaker resting on a magnetic stirrer which contained 1 $\mathrm{ml}$ of $2 \mathrm{~N}$ hydrochloric acid and a bar to permit continual agitation of the effluent. This was found necessary to prevent destruction of DOPA in the effluent. The column was then washed with two 10-ml portions of distilled water which was combined with the effluent (E-1). The dopamine was then eluted from the column using two separate $5 \mathrm{ml}$ portions of $2 \mathrm{~N}$ hydrochloric acid. A $3 \mathrm{ml}$ allquot of this was assayed for dopamine content as previously described. The volume of the combined effluent and washings (E-1) was adfusted to $50 \mathrm{ml}$ with distilled water, and a $5 \mathrm{ml}$ aliquot taken for extraction and assay of the DOPA content using alumina columns at $\mathrm{pH} 8.4$ and the fluorimetric procedure as previously described for the urine samples. The method as described achieved an excellent separation of DOPA and dopamine with a $94.62 \pm 4.30 \%$ recovery of dopamine and a $78.67 \pm 4.6 \%$ recovery of DOPA as determined from known mixtures of the two substances (see Table 3). 
TABLE 3

Percent recovery of $\mathrm{DOPA}^{\mathrm{a}}$ and dopamine from mixtures in $10 \%$ trichloroacetic acid

\begin{tabular}{|c|c|c|c|c|c|}
\hline \multirow[b]{2}{*}{$\operatorname{Added}(\mu \mathrm{g})$} & \multicolumn{2}{|c|}{ Dopamine } & \multicolumn{2}{|c|}{ DOPA } & \multirow[b]{2}{*}{$\begin{array}{l}\text { Percent } \\
\text { Recovered }\end{array}$} \\
\hline & Found $(\mu g)$ & $\begin{array}{l}\text { Percent } \\
\text { Recovered }\end{array}$ & Added $(\mu g)$ & Found $(\mu g)$ & \\
\hline 4 & 3.83 & 95.75 & 4 & 3.05 & 76.25 \\
\hline 4 & 4.17 & 104.25 & 4 & 3.14 & 78.50 \\
\hline 4 & 3.63 & 90.75 & 4 & 3.25 & 81.25 \\
\hline 4 & 3.95 & 98.75 & 6 & 4.13 & 68.83 \\
\hline 4 & 3.65 & 91.25 & 6 & 4.61 & 76.83 \\
\hline 4 & 3.57 & 89.25 & 6 & 4.87 & 81.17 \\
\hline 4 & 3.69 & 92.25 & $20^{b}$ & 16.87 & 84.35 \\
\hline 4 & 3.91 & 97.75 & $20^{b}$ & 16.30 & 81.50 \\
\hline 4 & 3.77 & 94.25 & $20^{b}$ & 15.48 & 77.40 \\
\hline 0 & 0 & 0 & $20^{b}$ & 15.65 & 78.25 \\
\hline 0 & 0 & 0 & $20^{b}$ & 16.70 & 83.50 \\
\hline 0 & 0 & 0 & $20^{b}$ & 15.25 & 76.25 \\
\hline 4 & 3.71 & 92.75 & 0 & 0 & 0 \\
\hline 4 & 3.89 & 97.25 & 0 & 0 & 0 \\
\hline 4 & 3.65 & 91.25 & 0 & 0 & 0 \\
\hline
\end{tabular}

a dihydroxyphenylalanine

$\mathrm{b}$ an allquot one-fifth the volume of the combined washings and effluent from the dowex column was assayed for DOPA content. 
C. RESULTS

All of the results of the varlous phases of this study, which Include the values from the control and experimental rat study on the relationship of urinary dopamine levels to renal hypertension and the statistical evaluation of these results; the results from the assay of the plasma obtained upon sacrifice of the hypertensive rats surviving the twentyweek study; the results from the assay of the left ischemic kidneys from a group of hypertensive rats; the urinary and blood dopamine levels from the study In $\operatorname{dog} 8$; and the results obtained when d,1-DOPA was infused Into cats with and without functional kidney tiosue, are presented in this section.

1. Data for the Control Group of Rats in the Urinary Dopamine Study are presented in TABLES 4-14. Each entry in these tables represents the results obtalned from a pooled sample comprised of two animals. 
TABLE 4

Control Group (week one). Relationship of urinary dopamine levels (paired samples) to arterlal blood pressure (paired means) in male rats.a

\begin{tabular}{|c|c|c|c|}
\hline $\begin{array}{c}\text { Blood } \\
\text { Pressure } \\
\text { mm Hg }\end{array}$ & $\begin{array}{c}\text { Dopamine } \\
\mu \mathrm{g} / 1\end{array}$ & $\begin{array}{r}\text { Dopamine } \\
\mu \mathrm{g} / 24 \mathrm{~h}\end{array}$ & $\begin{array}{l}\text { Dopamine } \\
\mu \mathrm{g} / \mathrm{kg} / 24 \mathrm{~h}\end{array}$ \\
\hline 130 & 420 & 4.20 & 12.28 \\
\hline 140 & 178 & 2.31 & 7.86 \\
\hline 130 & 453 & 6.34 & 18.43 \\
\hline 135 & 320 & 4.96 & 14.21 \\
\hline 123 & 250 & 4.87 & 13.16 \\
\hline 120 & 380 & 3.42 & 9.83 \\
\hline 115 & 440 & 5.28 & 15.00 \\
\hline 125 & 600 & 6.30 & 17.40 \\
\hline 113 & 540 & 3.78 & 11.32 \\
\hline \multicolumn{4}{|c|}{ Mean \pm standard deviation } \\
\hline
\end{tabular}

a control values prior to any operative procedures 
TABLE 5

Control Group (week two). Relationship of urinary dopamine levels (paired samples) to arterial blood pressure (palred means) in male rats. ${ }^{a}$

\begin{tabular}{cccc}
\hline $\begin{array}{c}\text { Blood } \\
\text { Pressure } \\
\mathrm{mm} \mathrm{Hg}\end{array}$ & $\begin{array}{c}\text { Dopamine } \\
\mu \mathrm{g} / 1\end{array}$ & $\begin{array}{c}\text { Dopamine } \\
\mu \mathrm{g} / 24 \mathrm{~h}\end{array}$ & $\begin{array}{c}\text { Dopamine } \\
\mu \mathrm{g} / \mathrm{kg} / 24 \mathrm{~h}\end{array}$ \\
\hline 115 & 163 & 5.22 & 11.25 \\
128 & 237 & 4.38 & 11.46 \\
120 & 597 & 6.87 & 15.10 \\
110 & 440 & 8.58 & 20.57 \\
120 & 400 & 7.60 & 16.89 \\
118 & 514 & 4.11 & 9.34 \\
120 & 437 & 10.49 & 24.11 \\
100 & 323 & 5.81 & 13.83 \\
116 & 353 & 7.94 & 17.30 \\
\hline $\begin{array}{l}\text { Mean } \pm \text { standard devlat1on } \\
115.7 \pm 15.3\end{array}$ & $384.9 \pm 134$ & $6.78 \pm 2.10$ & $15.54 \pm 4.75$ \\
\hline control values prior to any operative procedures &
\end{tabular}


TABLE 6

Control Group (week four). Relationship of urinary dopamine levels (paired samples) to arterial blood pressure (palred means) in male rats. ${ }^{a}$

\begin{tabular}{cccc}
\hline $\begin{array}{c}\text { Blood } \\
\text { Pressure } \\
\text { m Hg }\end{array}$ & $\begin{array}{l}\text { Dopamine } \\
\mu g / 1\end{array}$ & $\begin{array}{l}\text { Dopamine } \\
\mu g / 24 \mathrm{~h}\end{array}$ & $\begin{array}{l}\text { Dopam1ne } \\
\mu \mathrm{g} / \mathrm{kg} / 24 \mathrm{~h}\end{array}$ \\
\hline 120 & 290 & 9.57 & 20.19 \\
125 & 186 & 6.42 & 13.78 \\
123 & 347 & 6.25 & 13.21 \\
120 & 253 & 3.41 & 7.41 \\
110 & 267 & 5.87 & 12.36 \\
108 & 254 & 6.22 & 13.40 \\
130 & 373 & 10.44 & 21.79 \\
105 & 120 & 4.02 & 8.20 \\
115 & 343 & 7.20 & 15.25 \\
\hline Mean & $270.3 \pm 80.9$ & $6.60 \pm 2.28$ & $13.95 \pm 4.76$ \\
\hline $117 \pm 8.59$
\end{tabular}

a one week following right renal nephrectomy 


\section{TABLE 7}

Control Group (week $\mathrm{s} 1 \mathrm{x}$ ). Relationshlp of urinary dopamine levels (paired samples) to arterlal blood pressure (palred means) in male rats. ${ }^{a}$

\begin{tabular}{|c|c|c|c|}
\hline $\begin{array}{c}\text { Blood } \\
\text { Pressure } \\
\text { mm Hg }\end{array}$ & $\begin{array}{l}\text { Dopamine } \\
\mu \mathrm{g} / 1\end{array}$ & $\begin{array}{l}\text { Dopamine } \\
\mu \mathrm{g} / 24 \mathrm{~h}\end{array}$ & $\begin{array}{l}\text { Dopamine } \\
\mu \mathrm{g} / \mathrm{kg} / 24 \mathrm{~h}\end{array}$ \\
\hline 115 & 213 & 7.24 & 14.51 \\
\hline 130 & 233 & 5.83 & 11.75 \\
\hline 113 & 340 & 7.82 & 15.83 \\
\hline 115 & 320 & 3.84 & 7.22 \\
\hline 120 & 350 & 8.75 & 17.71 \\
\hline 123 & 177 & 4.51 & 8.18 \\
\hline 115 & 113 & 2.77 & 5.53 \\
\hline 120 & 303 & 9.09 & 17.58 \\
\hline 110 & 414 & 7.45 & 13.45 \\
\hline \multicolumn{4}{|c|}{ Mean \pm standard devlation } \\
\hline $117.9 \pm$ & $274 \pm 95.8$ & $6.37 \pm 2.24$ & $12.42 \pm 4.53$ \\
\hline
\end{tabular}

a one week following left renal artery manipulation 
TABLE 8

Control Group (week eight). Relationship of urinary dopamine levels (paired samples) to arterial blood pressure (paired means) in male rats. ${ }^{a}$

\begin{tabular}{|c|c|c|c|}
\hline $\begin{array}{c}\text { Blood } \\
\text { Pressure } \\
\text { mm Hg }\end{array}$ & $\begin{array}{l}\text { Dopamine } \\
\mu \mathrm{g} / 1\end{array}$ & $\begin{array}{l}\text { Dopamine } \\
\mu \mathrm{g} / 24 \mathrm{~h}\end{array}$ & $\begin{array}{l}\text { Dopamine } \\
\mu g / \mathrm{g} / 24 \mathrm{~h}\end{array}$ \\
\hline 118 & 276 & 6.21 & 11.52 \\
\hline 110 & 260 & 7.14 & 12.53 \\
\hline 105 & 296 & 9.03 & 15.28 \\
\hline 123 & 331 & $\cdot 8.11$ & 15.24 \\
\hline 125 & 251 & 6.78 & 11.87 \\
\hline 120 & 318 & 5.72 & 9.48 \\
\hline 110 & 298 & 8.34 & 14.30 \\
\hline 120 & 402 & 7.63 & 13.43 \\
\hline 110 & 338 & 7.43 & 12.70 \\
\hline \multicolumn{4}{|c|}{ Mean \pm standard deviation } \\
\hline
\end{tabular}

a three weeks following left renal artery manipulation 
TABLE 9

Control Group (week ten). Relationship of urinary dopamine levels (paired samples) to arterial blood pressure (paired means) in male rats.a

\begin{tabular}{|c|c|c|c|}
\hline $\begin{array}{c}\text { Blood } \\
\text { Pressure } \\
\mathrm{mm} \mathrm{Hg}\end{array}$ & $\begin{array}{l}\text { Dopamine } \\
\mu \mathrm{g} / 1\end{array}$ & $\begin{array}{l}\text { Dopamine } \\
\mu \mathrm{g} / 24 \mathrm{~h}\end{array}$ & $\begin{array}{l}\text { Dopamine } \\
\mu \mathrm{g} / \mathrm{kg} / 24 \mathrm{~h}\end{array}$ \\
\hline 117 & 175 & 5.15 & 9.35 \\
\hline 130 & 314 & 10.37 & 17.51 \\
\hline 115 & 262 & 4.72 & 7.89 \\
\hline 120 & 385 & 7.13 & 13.06 \\
\hline 110 & 318 & 8.76 & 14.29 \\
\hline 110 & 196 & 5.89 & 9.88 \\
\hline 120 & 304 & 8.21 & 14.11 \\
\hline 113 & 466 & 6.76 & 11.76 \\
\hline 125 & 372 & 9.11 & 15.16 \\
\hline \multicolumn{4}{|c|}{ Mean \pm standard deviation } \\
\hline
\end{tabular}

a five weeks following left renal artery manipulation 
TABLE 10

Control Group (week twelve). Relationship of urinary dopamine levels (paired samples) to arterial blood pressure (palred means) in male rats. ${ }^{a}$

\begin{tabular}{cccc}
\hline $\begin{array}{c}\text { Blood } \\
\text { Pressure }\end{array}$ Hg & $\begin{array}{c}\text { Dopamine } \\
\mu g / 1\end{array}$ & $\begin{array}{c}\text { Dopamine } \\
\mu g / 24 \mathrm{~h}\end{array}$ & $\begin{array}{c}\text { Dopamine } \\
\mu g / \mathrm{kg} / 24 \mathrm{~h}\end{array}$ \\
\hline 125 & 257 & 8.22 & 14.12 \\
130 & 332 & 9.13 & 14.54 \\
123 & 458 & 6.41 & 9.97 \\
118 & 324 & 7.95 & 13.68 \\
110 & 445 & 10.24 & 15.68 \\
115 & 210 & 5.79 & 9.12 \\
125 & 336 & 6.21 & 10.02 \\
110 & 394 & 7.89 & 13.30 \\
125 & 389 & 10.88 & 17.24 \\
\hline $\begin{array}{l}\text { Mean } \\
120.1 \pm 7.19\end{array}$ & $349.4 \pm 81.9$ & $8.08 \pm 1.8$ & $13.07 \pm 2.79$ \\
\hline seven weeks following left renal artery manipulation & \\
\hline
\end{tabular}


TABLE 11

Control Group (week fourteen). Relationship of urinary dopamine levels (paired samples) to arterial blood pressure (paired means) in male rats.a

\begin{tabular}{llll}
\hline $\begin{array}{c}\text { Blood } \\
\text { Pressure } \\
\text { mm Hg }\end{array}$ & $\begin{array}{l}\text { Dopamine } \\
\mu \mathrm{g} / 1\end{array}$ & $\begin{array}{l}\text { Dopamine } \\
\mu \mathrm{g} / 24 \mathrm{~h}\end{array}$ & $\begin{array}{l}\text { Dopamine } \\
\mu \mathrm{g} / \mathrm{kg} / 24 \mathrm{~h}\end{array}$ \\
135 & 435 & 6.31 & 9.55 \\
123 & 321 & 8.82 & 13.12 \\
125 & 166 & 4.97 & 7.15 \\
118 & 371 & 10.21 & 14.77 \\
115 & 617 & 15.13 & 21.19 \\
110 & 378 & 6.99 & 9.55 \\
105 & 374 & 7.11 & 10.20 \\
130 & 336 & 8.23 & 11.38 \\
125 & 327 & 9.17 & 14.06 \\
\hline $\begin{array}{l}\text { Mean } \\
120.7 \pm 9.58\end{array}$ & $369.4 \pm 118.5$ & $8.55 \pm 2.94$ & $12.33 \pm 4.12$ \\
\hline n1ne weeks follow1ng left renal artery man1pulation &
\end{tabular}


TABLE 12

Control Group (week sixteen). Relationship of urinary dopamine levels (paired samples) to arterlal blood pressure (paired means) in male rats. ${ }^{a}$

\begin{tabular}{cccc}
\hline $\begin{array}{c}\text { Blood } \\
\begin{array}{c}\text { ressure } \\
\mathrm{mm} \mathrm{Hg}\end{array}\end{array}$ & $\begin{array}{l}\text { Dopamine } \\
\mu \mathrm{g} / 1\end{array}$ & $\begin{array}{l}\text { Dopamine } \\
\mu \mathrm{g} / 24 \mathrm{~h}\end{array}$ & $\begin{array}{l}\text { Dopamine } \\
\mu \mathrm{g} / \mathrm{kg} / 24 \mathrm{~h}\end{array}$ \\
\hline 95 & 397 & 9.13 & 13.50 \\
130 & 399 & 10.78 & 15.69 \\
117 & 410 & 6.97 & 9.79 \\
135 & 319 & 9.41 & 13.09 \\
110 & 316 & 6.48 & 8.91 \\
115 & 403 & 13.29 & 17.64 \\
125 & 368 & 11.03 & 15.27 \\
110 & 263 & 7.24 & 9.88 \\
130 & 323 & 5.98 & 8.64 \\
\hline $\begin{array}{l}\text { Mean } \\
118.5 \pm 12.7\end{array}$ & $355.3 \pm 51.8$ & $8.92 \pm 2.46$ & $12.49 \pm 3.31$ \\
\hline eleven weeks following left renal artery manipulation &
\end{tabular}


TABLE 13

Control Group (week eighteen). Relationship of urinary dopamine levels (paired samples) to arterial blood pressure (paired means) in male rats.a

\begin{tabular}{|c|c|c|c|}
\hline $\begin{array}{c}\text { Blood } \\
\text { Pressure } \\
\text { mm Hg }\end{array}$ & $\begin{array}{l}\text { Dopamine } \\
\mu \mathrm{g} / 1\end{array}$ & $\begin{array}{l}\text { Dopamine } \\
\mu \mathrm{g} / 24 \mathrm{~h}\end{array}$ & $\begin{array}{l}\text { Dopamine } \\
\mu \mathrm{g} / \mathrm{kg} / 24 \mathrm{~h}\end{array}$ \\
\hline 125 & 400 & 9.21 & 12.68 \\
\hline 120 & 417 & 11.47 & 15.29 \\
\hline 130 & 322 & 10.29 & 13.48 \\
\hline 135 & 366 & 6.77 & 9.04 \\
\hline 110 & 560 & 14.01 & 17.57 \\
\hline 123 & 704 & 10.21 & 13.41 \\
\hline 120 & 470 & 8.23 & 10.46 \\
\hline 115 & 229 & 6.31 & 8.62 \\
\hline 130 & 300 & 9.01 & 11.36 \\
\hline \multicolumn{3}{|c|}{ Mean \pm standard deviation } & $12.43 \pm$ \\
\hline
\end{tabular}

a thirteen weeks following left renal artery manipulation 
TABLE 14

Control Group (week twenty). Relationship of urinary dopamine levels (paired samples) to arterlal blood pressure (pafred means) in male rats. ${ }^{a}$

\begin{tabular}{|c|c|c|c|}
\hline $\begin{array}{l}\text { Blood } \\
\text { Pressure } \\
\text { mm Hg }\end{array}$ & $\begin{array}{l}\text { Dopamine } \\
\mu \mathrm{g} / 1\end{array}$ & $\begin{array}{l}\text { Dopamine } \\
\mu g / 24 h\end{array}$ & $\begin{array}{l}\text { Dopam1ne } \\
\mu \mathrm{g} / \mathrm{kg} / 24 \mathrm{~h}\end{array}$ \\
\hline 135 & 412 & 5.97 & 7.67 \\
\hline 125 & 413 & 13.23 & 16.51 \\
\hline 123 & 595 & 16.37 & 19.81 \\
\hline 117 & 266 & 6.53 & 8.17 \\
\hline 130 & 623 & 11.21 & 13.29 \\
\hline 115 & 314 & 7.23 & 9.07 \\
\hline 130 & 321 & 9.15 & 10.92 \\
\hline 120 & 213 & 6.71 & 8.48 \\
\hline 125 & 305 & 8.23 & 9.66 \\
\hline \multicolumn{4}{|c|}{ Mean \pm standard deviation } \\
\hline
\end{tabular}

a fifteen weeks following left renal artery manipulation 
2. Data for the Experimental Group of Rats in the Urinary Dopamine Study are presented in TABLES 15-25. Each entry in these tables represents the results obtalned from a pooled sample comprised of two animals. 
TABLE 15

Experimental Group (week one). Relationship of urinary dopamine levels (paired samples) to arterial blood pressure (paired means) in male rats.a

\begin{tabular}{cccc}
\hline $\begin{array}{c}\text { Blood } \\
\text { Pressure } \\
\text { mm Hg }\end{array}$ & $\begin{array}{c}\text { Dopamine } \\
\mu \text { g/1 }\end{array}$ & $\begin{array}{c}\text { Dopamine } \\
\mu \text { g/24h }\end{array}$ & $\begin{array}{l}\text { Dopamine } \\
\mu \text { g/kg/24h }\end{array}$ \\
\hline 115 & 294 & & \\
120 & 270 & 8.82 & 22.16 \\
120 & 282 & 4.86 & 15.43 \\
113 & 365 & 4.94 & 14.57 \\
140 & 487 & 8.58 & 25.61 \\
130 & 200 & 6.82 & 16.24 \\
115 & 274 & 5.50 & 21.74 \\
120 & 229 & 8.50 & 25.52 \\
135 & 295 & 5.50 & 18.09 \\
135 & 337 & 8.40 & 21.82 \\
125 & 320 & 6.40 & 16.33 \\
120 & 307 & 7.04 & 18.57 \\
120 & 652 & 5.53 & 15.36 \\
110 & - & 8.48 & 20.82 \\
115 & 350 & - & - \\
118 & 250 & 5.60 & 15.38 \\
108 & 337 & 7.50 & 21.55 \\
123 & 347 & 5.90 & 16.34 \\
105 & 383 & 9.72 & 26.41 \\
110 & 473 & 7.66 & 13.30 \\
115 & 300 & 8.04 & 15.00 \\
120 & 313 & 10.5 & 21.52 \\
105 & 373 & 8.45 & 15.01 \\
103 & 460 & 6.71 & 11.39 \\
110 & 400 & 8.51 & 15.70 \\
118 & 493 & 10.00 & 19.01 \\
110 & 363 & 10.85 & 18.47 \\
\hline Mean & & & \\
$117.7 \pm 9.37$ & $352 .+97.8$ & 7.29 & \\
\hline
\end{tabular}

a control values prior to any operative procedures 
!.E 16

ierimental G

1 aj rod sample
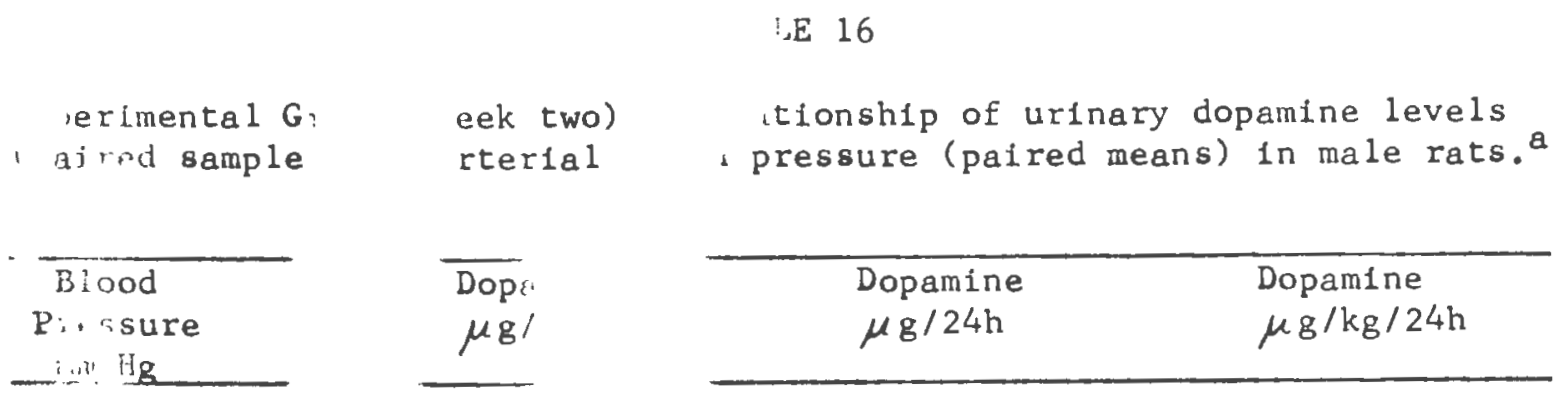

424

466

199

438

624

325

382

390

345

410

120

387

95

$-$

133

327

110

457

123

413

110

337

110

347

115

$-$

115

320

110

390

115

317

120

240

125

347

120

277

353

125

477

pressure (paired means) in male rats.a

115

200

\begin{tabular}{ll}
\hline Dopamine & Dopamine \\
$\mu \mathrm{g} / 24 \mathrm{~h}$ & $\mu \mathrm{g} / \mathrm{kg} / 24 \mathrm{~h}$
\end{tabular}

115

9.54

7.92

4.29

6.35

12.17

7.48

8.59

7.02

7.60

8.61

6.97

$-$

7.52

10.28

8.26

6.74

7.46

$-$

5.04

4.68

3.80

4.92

4.51

4.43

5.12

5.96

3.60
17.73

14.45

8.46

12.40

21.02

14.38

16.61

13.98

15.17

16.40

12.38

12.99

18.97

14.59

12.76

13.23

-

11.56

9.79

8.08

11.55

9.84

9.42

12.86

13.42

7.83

Mean \pm standard deviation $117.0 \pm 7.91 \quad 367.7 \div 01.5$ $6.75+2.16$ $13.19 \pm 3.34$

a control values prior to any operative procedures 
TABLE 17

Experimental Group (week four). Relationship of urinary dopamine levels (paired samples) to arterial blood pressure (paired means) in male rats.a

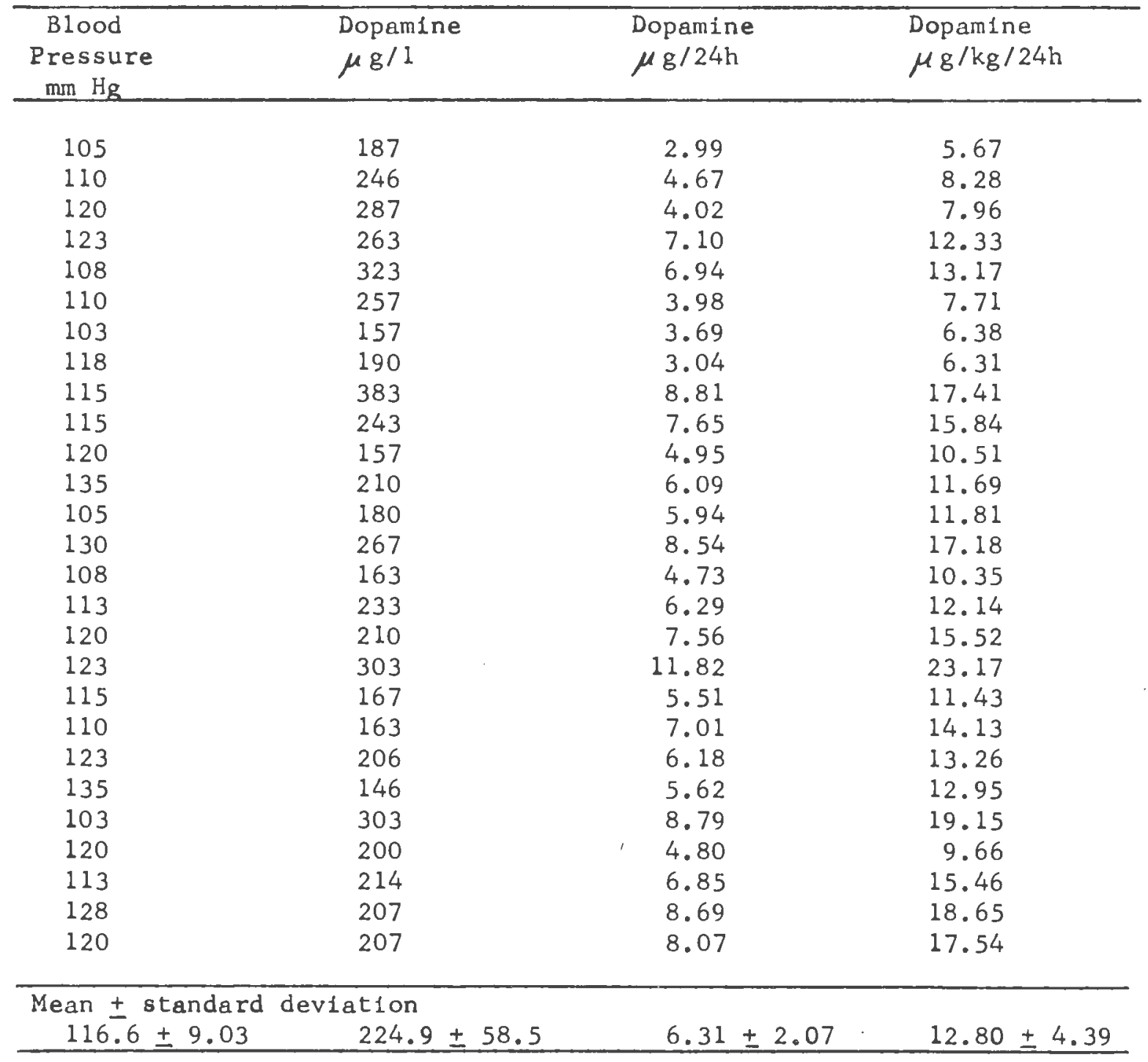

a one week following right renal nephrectomy 
TABLE 19

Experimental Group (week elght). Relationship of urinary dopamine levels (paired samples) to arterlal blood pressure (palred means) in male rats.a

\begin{tabular}{|c|c|c|c|}
\hline $\begin{array}{c}\text { Blood } \\
\text { Pressure } \\
\text { mm } \mathrm{Hg}\end{array}$ & $\begin{array}{l}\text { Dopamine } \\
\mu \mathrm{g} / 1\end{array}$ & $\begin{array}{l}\text { Dopamine } \\
\mu \mathrm{g} / 24 \mathrm{~h}\end{array}$ & $\begin{array}{l}\text { Dopamine } \\
\mu \mathrm{g} / \mathrm{kg} / 24 \mathrm{~h}\end{array}$ \\
\hline 155 & 186 & 6.14 & 11.41 \\
\hline 150 & 274 & 9.32 & 17.10 \\
\hline 163 & 214 & 7.49 & 12.98 \\
\hline 163 & 254 & 7.24 & 12.64 \\
\hline 135 & 160 & 5.76 & 10.59 \\
\hline 173 & 90 & 5.76 & 9.23 \\
\hline 205 & 166 & 10.37 & 14.65 \\
\hline 150 & 103 & 6.39 & 9.86 \\
\hline 173 & 170 & 7.39 & 16.42 \\
\hline 168 & 180 & 8.46 & 13.22 \\
\hline 190 & 100 & 6.15 & 10.57 \\
\hline 183 & 146 & 6.64 & 11.37 \\
\hline 175 & 153 & 7.65 & 12.77 \\
\hline 145 & 555 & 7.22 & 12.73 \\
\hline 180 & 142 & 6.74 & 11.74 \\
\hline \multicolumn{4}{|c|}{ Mean \pm standard deviation } \\
\hline
\end{tabular}

a three weeks following left renal artery constriction 
TABLE 20

Experimental Group (week ten). Relationship of urinary dopamine levels (paired samples) to arterial blood pressure (paired means) in male rats.

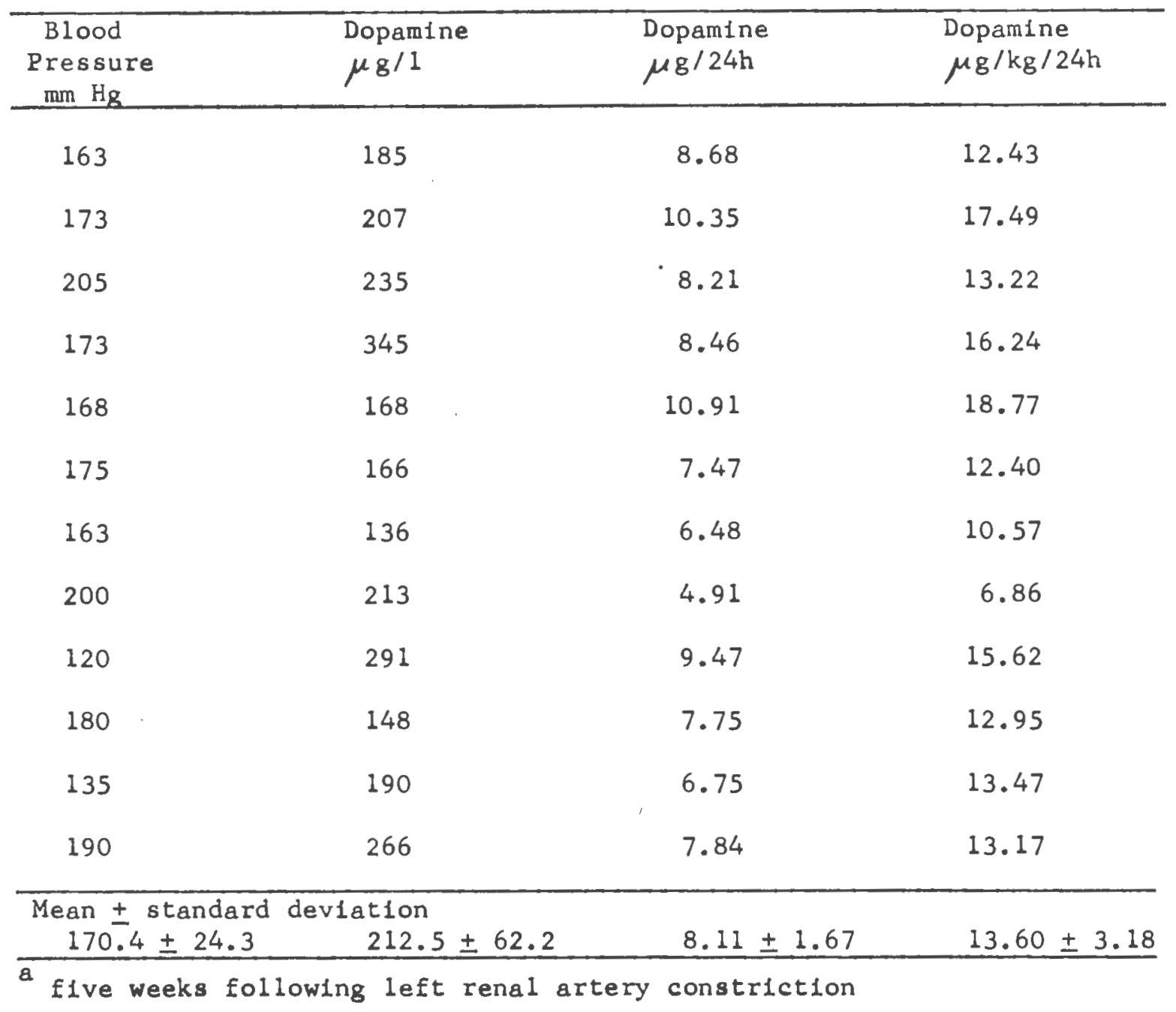


TABLE 21

Experimental Group (week twelve). Relationship of urinary dopamine levels (paired samples) to arterlal blood pressure (paired means) in male rats. ${ }^{a}$

\begin{tabular}{|c|c|c|c|}
\hline $\begin{array}{c}\text { Blood } \\
\text { Pressure } \\
\mathrm{mm} \mathrm{Hg}\end{array}$ & $\begin{array}{l}\text { Dopamine } \\
\mu \mathrm{g} / 1\end{array}$ & $\begin{array}{l}\text { Dopamine } \\
\mu \mathrm{g} / 24 \mathrm{~h}\end{array}$ & $\begin{array}{l}\text { Dopam1ne } \\
\mu \mathrm{g} / \mathrm{kg} / 24 \mathrm{~h}\end{array}$ \\
\hline 163 & 223 & 12.69 & 18.65 \\
\hline 163 & 114 & 7.10 & 10.51 \\
\hline 173 & 181 & 8.50 & 13.18 \\
\hline 155 & 129 & 3.81 & 6.67 \\
\hline 205 & 171 & 9.39 & 14.65 \\
\hline 173 & 145 & 6.20 & 9.42 \\
\hline 150 & 221 & 8.61 & 13.26 \\
\hline 205 & 103 & 4.96 & 7.83 \\
\hline 180 & 103 & 5.81 & 9.23 \\
\hline 150 & 172 & 10.66 & 14.23 \\
\hline 135 & 292 & 6.71 & 10.54 \\
\hline \multicolumn{4}{|c|}{ Mean \pm standard deviation } \\
\hline
\end{tabular}

a seven weeks following left renal artery constriction 
TABLE 22

Experimental Group (week fourteen). Relationship of urinary dopamine levels (paired samples) to arterlal blood pressure (paired means) in male rats.a

\begin{tabular}{|c|c|c|c|}
\hline $\begin{array}{c}\text { Blood } \\
\text { Pressure } \\
\mathrm{mm} \mathrm{Hg}\end{array}$ & $\begin{array}{l}\text { Dopamine } \\
\mu g / 1\end{array}$ & $\begin{array}{l}\text { Dopamine } \\
\mu g / 24 \mathrm{~h}\end{array}$ & $\begin{array}{l}\text { Dopamine } \\
\mu \mathrm{g} / \mathrm{kg} / 24 \mathrm{~h}\end{array}$ \\
\hline 173 & 206 & 10.84 & 15.17 \\
\hline 173 & 252 & 15.61 & 22.16 \\
\hline 150 & 373 & 17.91 & 25.61 \\
\hline 150 & 137 & 5.35 & 7.61 \\
\hline 175 & 403 & 9.27 & 13.26 \\
\hline 135 & 144 & 9.68 & 14.23 \\
\hline 180 & 489 & 11.24 & 13.98 \\
\hline 163 & 214 & 8.02 & 13.50 \\
\hline 205 & 89 & 6.19 & 8.97 \\
\hline \multicolumn{4}{|c|}{ Mean \pm standard deviation } \\
\hline
\end{tabular}

a nine weeks following left renal artery constriction 
TABLE 23

Experimental Group (week sixteen). Relationship of urinary dopamine levels (paired samples) to arterial blood pressure (palred means) in male rats. ${ }^{a}$

\begin{tabular}{cccc}
\hline $\begin{array}{c}\text { Blood } \\
\text { Pressure } \\
\text { m Hg }\end{array}$ & $\begin{array}{l}\text { Dopamine } \\
\mu \mathrm{g} / 1\end{array}$ & $\begin{array}{l}\text { Dopamine } \\
\mu \mathrm{g} / 24 \mathrm{~h}\end{array}$ & $\begin{array}{l}\text { Dopam1ne } \\
\mu \mathrm{k} / \mathrm{kg} / 24 \mathrm{~h}\end{array}$ \\
\hline 170 & 287 & 10.62 & 12.21 \\
180 & 207 & 11.80 & 15.55 \\
190 & 307 & 7.06 & 7.83 \\
190 & 283 & 6.51 & 8.75 \\
163 & 200 & 14.00 & 21.12 \\
200 & 130 & 7.15 & 8.97 \\
135 & 140 & 11.90 & 15.16 \\
180 & 429 & 9.86 & 12.80 \\
\hline $\begin{array}{l}\text { Mean } \\
176.0 \pm 20.3\end{array}$ & $247.9 \pm 98.96$ & $9.86 \pm 2.73$ & $12.80 \pm 4.45$ \\
\hline eleven weeks following left renal artery constriction &
\end{tabular}


TABLE 24

Experimental Group (week elghteen). Relationship of urinary dopamine levels (paired samples) to arterial blood pressure (paired means) in male rats.a

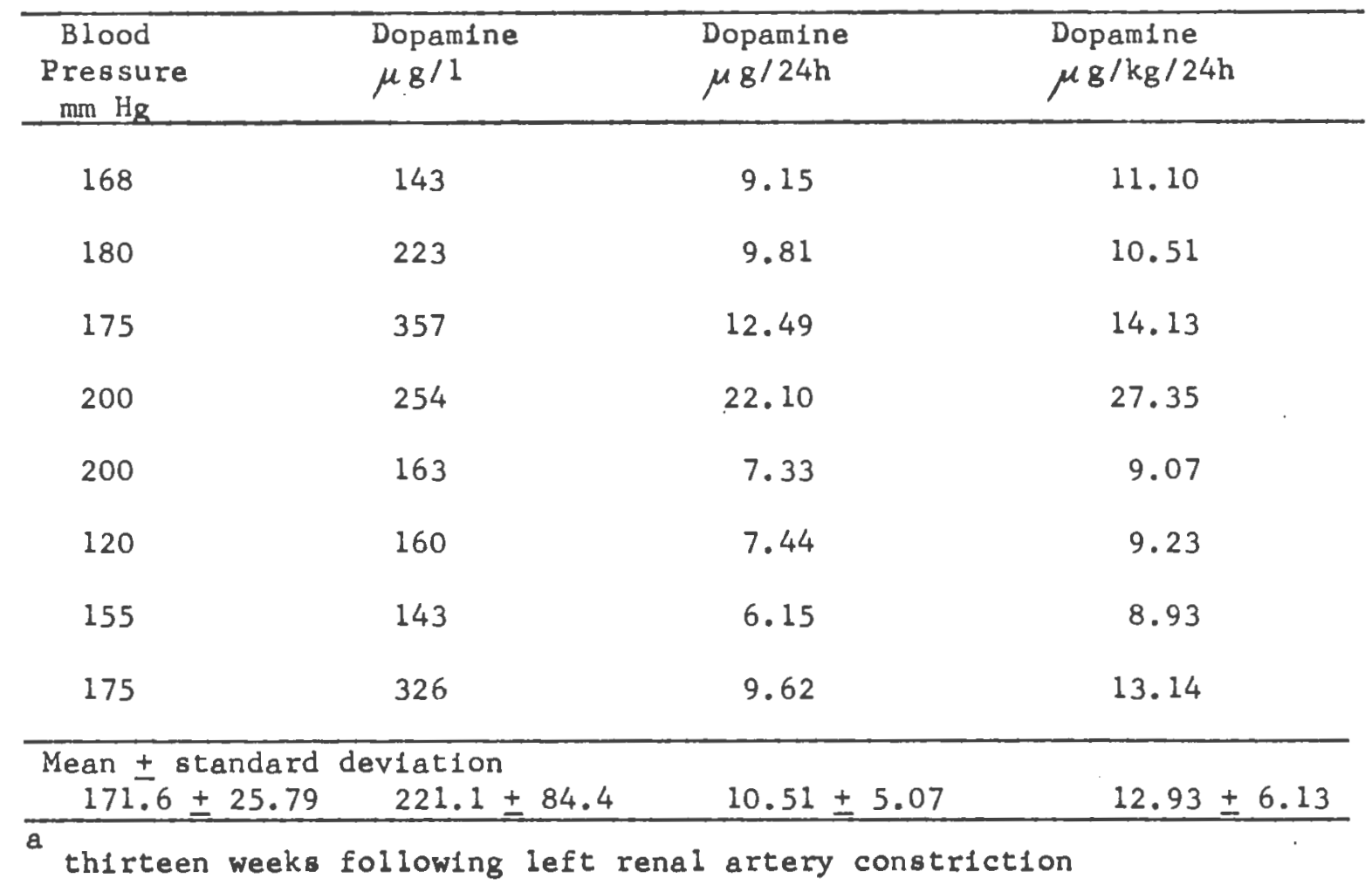




\section{TABLE 25}

Experimental Group (week twenty). Relationship of urinary dopamine levels (paired samples) to arterial blood (paired means) in male rats. ${ }^{a}$

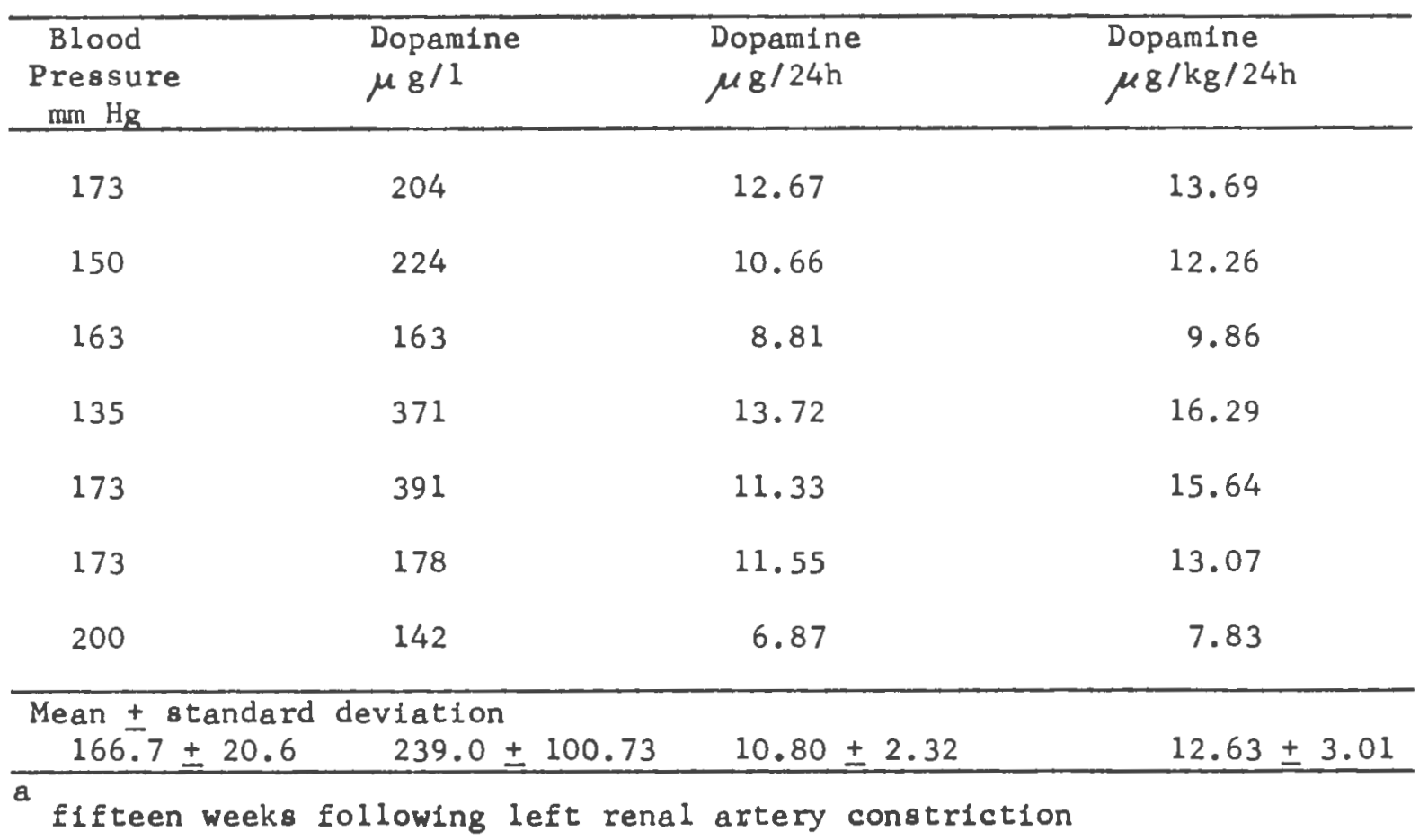


3. A Statistical Evaluation of the Results Obtained from the Study on the Relationship of Urinary Dopamine Levels in Arterial Blood

Pressure 18 presented in TABLES 26 and 27. 
TABLE 26

Comparisons of the means of the control and experimental groups using "Student's" $t$ distribution. ${ }^{2}$ The calculated /T/ is followed by the tabulated $t$ ( 1 parentheses) at the 0.05 confidence level and corresponding degrees of freedom.

\begin{tabular}{|c|c|c|c|c|}
\hline Week & $\mathrm{mm} \mathrm{Hg}$ & $\mu \mathrm{g} / 1$ & $\mu \mathrm{g} / 24 \mathrm{~h}$ & $\mu \mathrm{g} / \mathrm{kg} / 24 \mathrm{~h}$ \\
\hline 1 & $2.240(2.032) *$ & $1.102(2.035)$ & $3.404(2.035) \star \star$ & $3.536(2.035) * *$ \\
\hline 2 & $0.332(2.032)$ & $0.426(2.037)$ & $0.036(2.037)$ & $1.614(2.037)$ \\
\hline $4^{c}$ & $0.262(2.032)$ & $1.825(2.032)$ & $0.355(2.032)$ & $0.667(2.032)$ \\
\hline $6^{d}$ & $6.181(2.060) * \star \star *$ & $0.062(2.060)$ & $3.269(2.060) \star \star$ & $2.967(2.060) * \star$ \\
\hline 8 & $7.952(2.074) \star \star \star$ & $2.884(2.074) \star \star$ & $0.253(2.074)$ & $0.482(2.074)$ \\
\hline 10 & $6.275(2.093) * * *$ & $2.911(2.093) * \star$ & $0.985(2.093)$ & $0.750(2.093)$ \\
\hline 12 & 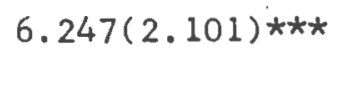 & $5.734(2.101) * \star \star$ & $0.392(2.101)$ & $1.212(2.101)$ \\
\hline 14 & $6.148(2.120) * * *$ & $1.877(2.120)$ & $1.134(2.120)$ & $1.109(2.120)$ \\
\hline 16 & $7.089(2.131) \star * \star$ & $2.846(2.131) *$ & $0.747(2.131)$ & $0.164(2.131)$ \\
\hline 18 & $5.388(2.131) \star \star \star *$ & $1.047(2.131)$ & $0.537(2.131)$ & $0.219(2.131)$ \\
\hline 20 & 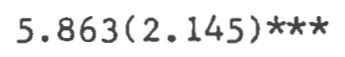 & $2.287(2.145) \star$ & $0.903(2.145)$ & $0.594(2.145)$ \\
\hline
\end{tabular}

a /T/ calculated according to Snedecor, 1956

$$
/ T /=\left(\bar{x}_{1}-\bar{x}_{2}\right) \quad \sqrt{\frac{n_{1} n_{2}\left(n_{1}+n_{2}-2\right)}{\left(n_{1}+n_{2}\right) \sum x^{2}}}
$$

$\mathrm{b}_{t}=/ \mathrm{T} / \mathrm{t}$ rejects Ho: $1-{ }_{2}=0$ indicating a significant difference between the control and experimental means

* signifies a difference at the 0.05 level or less

** signifles a difference at the 0.01 level or less

** signifles a difference at the 0.001 level or less

$c$ week following right renal nephrectomy in both experimental and control groups

d week following left renal artery constriction in the experimental group; left renal artery manipulation in the control group 
TABLE 27

Regression coefficlents and correlation coefficients with confidence intervals and tests of the hypotheses for the rat data of the control and experimental groups from week 6 through week 20.

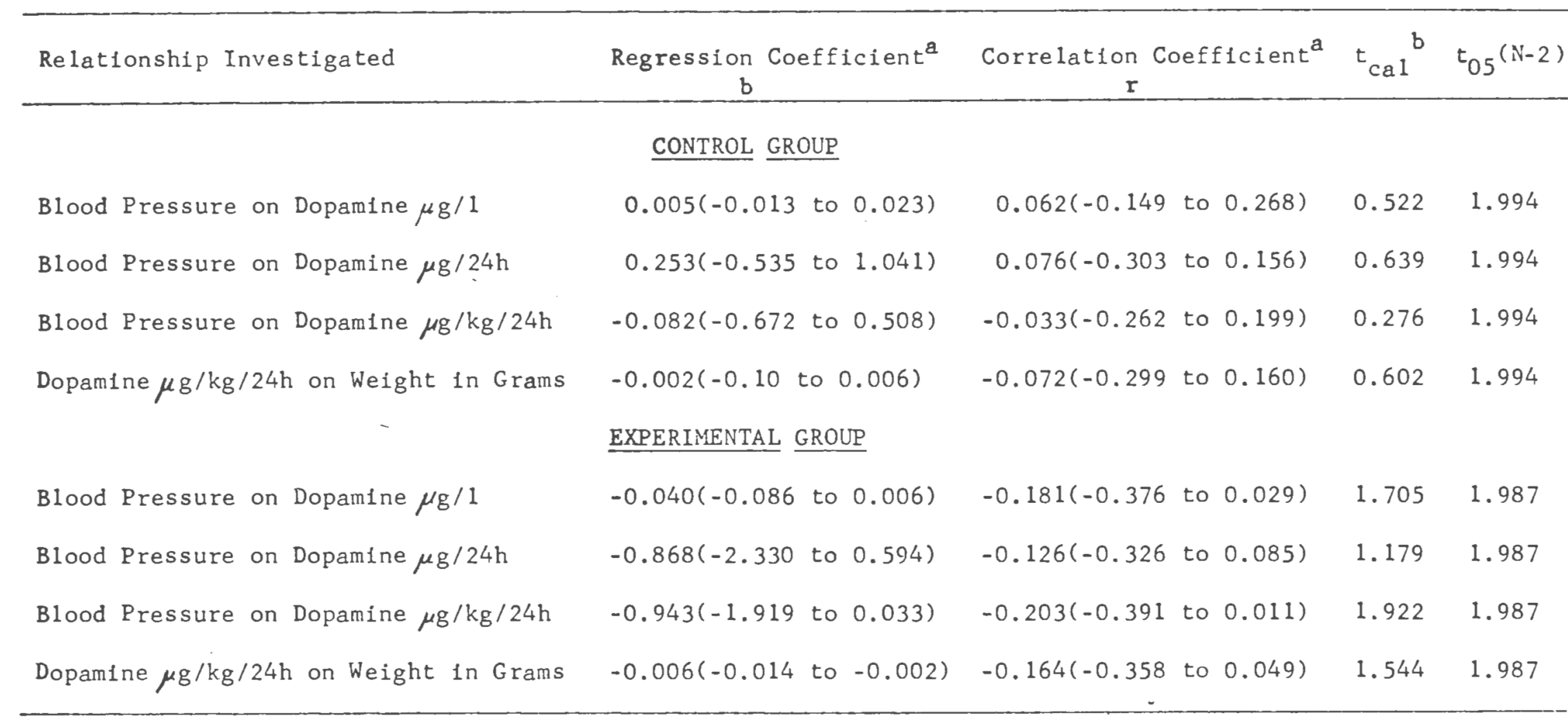

A Al calculation concerned with the regression coefficlents, correlation coefficlents and tests of hypotheses were carried out according to Snedecor, 1956.

b Since $t_{\text {cal }}$ does not exceed $t_{05}(\mathrm{~N}-2)$ in any instance the hypotheses: Ho: $\beta=0$ and Ho: $\rho=0$ are not 
4. Analysis of the Plasma from Hypertensive Rats Sacrificed at the End of the Twentieth Week.

Assay of the individual plasmas obtalned from the 14 hypertensive rats which survived the 20 -week study falled to demonstrate the presence of dopamine in any of the samples regardless of the manner in which the plasma was treated prior to its subsequent passage through Dowex ${ }^{R}$ resin. 
5. The Results Obtained from the Assay of the Ischemic Left Kidneys of Hypertensive Rats for Dopamine Content are presented in TABLE 28. 
TABLE 28

Influence of renal hypertension of eight weeks duration on kidney dopamine content in male rats.

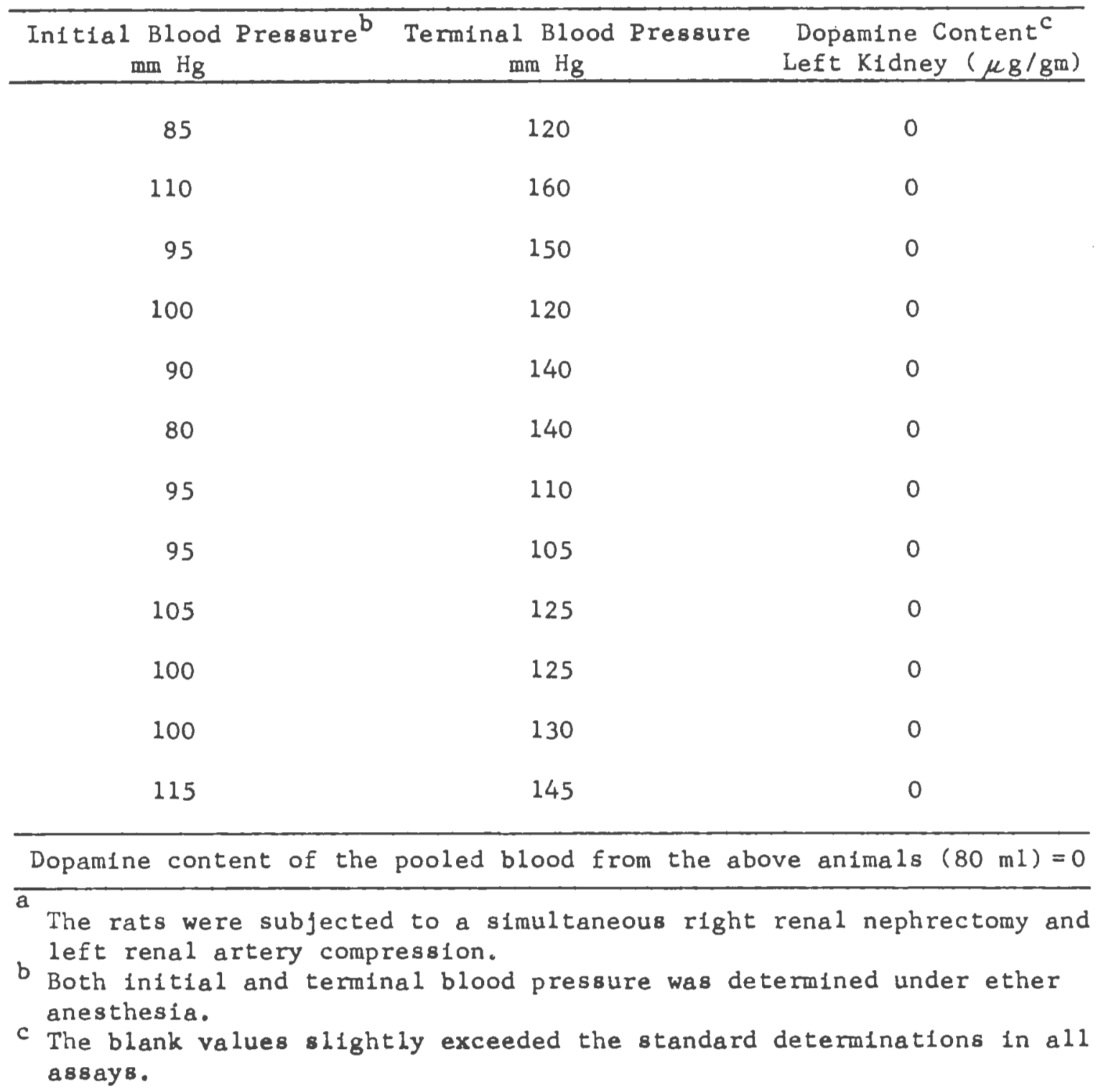


6. The Data for the Study of Urinary and Blood Dopamine Levels in Control and Renal Hypertensive Dogs are presented in TABLE 29. 
TABLE 29

Relationship of urinary dopamine and blood dopamine levels to arterial blood pressure in control and renal hypertensive dogs

\begin{tabular}{|c|c|c|c|c|c|c|c|c|}
\hline \multirow[b]{2}{*}{ Subject } & \multicolumn{8}{|c|}{ Week of Experiment } \\
\hline & 1 & 2 & $4^{a}$ & $6^{b}$ & 7 & 8 & 9 & 10 \\
\hline \multicolumn{9}{|l|}{ Male:Control } \\
\hline Blood Pressure (mmH) & 150 & 160 & 160 & 155 & 160 & 160 & 165 & 160 \\
\hline Urinary Dopamine $(\mu \mathrm{g} / 24 \mathrm{~h})$ & 1342 & 497 & 1220 & 406 & 105 & 318 & 346 & - \\
\hline Blood Dopamine $(\mu \mathrm{g} / 20 \mathrm{~m} 1)$ & - & 0.13 & 0.07 & 0.13 & 0.17 & 0.07 & 0.17 & 0.20 \\
\hline \multicolumn{9}{|l|}{ Male:Unilateral Nephrectomy } \\
\hline Blood Pressure(mmHg) & 160 & 170 & 165 & 155 & 160 & 170 & 150 & 165 \\
\hline Urinary Dopamine $(\mu \mathrm{g} / 24 \mathrm{~h})$ & 518 & 246 & 215 & 199 & 373 & - & 414 & 105 \\
\hline Blood Dopamine $(\mu \mathrm{g} / 20 \mathrm{ml})$ & - & 0.10 & 0.13 & 0.17 & - & 0.07 & 0.13 & 0.23 \\
\hline \multicolumn{9}{|l|}{ Female:Hypertensive } \\
\hline Blood Pressure (mmHg) & 140 & 150 & 150 & - & 200 & 210 & 195 & 205 \\
\hline Urinary Dopamine $(\mu \mathrm{g} / 24 \mathrm{~h})$ & 271 & 231 & 333 & - & 278 & 320 & 209 & 366 \\
\hline Blood Dopamine $(\mu \mathrm{g} / 20 \mathrm{~m} 1)$ & - & 0.07 & 0.17 & 0.10 & 0.10 & 0.17 & 0.13 & 0.13 \\
\hline \multicolumn{9}{|l|}{ Male: Hypertensive } \\
\hline Blood Pressure (mmHg) & 175 & 160 & 170 & - & 180 & 200 & 210 & 215 \\
\hline Urinary Dopamine $(\mu \mathrm{g} / 24 \mathrm{~h})$ & 247 & 290 & 311 & - & 317 & 343 & 352 & 308 \\
\hline Blood Dopamine $(\mu \mathrm{g} / 20 \mathrm{ml})$ & - & 0.10 & 0.10 & 0.13 & 0.07 & 0.07 & 0.17 & 0.20 \\
\hline
\end{tabular}

a first week following right renal nephrectomy in latter three subjects

b first week following left renal artery constriction in the hypertensive subjects 
7. The Data Obtained from the Intravenous Infusion of $d, 1-D O P A$ in Cats are presented in TABLES $30-32$. 
TABLE 30

Levels of dopamine and DOPA in various tissues of the untreated cat

\begin{tabular}{|c|c|c|c|c|}
\hline Cat No. & $\begin{array}{c}\text { Heart } \\
(\mu \mathrm{g} / \mathrm{gm})\end{array}$ & $\begin{array}{c}\text { Liver } \\
(\mu \mathrm{g} / \mathrm{gm})\end{array}$ & $\begin{array}{c}\text { Spleen } \\
(\mu \mathrm{g} / \mathrm{gm})\end{array}$ & $\begin{array}{c}\text { Kidney } \\
(\mu \mathrm{g} / \mathrm{gm})\end{array}$ \\
\hline \multicolumn{5}{|c|}{ DOPAMINE } \\
\hline 1 & 0.18 & 0.16 & 0.31 & 0.07 \\
\hline 2 & 0.18 & 0.00 & 0.00 & 0.00 \\
\hline 3 & 0.07 & 0.01 & 0.005 & 0.02 \\
\hline 4 & 0.009 & 0.02 & 0.00 & 0.009 \\
\hline Average & 0.11 & 0.05 & 0.08 & 0.02 \\
\hline \multicolumn{5}{|c|}{ DOPA } \\
\hline 1 & 0.18 & 0.12 & 0.23 & 0.27 \\
\hline 2 & 0.00 & 0.00 & 0.00 & 0.00 \\
\hline 3 & 0.00 & 0.008 & 0.03 & 0.02 \\
\hline 4 & 0.01 & 0.01 & 0.03 & 0.05 \\
\hline Average & 0.05 & 0.03 & 0.07 & 0.08 \\
\hline
\end{tabular}




\section{TABLE 31}

Tissue levels of dopamine and DOPA in various tissues of the cat following intravenous infusion of $50 \mathrm{mg} / \mathrm{kg} \mathrm{d}, \mathrm{I}-\mathrm{DOPA}$ in cats with left kidney function.

\begin{tabular}{|c|c|c|c|c|c|c|c|c|}
\hline Cat No. & $\begin{array}{l}\text { Heart } \\
(\mu \mathrm{g} / \mathrm{gm})\end{array}$ & $\begin{array}{l}\text { Liver } \\
(\mu \mathrm{g} / \mathrm{gm})\end{array}$ & $\begin{array}{l}\text { Spleen } \\
(\mu g / g m)\end{array}$ & $\begin{array}{c}\text { Kidney } \\
(\mu \mathrm{g} / \mathrm{gm})\end{array}$ & $\begin{array}{l}\text { Rer } \\
\text { Arterial-1 } \\
\text { (10 minute }\end{array}$ & $\begin{array}{l}\text { nal Blood } \\
\text { Venous - } 1 \\
\text { samples) }\end{array}$ & $\begin{array}{l}(\mu g / 1) \\
\text { Arterial-2 } \\
\text { (one hour }\end{array}$ & $\begin{array}{c}\text { Venous-2 } \\
\text { samples) }\end{array}$ \\
\hline \multicolumn{9}{|c|}{ DOPAMINE } \\
\hline 1 & 1.91 & 2.6 & 3.30 & 7.22 & 74 & 106 & 74 & 60 \\
\hline 2 & 0.44 & 3.96 & 2.62 & 24.78 & 16 & 134 & 30 & 180 \\
\hline 3 & - & 1.07 & 0.83 & 4.78 & 30 & - & 30 & 30 \\
\hline 4 & 0.40 & 0.56 & $0.24^{a}$ & 4.40 & - & 106 & 30 & 30 \\
\hline Average & 0.92 & 2.05 & 2.25 & 10.29 & 40 & 115 & 41 & 75 \\
\hline \multicolumn{9}{|c|}{ DOPA } \\
\hline 1 & 23.62 & 8.40 & 13.75 & 111.55 & 22,296 & 16,560 & 4,966 & 3,980 \\
\hline 2 & 25.38 & 11.20 & 23.90 & 98.76 & 15,960 & 27,600 & 5,300 & 4,846 \\
\hline 3 & 28.60 & 18.70 & 48.24 & 59.02 & 2,984 & 9,142 & 1,320 & 1,306 \\
\hline 4 & 43.04 & 13.06 & 53.34 & 104.42 & 3,370 & 1,044 & 2,926 & 850 \\
\hline Average & 30.16 & 12.84 & 34.81 & 93.44 & 11,152 & 13,586 & 3,628 & 2,745 \\
\hline
\end{tabular}

a Some of this sample was lost during handling and the value is not included in the average. 
TABLE 32

Tissue levels of dopamine and DOPA in various tissues of the cat following intravenous infusion of $50 \mathrm{mg} / \mathrm{kg} \mathrm{d}, 1-D O P A$ in cats without kidney function

\begin{tabular}{|c|c|c|c|}
\hline Cat No. & $\begin{array}{l}\text { Heart } \\
(\mu \mathrm{g} / \mathrm{gm})\end{array}$ & $\begin{array}{l}\text { Liver } \\
(\mu \mathrm{g} / \mathrm{gm})\end{array}$ & $\begin{array}{c}\text { Spleen } \\
(\mu g / g m)\end{array}$ \\
\hline \multicolumn{4}{|c|}{ DOPAMINE } \\
\hline 1 & 1.54 & 1.22 & 2.08 \\
\hline 2 & 0.98 & 4.48 & 2.10 \\
\hline 3 & 0.80 & 2.43 & 3.60 \\
\hline 4 & 0.70 & 2.75 & 2.11 \\
\hline Average & 1.00 & 2.72 & 2.47 \\
\hline \multicolumn{4}{|c|}{ DOPA } \\
\hline 1 & 35.43 & 10.65 & 20.87 \\
\hline 2 & 31.02 & 18.84 & 16.48 \\
\hline 3 & 32.24 & 12.58 & 15.32 \\
\hline 4 & 22.42 & 14.10 & 18.10 \\
\hline Average & 30.28 & 14.04 & 17.69 \\
\hline
\end{tabular}




\section{DISCUSSION}

The data from the major portion of the study, dealing with the relationship of urinary dopamine levels to arterial hypertension in renal hypertensive rats are presented in Tables 4 through 25 . It is immediately apparent (Figure 5) that the method used to induce hypertension (Goldblatt et al., 1934; Dury, 1938) was successful. The mean blood pressure values of the control group varied within a rather narrow range of from 115.7 $\mathrm{mm} \mathrm{Hg}$ (Table 5) to $125.7 \mathrm{~mm} \mathrm{Hg}$ (Table 4), while those of the experimental group ranged from a low of $116.6 \mathrm{~mm} \mathrm{Hg}$ (Table 17) prior to left renal artery constriction to a maximum of $176 \mathrm{~mm} \mathrm{Hg}, 11$ weeks following constriction (Table 23).

The mean blood pressure of the control group was highest the first week and differed significantly $(.01<p<.05)$ from the experimental group for the same week. However, the mean blood pressure of the control group dropped the second week and then showed a tendency to rise slowly throughout the duration of the 20 -week study, never exceeding the first week's average. Individual variation within the control group, ignoring time as a possible factor, ranged from $95 \mathrm{~mm} \mathrm{Hg}$ to $140 \mathrm{~mm} \mathrm{Hg}$.

The mean of the experimental group showed a sharp increase in blood

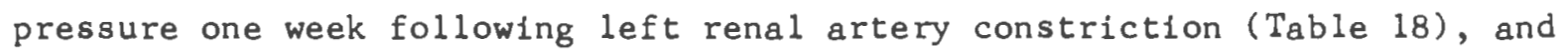
the group means remained significantly elevated above those of the controls for the duration of the study $(p<.001)$. Although the mean blood pressure continued to rise subsequent to renal artery constriction, the magnitude of the rise was offset by deaths which occurred within this group as a consequence of the severity of hypertension and its resultant complications. While 36 rats survived the first week subsequent to renal-artery 

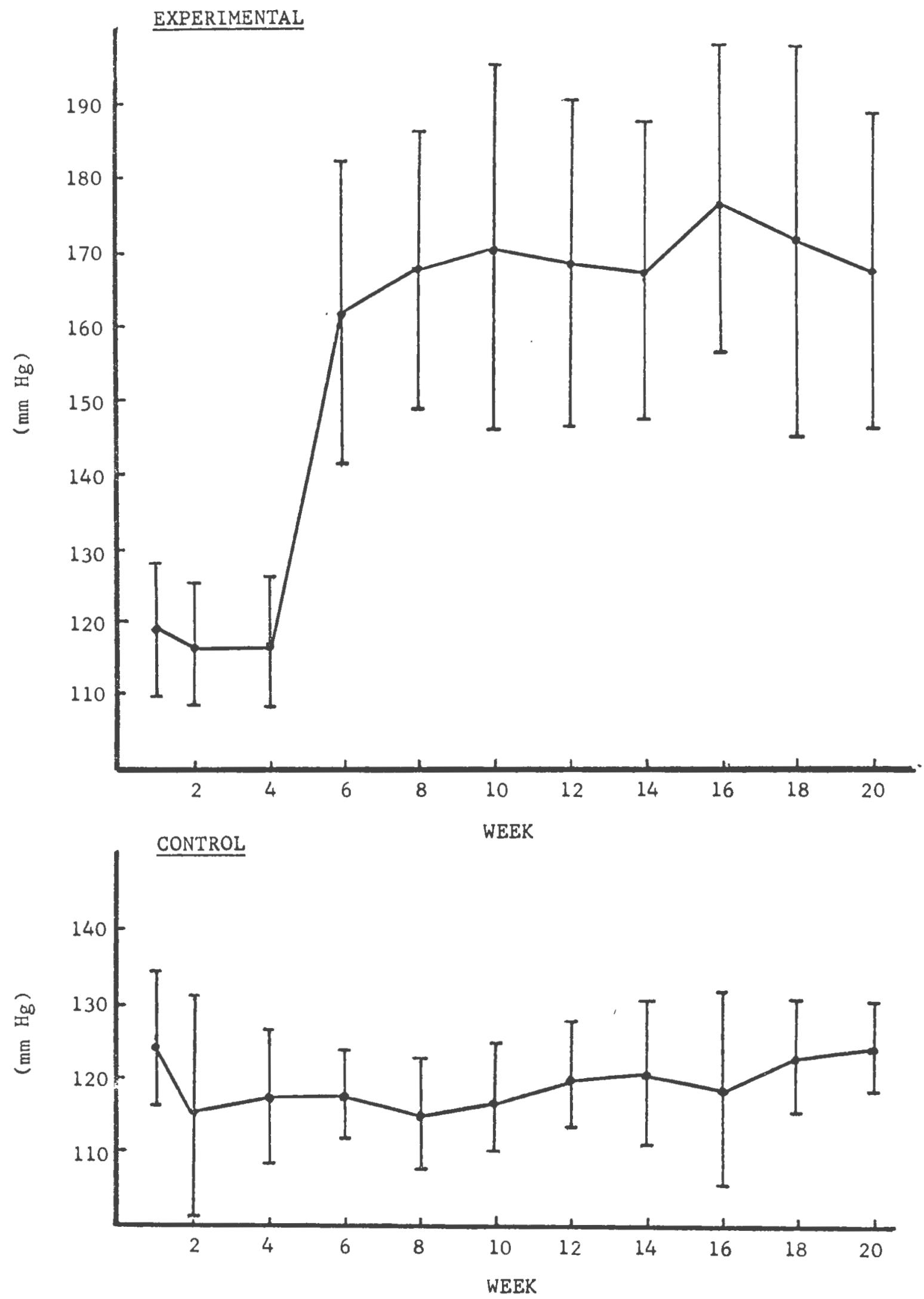

Fig. 5. Mean blood pressures and standard deviations ( $\mathrm{mm} \mathrm{Hg}$ ) for the experimental and control groups for week 1 through 20 . 
constriction, only 14 animals survived to the conclusion of the 20 -week study. Individual variation within the experimental group following renalartery constriction, ranged from $120 \mathrm{~mm} \mathrm{Hg}$ to $205 \mathrm{~mm} \mathrm{Hg}$, indicating that not all of the animals developed arterfal hypertension.

Urinary dopamine levels, expressed as micrograms per liter, remained relatively constant for the control group; the group means varfed between 270 and $418 \mu \mathrm{g} / 1$ (Figure 6). Individual variation ranged from 113 to $623 \mu \mathrm{g} / 1$. Dopamine concentration decreased in the control group the fourth week of the experiment (one week following right nephrectomy) and then progressively rose to reach a mean level, comparable to those obtalned inftially, about the twelfth week of the experiment.

The group means of the experimental group varied between 168 and 367 $\mu \mathrm{g} / 1$, while individual variation ranged between 89 and $652 \mu \mathrm{g} / 1$. A simllar decrease in dopamine concentration was seen in this group following right-renal nephrectomy (Figure 6). However, in the case of the exper1mental group rather than a tendency to rise, a tendency was noted for the dopamine concentration to decrease further. Comparisons between the group means of the control and experimental animals showed the urinary dopamine concentration to be significantly lower in the experimental animals for the elghth $(.01>p>.001)$, tenth $(.01>p>.001)$, twelfth $(p<.001)$, sixteenth $(p<.05)$ and twentfeth $(p<.05)$ weeks of the study (Table 26).

The regression and correlation coeffictents for the dependency of blood pressure on dopamine concentration $(\mu \mathrm{g} / 1)$ from the sixth through the twentieth week of the study are shown in Table 27 . The regression and correlation coefficients of the control group are $b=0.005$ and $r=0.062$ respectively, while those of the experimental group are $b=-0.040$ and $r=-0.181$ respectively. However, none of these values are statistically 

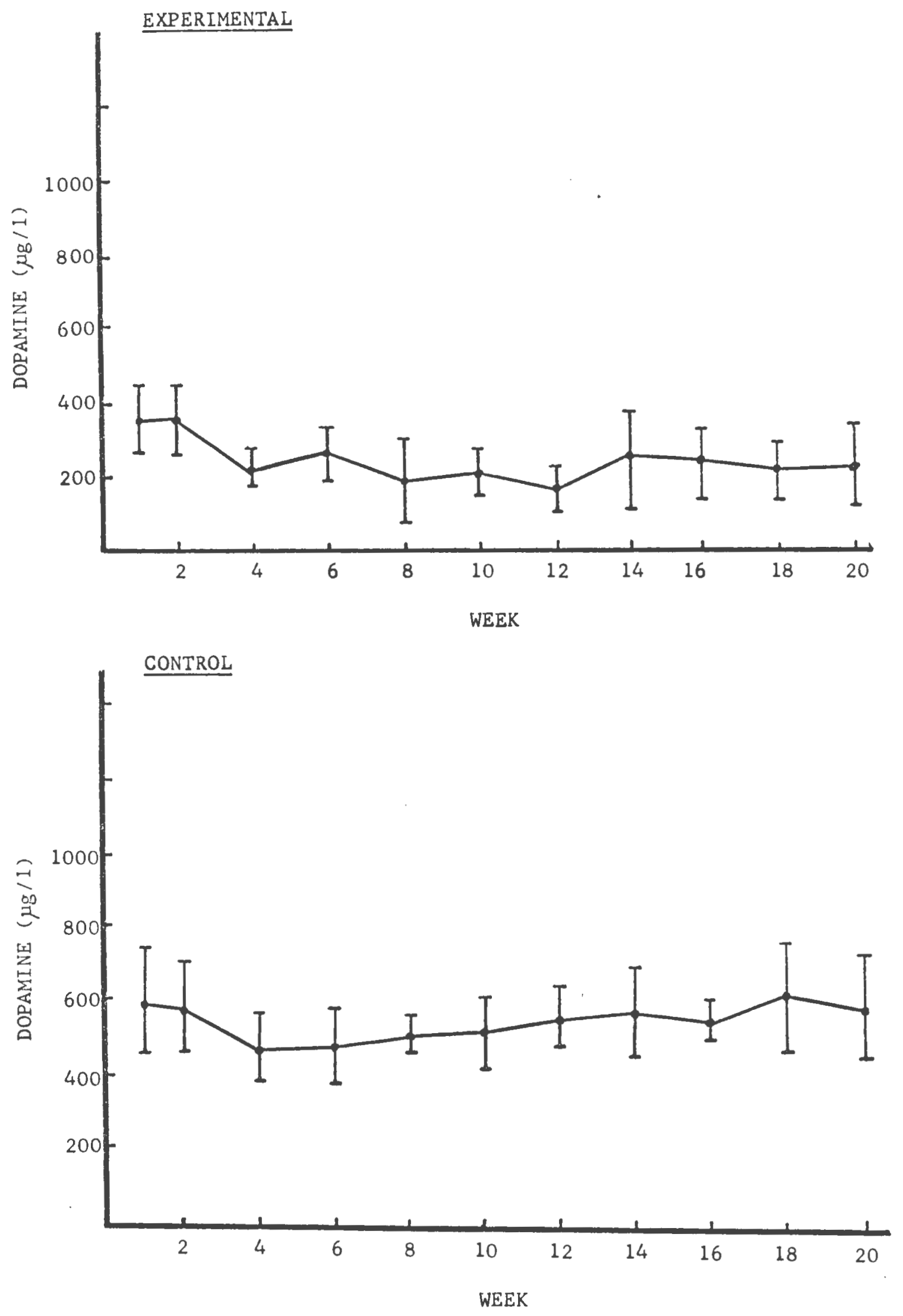

Fig. 6. Mean urinary dopamine levels and standard deviations $(\mu g / 1)$ for the experimental and control groups for week 1 through 20 . 
significant and the hypothesis Ho: $\beta=0$ and Ho: $\rho=0$ cannot be rejected;

this implies that no relationship exists between dopamine concentration and arterial blood pressure.

DeFanti (1961) reported finding a highly significant positive regression coefficient for dependency of blood pressure on logarithm dopamine concentration in hypertensive rats, for dopamine concentrations ranging from 500 to $1000 \mu \mathrm{g} / 1$. The above results are not in agreement with these findings. Possible explanations for the discrepancy lie in the different methods of statistical analysis and assay methods used in the two studies. DeFanti worked with six groups of experimental animals comprised of from one to six animals each which survived left renal artery compression. The mean values for blood pressure and dopamine concentration from these six groups were averaged to obtain pooled means and standard deviations of dopamine concentration and blood pressure for each week of the study. Apparently, the contribution of each group to the pooled mean was weighed equally despite variation in the number of animals comprising each group. These pooled means, from the first through the twelfth week following left renal artery compression, were then utflized in the regression analysis. In the present study, the values from 88 palred assays were utflized for the analysis.

Based upon the regression analysis statistics, DeFanti concluded that, "72\% of the variations occurring in blood pressure could be explained on the basis of the linear regression of blood pressure on dopamine." No direct comparisons were made between the dopamine levels of the control group and the experimental group. Dopamine levels were reported for the control group for the first, second, third, fourth, fifth, sixth, and elghth weeks following right nephrectomy. Non-statistical comparison of 
the dopamine levels of the control group with those of the experimental groups for these same weeks showed the dopamine levels in the control group to exceed those of the experimental group in 17 out of a possible 33 instances. In addition, the pooled means of the hypertensive animals were below that of the pooled control mean (obtained prior to left renal artery constriction) from these same animals for the first five weeks following left renal artery compression. However, during this five-week period the blood pressure had risen from a control value of $122+4.3 \mathrm{~mm}$ hg to 173 $+11.2 \mathrm{~mm} \mathrm{Hg}$. During this major rise in blood pressure, the dopamine levels remained below the pre-operational control value. Under these circumstances it is difficult to accept the dependancy of blood pressure on urinary dopamine levels.

Probably a more important contribution to the differences seen in the two studies was made by differences in methodology rather than differences in statistical evaluation of the data. While DeFanti used Dowex Sodium 50W-X8 to extract dopamine from the urine, the present study used alumina. In addition, changes were made in the assay procedure itself, particularly in the blank. These changes were necessitated by the discovery, early in the present study, that Dowex resin was extracting a substance with native fluorescence from the urine of hypertensive rats and that the blank (Carlsson and Waldeck, 1958) by quenching this fluorescence was resulting in erroneously high urinary dopamine levels. By using alumina and changing the order of addition of reagents in the blank, this difficulty was circumvented in the present study. The explanation seems compatible with the results; for while alumina extracted $82.43+11.73 \%$ of variable amounts of dopamine added to urine (Table 2) compared with $74.52+10.99 \%$ reported by DeFanti, the range of dopamine values was lower 
In the present study $(89-652 \mu \mathrm{g} / 1)$ than reported by DeFanti $(97-1569 \mu \mathrm{g} / 1)$. Other investigators have encountered difficulties with the dopamine assay, and various modifications can be found in the literature (Drujan et al., 1959; McGeer and McGeer, 1962; Brodie et al., 1962; Carlsson and Lindquist, 1962; Anton and Sayre, 1964). The strong cation exchange resins (e.g. Dowex 50W-X8) have been reported to give off fluorescent material (Haggenda1, 1962; Ibid., 1966); and absorption on to alumina at pH 8.6 seems superior and more specific, particularly for urine (Anton and Sayre, 1962; Ibid., 1964; Haggenda1, 1966).

(Tables 4 through 25 also present urinary dopamine levels as total micrograms excreted per 24 hours $(\mu \mathrm{g} / 24 \mathrm{hr}$ ) and micrograms per killogram per 24 hours $(\mu \mathrm{g} / \mathrm{kg} / 24 \mathrm{hr})$. Since a change in the volume of urine produced in a 24-hour period could have a significant influence on dopamine levels when reported as concentration, it was thought necessary to compare the total micrograms excreted per 24 hours between the control and experimental groups. The results of the two groups differed significantly only for the first and sixth weeks of the experiment $(.001<p<.01)$. The discrepancy for the first week could possibly be attributed to variable adaptation to experimental procedure. The difference seen the sixth week (first week following left renal artery constriction) probably is a result of temporary alteration of renal function or a rebound phenomenon consequent to renal impairment. The excretion of dopamine $(\mu \mathrm{g} / 24 \mathrm{hr})$ tended to increase (Figure 7) in both groups over the duration of the study, indicating a possible relationship with time (e.g. age). This possibility was not statistically evaluated, but is in agreement with other studies (Burn, 1953). The relationship between blood pressure and dopamine $(\mu \mathrm{g} / 24 \mathrm{hr})$, however, was investigated for both groups. No relationship 

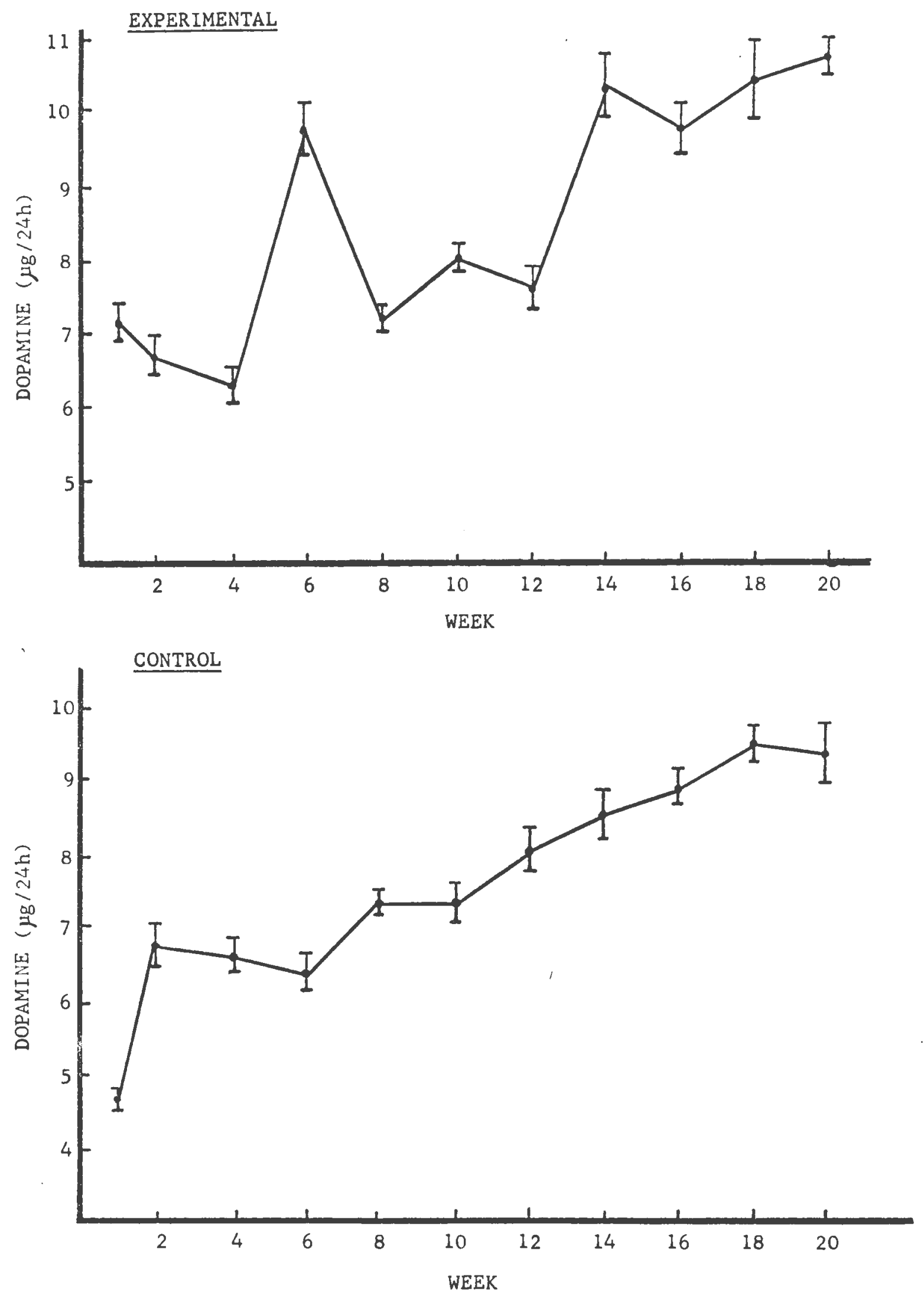

Fig. 7. Mean urinary dopamine levels and standard deviations ( $\mu \mathrm{g} / 24 \mathrm{~h}$ ) for the experimental and control groups for week 1 through 20 . 
was found to exist for elther of the groups when the data from the sixth week on, independent of time, was subjected to a determination of the regression and correlation coefficients. The values are shown in Table 27. The regression coefficient (b) for the control group was 0.253 and for the experimental group -0.868 . The correlation coefficient ( $r$ ) was 0.076 for the control group and-0.126 for the experimental group. Although these values took different directions, it is important to note that they were not statistically significant.

Urinary dopamine values expressed as micrograms per kilogram per 24 hours were reported because DeFanti and DeFeo (1963) reported finding an increased excretion of dopamine $(\mu \mathrm{g} / \mathrm{kg} / 24 \mathrm{hr})$ when plotted against weight ( $\mathrm{gm})$ for hypertensive rats, contrasted with a decrease in normotensive rats. Leduc (1961) also reported a decrease in urinary dopamine levels $(\mu \mathrm{g} / \mathrm{kg} / 24 \mathrm{hr})$ in normotensive rats as body weight increased. In the present study a slight tendency for dopamine levels ( $\mu \mathrm{g} / \mathrm{kg} / 24 \mathrm{hr}$ ) to decrease with increased weight was noted for both the experimental and control groups; however, neither trend proved statistically significant (Table 27). Also subjection of the data on dependency of blood pressure to dopamine levels $(\mu \mathrm{g} / \mathrm{kg} / 24 \mathrm{hr})$ to a determination of the regression and correlation coefficients resulted in values of low magnitude which were not statistically significant. Comparisons between the two groups (Table 26; Figure 7) disclosed a significant difference between the two groups for only the first and sixth weeks, resulting in a situation similar to that encountered when dopamine levels ( $\mu \mathrm{g} / 24 \mathrm{hr})$ were compared.

In light of the above findings, it appears that the quantity of dopamine excreted in the urine, expressed either as total micrograms per 24 hours or as micrograms per k1llogram per 24 hours, follows a similar 

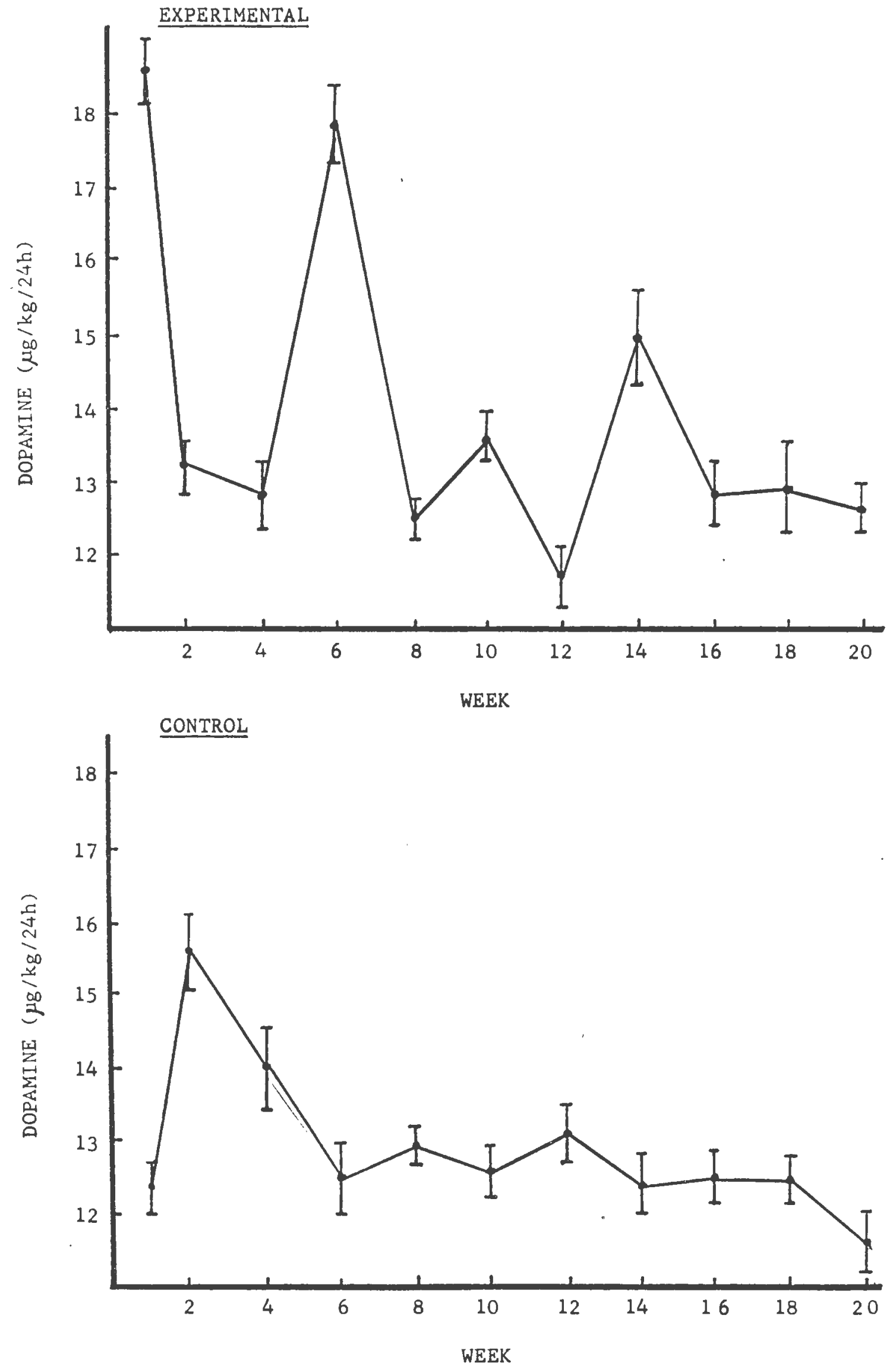

Fig. 8. Mean urinary dopamine levels and standard deviations $(\mu \mathrm{g} / \mathrm{kg} / 24 \mathrm{~h})$ for the experimental and control groups for week 1 through 20 . 
pattern in normotensive and hypertensive rats. It also appears that the total quantity of dopamine excreted per 24 hours tends to increase with time (e.g., age), while the dopamine levels reported as micrograms per killogram per 24 hours tend to remain relatively constant or display a slightly downward trend as body weight increases. Since dopamine levels expressed as micrograms per liter were significantly lower on several occasions in the hypertensive groups of animals, an explanation is necessary. The explanation would seem to be an increase in urinary volume which occurred in the experimental group subsequent to left renal artery constriction. An increase in urinary output is commonly encountered in renal hypertension as the kidneys lose their power to concentrate the urine. If this dilution factor is taken into account, as it is when dopamine levels are reported as micrograms excreted per 24 hours or micrograms excreted per k1llogram per 24 hours, then no consistent significant differences are seen to exist between the normotensive and hypertensive animals. The only possible conclusion is that urinary dopamine levels bear no relationship to the increase in blood pressure as a result of renal ischemia in rats.

The urinary dopamine levels $(\mu \mathrm{g} / 24 \mathrm{hr}$ ) for the study carried out in dogs are presented in Table 29. These values are quite varlable; however, there are no obvious differences between the values for the hypertensive dogs, the control dog or the unilaterally nephrectomized control dog. The infusion of $d, 1-D O P A$ in cats with and without functional renal tissue (Tables 30,31 and 32 ) was carried out to determine the role of the kidneys in the increased tissue levels of dopamine reported to occur following DOPA infusion (Wegmann, 1963). The t1ssue levels of dopamine and DOPA found in the untreated control cats are presented in Table 30. 
The dopamine levels were low in all the tissues examined; the mean levels were highest in the heart $(0.11 \mu \mathrm{g} / \mathrm{gm})$, next highest in the spleen $(0.08$ $\mu \mathrm{g} / \mathrm{gm})$, next in the liver $(0.05 \mu \mathrm{g} / \mathrm{gm})$, and lowest in the kidney $(0.02$. $\mu \mathrm{g} / \mathrm{gm})$. Mean DOPA levels were very low $(0.08 \mu \mathrm{g} / \mathrm{g}$ in all $\mathrm{t}$ issues). Wegmann (1963) reported detectable levels of dopamine in the spleen and kidney of untreated dogs but not in heart and liver. Anton and Sayre (1964) reported finding very low levels of dopamine in the tissues of the $\mathrm{dog}$, the highest value being found in the heart $(0.05 \mu \mathrm{g} / \mathrm{gm})$. These same investigators reported the highest level of dopamine in the cat spleen $(0.12 \mu \mathrm{g} / \mathrm{gm})$ and similar levels in the heart, liver, and kidney $(0.07$ $\mu \mathrm{g} / \mathrm{gm})$. Both investigators failed to detect DOPA in any of these tissues. Following the infusion of $d, 1-D O P A$ in cats with left renal function, there was an increase in the dopamine content of all the tissues examined. The pattern of increase was the same as that obtained by Wegmann, the dopamine level being highest in the kidney $(10.29 \mu \mathrm{g} / \mathrm{gm})$ followed in order by the spleen $(2.25 \mu \mathrm{g} / \mathrm{gm})$, liver $(2.05 \mu \mathrm{g} / \mathrm{gm})$, and heart $(0.92 \mu \mathrm{g} / \mathrm{gm})$. The DOPA level was highest in the kidney $(93.44 \mu \mathrm{g} / \mathrm{gm})$, followed in order by the spleen $(34.81 \mu \mathrm{g} / \mathrm{gm})$, heart $(30.16 \mu \mathrm{g} / \mathrm{gm})$, and liver $(12.84 \mu \mathrm{g} / \mathrm{gm})$; again the pattern was similar to that reported by Wegmann. Blood samples taken during the experiment showed that some synthesis of dopamine was taking place in the kidney. An arterial blood sample taken midway through the infusion period from the abdominal aorta near the origin of the left renal artery showed a dopamine content of $40 \mu \mathrm{g} / \mathrm{l}$, while a venous blood sample obtained from the left renal vein via the, ovarian vein for the same time showed a dopamine content of $115 \mu \mathrm{g} / 1$. Blood samples obtained in a similar manner one hour after initiation of the infusion (40 minutes after conclusion of the infusion) showed an arterial dopamine level of $41 \mu \mathrm{g} / 1$ and 
a venous level of $75 \mu \mathrm{g} / 1$. As might be expected, the blood levels of DOPA were very high. The values presented in the same order as above were arterial: $11,152 \mu \mathrm{g} / 1$; venous, $13,586 \mu \mathrm{g} / 1$; arterial, 3.628 ; venous, $2.745 \mu \mathrm{g} / 1$. The high value obtained for the first venous sample probably represents a slight contamination of the sample with blood from the abdominal vein through which DOPA was being infused. Similar tissue levels of dopamine were obtained in the heart $(1.00 \mu \mathrm{g} / \mathrm{gm})$, liver $(2.72 \mu \mathrm{g} / \mathrm{gm})$, and spleen $(2.47 \mu \mathrm{g} / \mathrm{gm})$ when $d, 1-D O P A$ was infused into cats without kidney function. This finding would imply that the kidney contributes very little to the increased dopamine levels seen in these tissues. Dopamine synthesis either takes place in situ within the heart, liver, and spleen or as suggested by Wegmann, possibly the liver contributes to the tissue levels in the other two organs. Circumstantial evidence might support this. The liver is known to possess a high degree of DOPA decarboxylase activity (Blaschko, 1939) and yet the dopamine level in this organ following DOPA infusion is surprisingly low. However, the DOPA content of the liver is also relatively low following DOPA infusion. This could indicate a rapid turnover of DOPA in the liver with subsequent release of dopamine into the circulation.

None of the results from this investigation implicate dopamine in the renal hypertensive process. No relationship was established between urinary dopamine levels and arterial blood pressure in hypertensive rats or dogs. In addition, dopamine could not be demonstrated in the blood of hypertensive rats or dogs or in the renal tissue of hypertensive rats. Doubt was also cast upon the role of the kidney in contributing to an increase in tissue dopamine levels following the infusion of d,1-DOPA. Evidence was presented that the kidney does decarboxylate DOPA, but 
evidence was also presented that this had little influence on dopamine levels in heart, liver and spleen.

A question raised by the investigation is the nature of the native fluorescence found present in Dowex 50W-X8 extracts of hypertensive rat urines. High blanks were also encountered in the assay of the ischemic kidneys. Is it possible that the substances are one and the same and may be involved in the hypertensive process? Further investigation along this line might prove profitable. 


\section{SUMMARY AND CONCLUSIONS}

Arterial hypertension was induced in male rats of the Wistar strain and in mongrel dogs by right renal nephrectomy and left renal artery constriction for the purpose of studying the relationship of urinary, blood, and kidney dopamine levels to the resulting increase in blood pressure. In the rats a significant increase in blood pressure was obtained the first week following left renal artery constriction, and the pressure remained signiffcantly elevated above that of a sham-operated control group for the duration of the study. The highest mean blood pressure for the hypertensive group (176 mm $\mathrm{Hg}$ ) was obtained on the eleventh week following renal artery constriction. Individual blood pressures ranged as high as $205 \mathrm{~mm} \mathrm{Hg}$. Simflar results were obtained in the hypertensive dogs.

A new method was developed for the fluorimetric assay of urinary dopamine by modification of existing methods. Alumina was used to extract dopamine, and this eliminated certain difficulties which were inftially encountered when Dowex sodium $50 \mathrm{~W}-\mathrm{X} 8$ was used. Recovery of known quant1ties of dopamine added to urine samples averaged $82.43+11.73 \%$. Dopamine was extracted from blood and tissues principally by homogenization in $10 \%$ trichloroacetic acid followed by passage through alumina. A method was also devised to separate DOPA from dopamine contained in the same tissue extract. This was accomplished by first passing a trichloroacetic acid extract through sodium Dowex to extract dopamine, then through alumina to extract DOPA. Excellent separation and recoveries were obtained.

Comparisons of urinary dopamine levels were carried out between the control and hypertensive groups of rats. Dopamine concentration $(\mu g / 1)$ 
was significantly lower on several occasions in the hypertensive group. However, dopamine levels reported as micrograms per 24 hours or micrograms per kilogram per 24 hours differed significantly on only two occasions-once during the pre-operational control period and again on the first week following left renal artery constriction. A diuresis was observed in the hypertensive rats, which could explain the apparent decrease in dopamine concentration $(\mu \mathrm{g} / \mathrm{l})$. Dopamine levels $(\mu \mathrm{g} / 24 \mathrm{hr})$ showed a tendency to increase in both the control and experimental groups during the period of the study while dopamine levels $(\mu \mathrm{g} / \mathrm{k} / 24 \mathrm{hr})$ remained relatively constant and displayed only a slight tendency to decrease. Regression and correlation coefficients were determined in both groups of rats for the following relationships: blood pressure on urinary dopamine $(\mu \mathrm{g} / 1)$, blood pressure on urinary dopamine $(\mu \mathrm{g} / 24 \mathrm{hr})$, blood pressure on urinary dopamine $(\mu \mathrm{g} / \mathrm{kg} / 24 \mathrm{hr})$, and dopamine $(\mu \mathrm{g} / \mathrm{kg} / 24 \mathrm{hr})$ on weight $(\mathrm{gm})$. No statistically significant relationships were discovered. Dopamine could not be detected in the blood or kidneys of hypertensive rats or in the blood of hypertensive dogs.

A relationship between dopamine and the hypertensive process was not established in the present study, and it is doubtful that dopamine plays a role in the elevation of blood pressure which takes place following right nephrectomy and left renal artery constriction in the rat or dog. d, I-DOPA was infused into cats with and without functional renal tissue to determine the contribution of the kidneys to tissue levels of dopamine. Tissue dopamine levels were elevated to a similar degree in liver, spleen, and heart in both instances; however, renal arterio-venous differences indicated that some decarboxylation of DOPA to dopamine did take place in the kidney. The similar tissue levels were probably a 
result of saturation of uptake sites in the tissues, and it was suggested that the liver may have contributed to the tissue levels in the heart and spleen of the totally nephrectomized cats. 


\section{REFERENCES}

Allwood, M. J. and Ginsburg, J.: Peripheral vascular and other effects of dopamine infusion in man. Clin. Sci. 27:271, 1964.

Ames, R. P., Borkowski, A. J., Sincinski, A. M., and Laragh, J. H.: Prolonged infusions of angiotensin II and norepinephrine on blood pressure, electrolyte balance, and aldosterone and cortisol secretion in normal man and in cirrhosis with ascities. J. clin. Invest. 44:1171, 1965.

Anden, N. E., Roos, B. E. and Werdinius, B.: On the occurrence of homovanillic acid in brain and cerebrospinal fluid and its determination by a fluorimetric method. Life Sci. 2: 448, 1963.

Anton, A. H. and Sayre, D. F.: A study of the factors affecting the aluminum oxide-trihydroxy-indole procedure for the analysis of catecholamines. J. Pharmaco1. exp. Therap. 138:360, 1962.

Anton, A. H. and Sayre, D. F.: The distribution of dopamine and DOPA in various animals, and a method for their determination in deverse blological material. J. Pharmacol. exp. Therap. 145:326, 1964.

Armstrong, M. D., McMillan, A. and Shaw, K. N.: 3-methoxy-4-hydroxy-Dmandelic acid, a urinary metabolite of norepinephrine. Biochim. biophys. Acta 25:422, 1957.

Axelrod, J.: Purification and properties of phenylethanolamine-N-methyl transferase. J.biol. Chem. 237: 1657, 1962a.

Axelrod, J.: The enzymatic $\mathrm{N}$-methylation of serotonin and other amines. J. Pharmaco1. exp. Therap. $\underline{138: 28,1962 b .}$

Axelrod, J.: Methylation reactions in the formation and metabolism of catecholamines and other biogenic amines. Second Symposium on Catecholamines. Pharmacol. Rev. 18:95, 1966.

Axelrod, J. and Tomchick, R.: Enzymatic 0-methylation of epinephrine and other catechols. J. biol. Chem. 233:702, 1958.

Baum, T. and Shropshire, A. T.: Sympathetic and humoral vasoconstrictor responses in deoxycorticosterone hypertension. Am. J. Physiol. 213:499, 1967.

Bertler, A., Carlsson, A. and Rosengren, E.: A method for the fluorimetric determination of adrenaline and noradrenaline in tissues. Acta physiol. scand. $44: 273,1958$.

Biron, P., Koiw, E., Nowaczynski, W., Brovillet, J. and Genest, J.: The effects of intravenous infections of valine angiotensin II and other pressor agents on urinary electrolytes and corticosteroidsincluding aldosterone. J. clin. Invest. 40:338, 1961. 
Bischoff, F. and Torres, A.: Determination of urine dopamine. Clin. Chem. $\underline{8}: 370,1962$.

Blaschko, H.: The specific action of 1-DOPA decarboxylase. J. Physiol. 96: 50p, 1939.

Blaschko, H., Hagen, J. and Hagen, P.: Mitochondrial enzymes and chromaffin granules. J. Physiol. (London) 139:316, 1957.

Burn, J. H., Philpot, F. J. and Trandelenburg, U.: Effect of denervation on enzymes in iris and blood vessels. Brit. J. Pharmacol. 9:423, 1954.

Burns, G. P.: Urinary excretion of pressor amines in relation to phaeochromcytoma. Brit. med. J. $1: 697,1953$.

Bridgers, W. F. and Kaufman, S.: The enzymatic conversion of epinine to epinephrine. J. blol. Chem. 237:526, 1962.

Brodie, B. B., Kuntzman, R., Hirsch, C. W. and Costa, E.: Effects of decarboxylase inhibition on the biosynthesis of brain monoamines. Life Sci. I: 81,1962 .

Brunjes, S.: Catechol amine metabolism in essential hypertension. New. Eng. J. Med. 271: 120, 1964.

Carlsson, A.: The occurrence, distribution and physiological role of catecholamines in the nervous system. Symposium on Catecholamines. Pharmacol. Rev. 11:490, 1959 .

Carlsson, A. and H1llarp, N. A.: Formation of phenolic acids in brain after administration of 3,4-dihydroxyphenylalamine. Acta physio1. scand. 55:95, 1962.

Carlsson, A. and Waldeck, B.: A fluorimetric method for the determination of dopamine (3-hydroxytyramine). Acta physiol. scand. 44:295, 1958.

Carlsson A., and Waldeck, B.: A method for the fluorimetric determination of 3-methoxy-tyramine in tissues and the occurrence of this amine in brain, Scand. J. clin. Lab. Inv. 16:133, 1964.

Chrivos, M. A., Greengard, P. and Udenfriend, S.: Uptake of tyrosine by rat brain in vivo. J. biol. Chem. 235:2075, 1960.

Corcoran, W. C., Taylor, R. D. and Page, I. H.: Controlled observations on the effect of low sodium dietotherapy in essential hypertension. Circulation $3: 1$, 1951 .

Crawford, T. B. B. and Law: A method for the estimation of adrenaline and noradrenaline in urine. J. Pharm. and Pharmacol. 10:179, 1958.

Crout, J. R., Creveling, C. R. and Udenfriend, S.: Norepinephrine metabol18m in rat brain and heart. J. Pharmacol. exp. Therap. 132:269, 1961. 
Dahistrom, A., Fuxe, K. and Hillarp, N. A.: Site of action of reserpine. Acta Pharmacol. (Kobenhavn) 22:277, 1965.

DeChamplain, J., Krakoff, L. R. and Axelrod, J.: Catecholamine metabolism in experimental hypertension in the rat. Circulation Res. 20:136, 1967.

DeFanti, D. R.: Ph.D. Dissertation: The relationship of dopamine to blood pressure and monoamine oxidase activity in hypertensive rats. Univ. of Rhode Island, 1961.

DeFant1, D. R. and DeFeo, J. J.: Urinary dopamine levels and kidney monoamine oxidase activity in hypertensive rats. Biochem. Pharmacol. 12: $173,1963$.

Doyle, A. E. and Fraser, J. R. E.: Vascular reactivity in hypertension. Circulation Res. 9: 755, 1961.

Drujan, R. D., Sourkes, T. L., Layne, D. S. and Murphy, G. F.: The differential determination of catecholamines in urine. Canad. J. Biochem. Physio1. 37:1153, 1959.

Duchon, J. and Gregora, V.: Homovanilic acid and its relation to tyrosine metabolism in melanoma. Ciin. Chem. Acta. 7:443, 1962.

Dury, D. R.: The production of hypertension in the rabbit by a new method of renal insufficiency. J. exp. Med. 68:695, 1938.

Eble, J. N.: A proposed mechanisms for the depressor effect of dopamine in the anethetized dog. J. Pharmacol. exp. Ther. 145:64, 1964.

Euler, U. S, von, Hellner, S, and Purkhold, A.: Excretion of noradrenaline in urine in hypertension. Scand. J. clin. Lab. Invest. 6:54, 1954.

Euler, U. S. von, and Lishajko, F.: Dopamine in mammalian lung and spleen. Acta physiol. pharm. neerl. 6:295, 1957.

Euler, U. S. von and Lishajko, F.: The estimation of catecholamines in urine. Acta physiol. scand. 45:122, 1959.

Feldberg, W. and Lewis, G. P.: The action of peptides on the adrenal medulla. Release of adrenaline by bradykinin and angiotensin. J. Physiol. (London) 171:98, 1964.

Feldberg, W. and Lewis, G. P.: Further studies of the effects of peptides on the suprarenal medulla of cats. J. Physiol. (London) 178:239, 1965.

Genest, J., Broucher, R., DeChamplain, J., Veyrat, R., Chretien, M., Biron, P., Tembloy, G., Roy, P. and Cartier, P.: The renin angiotensin system in hypertensive patients. Canad. Med. Assoc. J. 90:263, 1964.

Genest, J., Koiw, E., Nowaczynski, W. J. and Leboeuf, G.: Urinary aldosterone in human arterial hypertension. Proc. Soc. exper. Biol. \& Med., 97:676, 1958 . 
Gitlow, S., Mendlowitz, M., Kruk, E., Wilk, S. and Wolf, R.: Excretion of catecholamines and their metabolites in hypertension. Fed. Proc. 22:389, 1963.

Gitlow, S. E., Mendlowitz, M., Smith, A., Gal1, E., Wolf, R. L, and Naftchi, N. E.: The dynamics of norepinephrine metabolism. In Hypertension: Recent advances, ed. by.A. N. Best and J. H. Moyers, p.335, Lea \& Febiger, Philadelphia, 1961.

Gitlow, S. E., Mendlowitz, M., Smith, A., Gall, E., Wolf, R. L. and Naftchi, N. E.: Pharmacology and metabolism of norepinephrine in patients with essential hypertension. Am. J. Cardio. 9:717, 1962.

Gitlow, S. E., Mendlowitz, M., Wilk, E. K., Wilk, S., Wolf, R. L. and Naftchi, N. E.: Plasma clearance of $d, 1-B-H^{3}$ norepinephrine in normal human subjects and patients with essential hypertension. J. clin. Invest. 43:2009, 1964 .

Goldblatt, H.: Factors regulating blood pressure. J. Macy Found., 5th Conference, 1951.

Goldblatt, H., Lynch, J., Hanzel, R. F. and Summerville, W. W.: Studies on experimental hypertension. J. exp. Med. 59:3347, 1934.

Goldberg, L. I. and Sjoerdsma, A.: Effects of several monoamine oxidase inhibitors on the cardiovascular actions of naturally occurring amines in the dog. J. Pharmacol, exp. Ther. 127:212, 1959.

Green, D. E., Lelair, L. F, and Nocito, V.: Tramsaminases. J. biol. Chem. 161:559, 1945 .

Griesemer, E., Barsky, C., Dragstedt, C. A., Welk, J. A. and Zeller, E. A.: Potentiating effect of iproniazid on the pharmacological actions of sympathomimetic amines. Proc. Soc. exp. Biol. Med. 84:699, 1953.

Grollman, A., Muirhead, E. E. and Vanatta, J.: Role of the kidney in pathogenesis of hypertension as determined by a study of the effects of bilateral nephrectomy and other experimental procedures on the blood pressure of the dog. Am. J. Physiol. 157:21, 1949.

Haggendahl, J.: On the use of strong exchange resins for determinations of small amounts of catecholamines. Scand. J. clin. Lab. Invest. 14:537, 1962 .

Haggendahl, J.: The presence of conjugated adrenaline and noradrenalin in human blood.plasma. Acta physiol. scand. 59:255, 1963.

Haggendahl, J.: Newer developments in catecholamine assay. Second Symposium on Catecholamines. Pharmacol. Rev. 18:325, 1966.

Haynes, F. W., and Dexter, L.: Renin hypertensinogen, and hypertensinase concentration of blood of dogs during the development of hypertension by constriction of the renal artery. Am. J. Physiol. 150:190, 1947. 
Healy, J. K.: Effect of intravenous angiotensin infusion on adrenal medullary function in man. Proc. Soc. expl. B1ol. Med. 125:679, 1967.

Helmer, O. M. and Griffith, R. E.: Biological activity of sterolds as determined by assay of renin-substrate (Hypertensinogen). Endrocrinology 49:154, 1951 .

Hess, S. M., Connamacher, R. H., Ozake, M. and Udenfrlend, S.: The effects of alpha-methyl DOPA and alpha-methyl-meta-tyrosine on the metabolism of norepinephrine and serotonin in vivo. J. Pharmacol. exp. Therap. 134:129, 1961.

Holmes, J. C. and Fowler, N. O.: Di rect cardiac effects of dopamine. Circulation Res. 10:68, 1962.

Holtz, P., Credner, K. and Koepp, W.: Die enzymatische entstchunt vonxytramine in organismus and die physiologische beduntung der DOPA decarboxylase. Arch. exper. Pathol. u. Pharmakol. 200:356, 1942.

Holtz, P., Stock, K. and Westermann, E.: Uber de Brutdruckwirkung des dopamine. Arch. Expt1. Pathol. Pharmakol. 246:133, 1963.

Hornykiewicz, 0.: Dopamine (3-hydroxy-tyramine) and brain function. Pharmacol. Rev. 18:925, 1966.

Horwitz, D., Fox, S. M. III and Goldberg, L. I.: Effects of dopamine in man. Circulation Res. 10:237, 1962.

Horwitz, D., Goldberg, L. I., Sjoerdsma, A. and Ambrose, I.: Increased blood pressure responses to dopamine and norepinephrine produced by MAO inhibitors in man. J. Lab. clin. Med. 56:747, 1960.

Kaser, H.: Catecholamine-producing neural tumors other than pheochromocytoma. Second symposium on the catecholamines. Pharmacol. Rev. 18:59, 1966.

Kirshiner, N.: Uptake of catecholamines by a particulate fraction of the adrenal medulla. J. biol. Chem. 237:2311, 1962 .

Koplin, I. J.: Storage and metabolism of catecholamines: The role of monoamine oxidase. Phamacol. Rev. 16:179, 1964.

Laragh, J. H.: Introductory remarks, Physiology Society Symposium: Renin angiotensin, aldosterone and hormonal regulation of arterial pressure and salt balance. Fed. Proc. 26:39, 1967.

Laragh, J. H., Angers, M., Kelly, W. G. and Lieberman, S.: Hypotensive agents and pressor substances. The effect of epinephrine, norepiangiotensin II, and others on the secretory rate of aldosterone in man. J. Am. Med. Assoc. 174:234, 1960.

Laragh, J. H., Sealey, J. E. and Somers, S. C.: Patterns of adrenal secretion and urinary secretion of aldosterone and plasma renin activity in normal and hypertensive subjects. Circulation Res. 18-19: suppl. I, 158: 1966. 
Laragh, J. H., Ulick, S., Januszewicz, V., Demerig, Q. B., Kelly, W. G. and Lieberman, S.: Aldosterone secretion and primary and malignant hypertension. J. clin. Invest. 39:1091, 1960a.

Laragh, J.H., Ulick, S., Januszewicz, V., Kelly, W. G. and Lieberman,. S.: Electrolyte metabolism and aldosterone secretion in benign and malignant hypertension. Ann. int. Med. 53:259, 1960b.

Leduc, J.: Catecholamine production and release in exposure and acclimation to cold. Acta physiol. scand. 53: Supp1. 183, 1961.

Levin, E. Y., Levenberg, B. and Kaufman, S.: The enzymatic conversion of 3,4-dihydroxy-pheny le thy lamine to norepinephrine. J. biol. Chem. 235:208, 1960 .

Lovenberg, W., Weissbach, H. and Udenfriend, S.: Aromatic L-amino acid decarboxylase. J. biol. Chem. 237:89, 1962 .

Marsha11, C. S.: The use of Sephadex G-25 for the separation of catecholamines from plasma. Blochem. Blophys. Acta 74:158, 1963.

Maxwe 11, G. M., Rowe, G. G., Costello, C. A., Clifford, J. E., Alonso, S. and Crumpton, C. W.: The effect of dopamine (3-hydroxytyranine) upon the systematic, pulmonary, and cardiac Hemodynamics and metabolism of intact dogs. Arch. int. Pharmacodgn. 129:62, 1960.

McCubbin, J. W. and Page, I. H.: Renal pressor system and neurogenic control of arterial pressure. Circulation Res. 12:553, 1963.

McDonald, R. H.Jr, and Goldberg, L. I.: Analysis of the cardiovascular effects of dopamine in the dog. J. Pharmacol. exp. Therap. 140:60, 1963.

McGeer, E. G. and McGeer, P. L.: Catecholamine content of spinal cord. Canad. J. Biochem. Phys1o1. 40:1141, 1962.

McMay, J. L. and Goldberg, L. I.: Comparison of the effects of dopamine isoproterenol, norepinephrine and bradykinin on canine renal and femoral blood flow. J. Pharmacol. exp. Ther. 151:23, 1966.

Melmon, K. L., Rivlin, R., Oates, J. A. and Sjoerdsma, A.: Further studies of plasma tyrosine in patients with altered thyroid function. J. clin. Endocrin. 24:691, 1964.

Mendlowitz, M., Gitlow, S. and Naftchi, N.: Course of essential hypertension. Prospectives Biol. Med. 2: $354,1959$.

Mendlowitz, M., Naftchi, N. E., Wolf, R. L. and Gitlow, S. F.: Renal mechanisms in hypertension. Hypertenston, Recent advances, The Second Hahnemann Symposium on Hypertensive Disease, p.137, Lea \& Febiger, Philadelphia, 1961.

Morris, R. E., Jr, and Robinson, R. R.: A method for determination of angiotensin II in human blood. Bul1. Johns Hopkins Hosp. 114:127, 1964. 


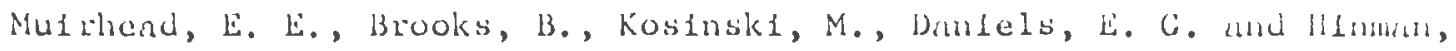
T.W.: Renonedullary antihypertensive principle in renal hypertension. J. Lab. clin. Med. 67:778, 1966.

Muirhead, E. E., Stiman, J. A. and Jones, F.: Renal autoexplantation and a functional characterization of nonexcretory renal tissue. J. clin. Invest. 38: 1027, 1959.

Muirhead, E. E., Stirman, J.A., Lesch, W. and Jones, F.: The reduction of postnephrectomy hypertension by renal homotransplant. Surg. Gyn. \& Obst. $\underline{103}: 673,1956$

Mulrow, P. J.: Rein-angiotensin system in the hypertension associated with renal vascular disease. Canad. Med. Assoc. J. 90:277, 1964.

Musacchio, J. M. and Welse, V. K.: Effects of decentralization on norepinephrine biosynthesis from tyrosine, DOPA, and dopamine. Pharmacologist 7: $156,1965$.

Musacchio, J., Kopin, I. J. and Snyder, S. H.: Effects of disulfuram on tissue norepinephrine content and subcellular distribution of dopamine, tyramine and their beta-hydroxylated metabolities. Life Sci. 3:769, 1964.

Nagatsu, T., Levitt, M. and Udenfriend, S.: Tyrosine hydroxylase, the initial step in norepinephrine biosynthesis. J. biol. Chem. 239:2910, 1964.

Nikodijevic, B., Creveling, C. R, and Udenfriend, S.: Inhibition of dopamine- $\beta$-oxidase $\underline{\text { in }}$ vivo by benzyloxamine and benzylhydrazine analogs. J. Pharmacol. exp. Therap. 140:224, 1963.

Oka, M., Kajikawa, K., Ohuchi, T., Yoshida, H. and Imaizumi, R.: Distribution of dopamine- $\beta$-oxidase in subcellular fractions of the adrenal medulla. Life Sci. (Oxford) 6:461, 1967.

Pert, W. S.: Catecholamines and hypertension Second. Symposium on Catecholamines. Pharmacol. Rev. 18:667, 1966.

Petrasek, J., Duborsky, J. and Charvat, J.: Clinical evaluation of catecholamine excretion. Endokinologie. 50:308, 1966.

Pickering, G. W.: The peripheral resistance in persistent arterial hypertension. Clin. Sc1. 2: 209, 1936.

Potter, L. T. and Axelrod, J.: Properties of norepinephrine storage particles of the rat heart. J. Pharmacol. exp. Therap. 142:299, 1963.

Raab, W.: Etiological role of catecholamine in essential hypertension. In: Hypertension: Recent advances, ed. by A. N. Brest and J. H. Moyer, p. 369. Lea \& Febiger, Philadelphia, 1961.

Redleaf, P. D. and Tobian, L., Jr.: The question of vascular hyperresponsiveness in hypertension. Circulation Res. 6: 185, 1958. 
Robinson, R., Smith, P., and Whittaker, R. F.: Secretion of catecholamines in malignant pheochromocytoma. Brit. Med. J. 1:1422, 1964.

Romano, R. and Indiveri, $F_{i}$ : Excretion of VMA in various hypertensive conditions. "E. Maragliano" Patol. Clin. 22:419, 1966. (C. A. 66:83967g, 1966):

Schumann, H. J.: Uber den hydroxytyraminegehalt sympathischer und sympathisch innervieter organe. Arch. exp. Pathol. u. Pharmakol. 236: 44, 1959.

Scornik, O. A. and Paladine, A. C.: Anglotensin blood levels in dogs with experimental hypertension. Am. J. Physiol. 201:526, 1961.

Shore, P. A.: The mechanism of norepinephrine depletion by reserpine, metaraminol and related agents. The role of monoamine oxidase. Second Symposium on Catecholamines. .Pharmaco1. Rev. 18:561, 1966.

Shore, P. A., Mead, J. A. R., Kuntzman, R. G., Spector, S., and Brodie, B. B.: On the physiological significance of monoamine oxidase in brain. Science 126:1063, 1957.

Singer, B., Lositio, C. and Salmon, S: Aldosterone and corticosterone secretion rates in rats with experimental renal hypertension. Acta Endocrinologica 44:505, 1963.

Sjoerdsma, A.: Relationships between alterations in amine metabolism and blood pressure. Circulation Res. 9:734, 1961.

Skeggs, L. T., Lentz, K. E., Gould, A. B., Hockstrasser, H. and Kahn, J. R.: Biochemistry and kinetics of the renin-anglotensin system. Fed. Proc. 26: 42, 1967.

Skeggs, L. T., Lentz, K. E., Kahn, J. R. and Shumway, P.: Synthesis of a tetradecapeptide renin substrate. J. exp. Med. 108:283, 1958.

Small, N. A.: The fluorimetric determination of total catecholamine in urine. Clin. Chem. Acta 8: 803, 1963.

Smlth, A., Taylor, D. T. and Wortis, S. B.: Abnormal catecholamine metabolism in familial dysautonomia. New Eng. J. Med. 268:705, 1963.

Snedecor, G. W.: Statistical Methods, The Iowa State University Press, Ames, Iowa, 1956.

Snyder, S. H., Fischer, J. E. and Axelrod, J.: Evidence for the presence of monoamine oxidase in sympathetic nerve endings. Blochem. Pharmacol. 14: $363,1965$.

Spector, S., Sjoerdsma, W., Zaltzman-Nirenberg, P., Levitt, M. and Udenfriend, S.: Norepinephrine synthesis from tyrosine-Cl4 in isolated perfused guinea pig heart. Sclence 139:1299, 1963. 
Stone, C. A., Stavorsk1, J. M., Ludden, C. T., Wenger, H. C., Ross, C. A., Totaro, J. A. and Porter, C. C.: Comparison of some pharmacological effects of certain 6-substituted dopamine derivatives with reserpine guanethidine and metaraminol. J. Pharmacol. exp. Ther. 142:147, 1963.

Scott, A. W. and Robinson, R.: Urinary normethadrenaline excretion in essential hypertension. Clin. Chem. Acta 16:249, 1967.

Taquin1, A. C., Blaquier, P., and Taquin1, A. C., Jr.: Studies on the renal humoral mechanism of chronic experimental hypertension. Circulation 17:672, 1958.

Tobian, L., Janecek, J. and Tomboulian, W.: The effect of a high sodium intake on the development of permanent nephrosclerotic hypertension. J. Lab. clin. Med. 53:842, 1959.

Udenfriend, S.: Tyrosine hydroxylase, Second Symposium on catecholamines. Pharmaco1. Rev. 18:43, 1966.

Uuspaa, V. J.: A new method for the determination of dopamine(3-hydroxytyramine). Ann. Med. exp. Fenn. 41:194, 1963.

Vanov, S.: Effect of pronethalol on some inhibitory actions of catecholamines. J. Pharm. (London). 15: 723, 1963.

Vincent, W. P., Kashemsant, U., Cuddy, R. P., Fried, A. H., Smulyan, H. and Eich, R. H.: Vanillylmandelic acid excretion in labile hypertensive subjects: its varlations and response to norepinephrine and anglotensin infusion. Amer. J. Med. Sc1. 249:78, 1965.

Wegmann, A.: Determination of 3-hydroxy-tyramine and DOPA in various organs of dog after DOPA infusion. Arch. exp. Path. U. Pharmak. 246:184, 1963.

Wegmann, A. Kako,K. and Bing, R. J.: Catecholamine content of various organs in experimental hypertension. Am. J. Physiol. 203:607, 1962.

Weil-Malherbe, H. and Bone, A. D.: The chemical estlmation of adrenaline-like substances in blood. Biochem. J. 51:311, 1952.

Weil-Malherbe, H.: The fluorimetric estimation of catechol amines. Methods. Med. Res. 9: 130, 1961.

We1l-Malherbe, $\mathrm{H}_{0}:$ The simultaneous estimation of catechol amines and their metabolites. Z. Klin. Chem. 2: 161, 1964. 
David William Coates was born May 22, 1935 in Uniontown, Pennsylvania, the son of Mr. Lloyd W. Coates and the late Eleanor Nesmith Coates.

He entered the Unfversity of Pittsburgh, College of Pharmacy in 1953 and graduated with a Bachelor of Sclence in Pharmacy in 1957. He continued his education at the same institution where he served as a graduate assistant in pharmacognosy and pharmacology and received the degree of Master of Science in Pharmaceutical Sciences with a major in pharmacology in 1961. He accepted the position of instructor of pharmacology at the University of Rhode Island, College of Pharmacy that same year and entered the graduate school to continue work toward the doctorate. In 1965 he was promoted to the rank of assistant professor.

He is a member of the following societies and professional organizations, Rho Chi, national honor soclety, Kappa Psi Pharmaceutical Fraternity, Sigma Xi, honorary science society and the American Pharmaceutical Association. He is licensed to practice pharmacy in three states. He married Lois Judith Horton in 1957 and has a daughter, Amy Elizabeth and a son, David William, Jr. 